\begin{tabular}{|l|l|}
\hline $\begin{array}{l}\text { 2. To: (Receiving Organization) } \\
\text { Distribution }\end{array}$ & $\begin{array}{l}\text { 3. From: (Originating Organization) } \\
\text { Nuclear Safety \& Licensing }\end{array}$ \\
\hline $\begin{array}{l}\text { 5. Proj./Prog./Dept/Div:: } \\
\text { Nuclear Safety \& Licensing }\end{array}$ & $\begin{array}{l}\text { 6. Design Authority/Design Agent/Cog. Engr.: } \\
\text { D. R. Bratzel }\end{array}$ \\
\hline $\begin{array}{l}\text { 8. Originator Remarks: } \\
\text { This document is being released into the supporting document system } \\
\text { for retrievability purposes. }\end{array}$
\end{tabular}

11. Receiver Remarks:

For Release
11A. Design Baseline Document? $\square$ Yes $\square$ No
4. Related EDT No.:
N/A
7. Purchase Order No.:
N/A
9. Equip./Component No.:

$\mathrm{N} / \mathrm{A}$

10. System/BIdg./Facility:

$\mathrm{N} / \mathrm{A}$

12. Major Assm. Dwg. No.:

$\mathrm{N} / \mathrm{A}$

13. Permit/Permit Application No.:

$\mathrm{N} / \mathrm{A}$

14. Required Response Date:

\section{N/A}

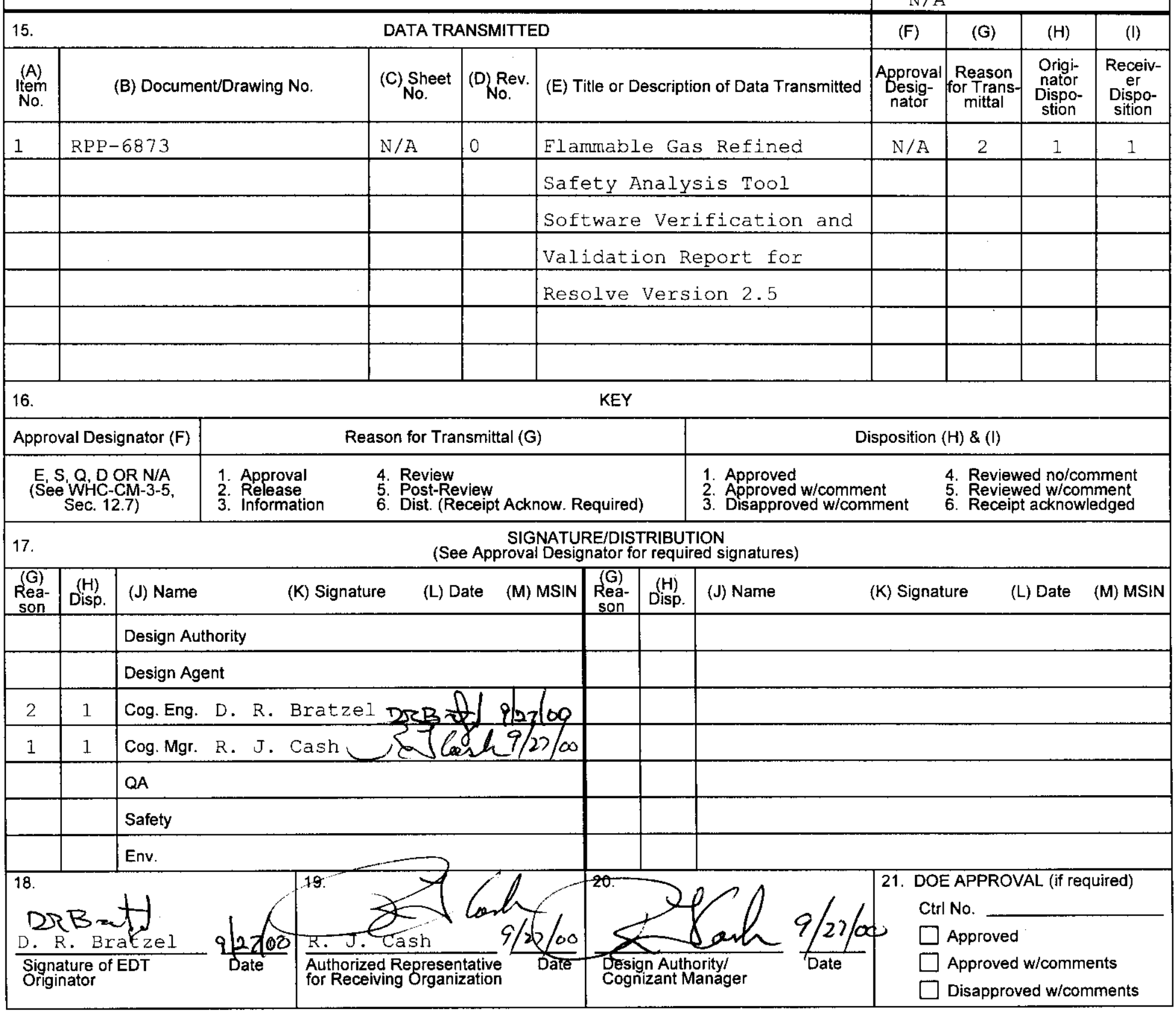




\section{DISTRIBUTION SHEET}

To

Distribution

Project Title/Work Order

Flammable Gas Refined Safety Analysis Tool Software Verification and

Validation Report for Resolve Version 2.5, RPP 6873, Rev. 0

\begin{tabular}{|c|c|c|c|c|c|}
\hline Name & MSIN & $\begin{array}{l}\text { Text } \\
\text { With All } \\
\text { Attach. }\end{array}$ & Text Only & $\begin{array}{l}\text { Attach./ } \\
\text { Appendix } \\
\text { Only }\end{array}$ & $\begin{array}{c}\text { EDT/ECN } \\
\text { Only }\end{array}$ \\
\hline \multicolumn{6}{|l|}{ CH2M HILL Hanford Group, Inc. } \\
\hline D. R. Bratzel (6 copies) & $\mathrm{R} 1-44$ & $\mathrm{x}$ & & & \\
\hline R. J. Cash & $R 1-44$ & $\mathrm{x}$ & & & \\
\hline S. A. Barker & $\mathrm{R} 1-44$ & $\mathrm{x}$ & & & \\
\hline K. M. Hodgson & $\mathrm{R} 2-11$ & $\mathrm{x}$ & & & \\
\hline J. M. Grigsby & $R 1-44$ & $x$ & & & \\
\hline \multicolumn{6}{|l|}{ PNNL } \\
\hline J. Young & K7-97 & $\mathrm{x}$ & & & \\
\hline \multicolumn{6}{|l|}{ M. Chew \& Associates } \\
\hline J. C. Lavender & GI-04 & $x$ & & & \\
\hline \multicolumn{6}{|l|}{ Sandia National Laboratories } \\
\hline \multicolumn{6}{|l|}{ P. O. Box 5800} \\
\hline \multicolumn{6}{|l|}{ Alburquerque, NM 87185} \\
\hline Chris E. Olsen & & $x$ & & & \\
\hline Eunice R. Young & & $\mathrm{x}$. & & & \\
\hline Scott E. Slezak & & $\mathrm{x}$. & & & \\
\hline & & & & & \\
\hline & & & & & \\
\hline & & & & & \\
\hline & & & & & \\
\hline & & & & & \\
\hline & & & & & \\
\hline & & & & & \\
\hline & & & & & \\
\hline & & & & & \\
\hline & & & & & \\
\hline & & & & & \\
\hline & & & & & \\
\hline
\end{tabular}




\title{
FLAMMABLE GAS REFINED SAFETY ANALYSIS TOOL SOFTWARE VERIFICATION AND VALIDATION REPORT FOR RESOLVE VERSION 2.5
}

\author{
S. E. Slezak \\ Sandia National Laboratories \\ Richland, WA 99352 \\ U.S. Department of Energy Contract DE-AC06-99RL14047 \\ EDT/ECN: $625137 \quad$ UC: \\ Cost Center: 73B00 Charge Code: 112829 \\ B\&R Code: Ewo/2 J2020 Total Pages: 130
}

D. R. Bratzel

CH2M HILL Hanford Group, Inc.

Key Words: Flammable Gas, Safety Issue

\begin{abstract}
The purpose of this report is to document all software verification and validation activities, results, and findings related to the development of Resolve Version 2.5 for the analysis of flammable gas accidents in Hanford Site waste tanks.
\end{abstract}

TRADEMARK DISCLAIMER. Reference herein to any specific commercial product, process, or service by trade name, trademark, manufacturer, or otherwise, does not necessarily constitute or imply its endorsement, recommendation, or favoring by the United States Government or any agency thereof or its contractors or subcontractors.

Printed in the United States of America. To obtain copies of this document, contact: Document Control Services, P.O. Box 950, Mailstop H6-08, Richland WA 99352, Phone (509) 372-2420; Fax (509) 376-4989.
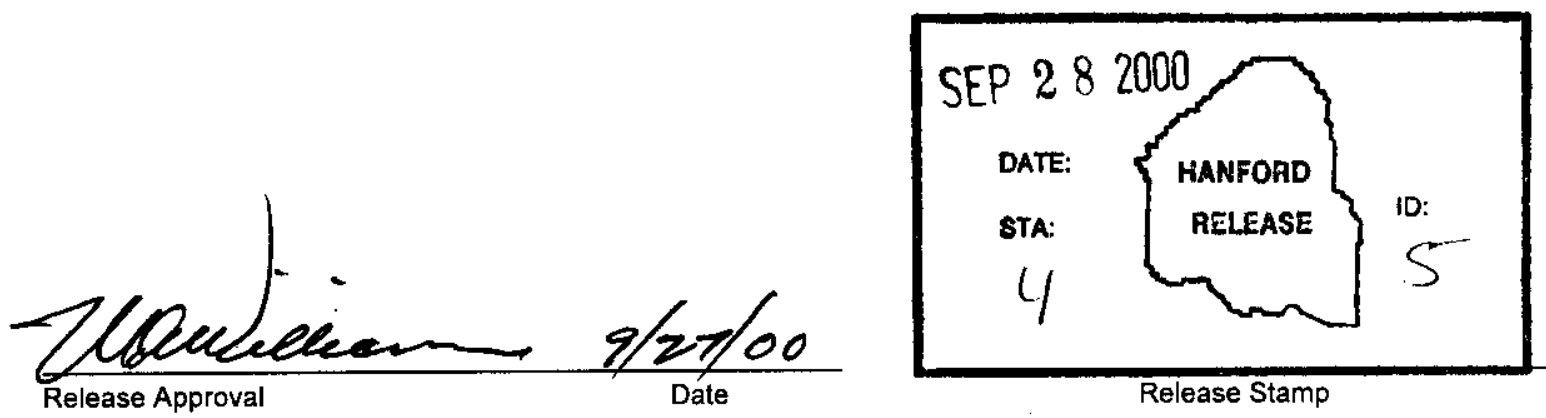

\section{Approved For Public Release}


RPP-6873

Revision 0

\section{Flammable Gas Refined} Safety Analysis Tool Software Verification and Validation Report for Resolve Version 2.5

Prepared for the U.S. Department of Energy

Assistant Secretary for Environmental Management

\section{CH2MHILL Hanford Group, Inc.}

Richland, Washington

Contractor for the U.S. Department of Energy

Office of River Protection under Contract DE-AC06-99RL14047

Approved for Public Release; Further Dissemination Unlimited 
LEGAL DISCLAIMER

This report was prepared as an account of work sponsored by an agency of the United States Government. Neither the United States Government nor any agency thereof, nor any of their employees, nor any of their contractors, subcontractors or their employees, makes any warranty, express or implied, or assumes any legal liability or responsibility for the accuracy, completeness, or any third party's use or the results of such use of any information, apparatus, product, or process disclosed, or represents that its use would not infringe privately owned rights. Reference herein to any specific commercial product, process, or service by trade name, trademark, manufacturer, or otherwise, does not necessarily constitute or imply its endorsement, recommendation, or favoring by the United States Government or any agency thereof or its contractors or subcontractors. The views and opinions of authors expressed herein do not necessarily state or reflect those of the United States Government or any agency thereof.

This report has been reproduced from the best available copy.

Available in paper copy and microfiche.

Available electronically at

http://www.doe.gov/bridge. Available for a processing fee to the U.S. Department of Energy and its contractors, in paper, from:

U.S. Department of Energy

Office of Scientific and Technical Information

P.O. Box 62

Oak Ridge, TN 37831-0062

phone: $865-576-8401$

fax: 865-576-5728

email: reports@adonis.osti.gov(423) 576-8401

Available for sale to the public, in paper, from:

U.S. Department of Commerce

National Technical information Service

5285 Port Royal Road

Springfield, VA 22161

Phone: 800-553-6847

fax: 703-605-6900

email: orders@ ntis.fedworld.gov

online ordering:

http://www.ntis.gov/ordering.htm 



\section{FLAMMABLE GAS REFINED SAFETY ANALYSIS TOOL SOFTWARE VERIFICATION AND VALIDATION REPORT FOR RESOLVE VERSION 2.5}

September 20, 2000

Sandia National Laboratories

Albuquerque, New Mexico 87185

\section{Prepared for:}

Hanford River Protection Project

Richland, Washington 99352

\section{Contributing Authors:}

CH2M HILL Hanford Group, Inc.

Steven A. Barker, David R. Bratzel

Innovative Technology Solutions Corporation

Scott G. Ashbaugh, William M. Guerra, Jonathan Kingson, Leigh F. McGlinchey

M. H. Chew \& Associates, Inc.

Jay C. Lavender

Sandia National Laboratories

Wu-Ching Cheng, Ann L. Hodges, Brian Lewis, Scott E. Slezak, Patricia A. Trellue Technadyne Engineering Consultants, Inc.

Anderson Riddle 
RPP-6873 REV 0

This page is intentionally left blank. 
RPP-6873 REV 0

\section{EXECUTIVE SUMMARY}

The Refined Safety Analysis Project was initiated as a multi-organizational effort in 1996 to support resolution of the Flammable Gas Safety Issue. As part of this activity, Sandia National Laboratories was tasked to develop a methodology for evaluating flammable gas accidents and control selection in the Hanford waste tanks. This methodology is termed the Analysis Framework (AF) and has been incorporated into a software Analysis Tool (AT) called Resolve.

The broad purpose of the Analysis Framework is to establish a physical basis for consistent evaluation of the impact of proposed flammable gas controls on operational risk. It is used to decompose flammable gas accident scenarios into component submodels. Those submodels identify key parameters that may have significant influence on the analysis results. Many of those parameters can be expressed quantitatively as uncertainty distributions constructed from Hanford Site data. Some of those parameters were quantified in uncertainty distributions developed by an expert panel because no actual tank data were available for these parameters. The expert panel evaluated the available information to estimate the range of uncertainty for the key parameters that could not be quantified directly from tank data.

By quantifying the uncertainty associated with each piece of the analysis and tracking the impact of the uncertainty on the computed accident consequences, the Analysis Tool can estimate the degree of technical confidence that may be assigned to the calculated safety risk for each accident analysis.

Both verification and validation seek to establish that the software is useful and accurate for the intended applications. Validation seeks to determine if the right products were built. Verification determines if the product was built right. A standard software engineering life cycle, based on Institute of Electrical and Electronics Engineers (IEEE) standards, includes seven distinct phases. These phases were used as a road map to identify work requiring verification and validation $(V \& V)$. 


\section{RPP-6873 REV 0}

Validation tests had as their general aim to determine whether or not a model's or submodel's calculations matched existing data or conformed to historical results or expert judgment. Since such matches can never be exact, it was necessary to establish prior ranges around known values within which the model results could be expected to lie. The model was then judged to have met validation expectations if it produced results that were within that range for a given parameter which the model calculated.

The purpose of this report is to document all verification and validation activities, results, and findings related to the development of Resolve Version 2.5, as prescribed by the Hanford Gas Release Event Safety Analysis Tool Version 2.0 Software Verification and Validation Plan (Hodges 1998d) and the Hanford Gas Release Event Safety Analysis Tool Version 2.5 Software Verification and Validation Plan (Hodges 1999). Section 1.0 provides an introduction to the Refined Safety Analysis Project, the Resolve software, and verification and validation in the context of the project. Sections 2.0 and 3.0 summarize all verification and validation tasks respectively. Section 4.0 presents detailed task descriptions for all V\&V tasks including task abstract, applicable requirements, inputs, methods, acceptance criteria, and results, including the status of any Discrepancy Reports that were issued as a result of the task. Section 5.0 provides a discussion of the Discrepancy Report process and the current status of outstanding DRs. Section 6.0 presents a discussion of overall software maturity, the impact on the project of the $\mathrm{V} \& \mathrm{~V}$ findings, and recommendations. Section 7.0 provides a complete list of all reference material used in the execution of the V\&V tasks.

The Resolve Analysis Tool underwent two extensive V\&V testing cycles, which accomplished all activities prescribed in the Resolve Version 2.0 and Resolve Version 2.5 V\&V Plans (Hodges 1998d, 1999). Eighteen interim model results, at all phenomenological stages of a hypothetical flammable gas accident, compared suitably to appropriate benchmark values, as established by tank data, experimental data, or expert judgements. In addition, requirements in the Analysis Framework document (Slezak and Williams 1998, Slezak et al. 1998) were identified and subsequent project documents and the code were reviewed for compliance to these requirements. All issues expected to significantly impact the applicability of the software results to RSA safety evaluations were resolved. 


\section{RPP-6873 REV 0}

Testing also has indicated four parameters calculated by the model that lie outside prior established ranges for one or more tanks. For example, the calculation of high flammable gas concentrations during salt well pumping results from conservatism in the way the model predicts ammonia concentrations during salt well pumping. This conservatism ensures that decisions made on the basis of these model results will tend to err on the side of greater safety, and not on the side of higher safety risk.

Comparison of consequence values between Resolve runs for burns in waste-intruding equipment, while trending as expected, showed higher consequence values than expected by expert judgment. There are no data on actual burns in waste-intruding equipment, so it is preferable for the model to calculate consequences that bound those likely to be seen in any real event. There is no absolute method for determining the accuracy of expert judgment in these cases.

Testing of the Buoyant Displacement Model indicated that model results for Tank 241-SY-101 do not match historical data precisely. This difference arises from the incompatibility of sparse existing data with the assumption of the model that liquid density in the tanks is constant. In fact, it is known that liquid densities in tanks that exhibit buoyant displacement behavior vary over time during a buoyant release cycle. The Tank 241-SY-101 analysis was an exception, and results for the other buoyant displacement tanks were acceptable.

The model for calculating combustion pressure during a hypothetical gas burn in a tank can result in pressure estimates that deviate from relevant experimental results by up to a factor of two. This difference was noted in the evaluation of some rare, high-consequence accidents. It should be noted, however, that this deviation will have little or no impact on risk calculations because of the relatively greater uncertainty in determining the source term of an accident.

The results of verification and validation tasks demonstrate that the Analysis Framework and its software implementation in Resolve are consistent with project requirements. In addition, model predictions for flammable gas risk and interim model results were consistent with and compared 


\section{RPP-6873 REV 0}

acceptably to tank data, results from other codes, and alternate expert judgement. The Analysis Framework and Resolve achieve their intended purpose of providing a decision support tool that evaluates risk plus uncertainty from flammable gas accidents and quantifies flammable gas accident control effectiveness in Hanford Site waste tanks. 


\section{ACKNOWLEDGEMENTS}

The Hanford Refined Safety Analysis Tool Project has been superbly guided by the leadership of Kenneth E. Washington and Eunice R. Young. Ann L. Hodges has diligently headed up the multidisciplinary verification and validation team. The Department of Energy, Office of River Protection and the CH2M HILL Hanford Group have also provided excellent guidance and leadership. The following individuals contributed to development and checkout of the project software. Their hard work and dedication to the success of the Hanford Refined Safety Analysis Tool project is evident in both the breadth and depth of the effort presented herein.

Sandia National Laboratories

Jaye H. Bullington

Wu-Ching Cheng

Kelly E. Gomez

Ann L. Hodges

Steven L. Humphreys

Chris E. Olson

Chris A. Saavedra

Scott E. Slezak

Patricia A. Trellue

Kenneth E. Washington

Eunice R. Young

Innovative Technology Solutions Corporation

Scott G. Ashbaugh

K. Noel Belcourt

William M. Guerra

Jonathan C. Kingson

Leigh F. McGlinchey

Ellen L. Nelson

Technadyne Engineering Consultants, Inc.

Nancy E. Nalda

Anderson Riddle 
RPP-6873 REV 0

This page is intentionally left blank. 


\section{TABLE OF CONTENTS}

1.0 INTRODUCTION.

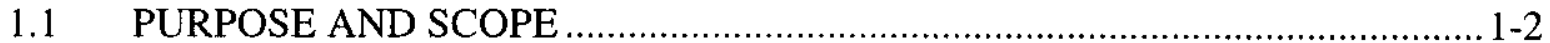

1.2 MEANING OF VERIFICATION AND VALIDATION FOR THE REFINED SAFETY ANALYSIS PROJECT AND THE SOFTWARE DEVELOPMENT LIFE CYCLE CONTEXT

1.3 RESOLVE SOFTWARE EVOLUTION AND VERIFICATION AND VALIDATION WORK HISTORY …........................................................... 1-3

1.4 QUALITY ASSURANCE TENETS …...................................................... $1-4$

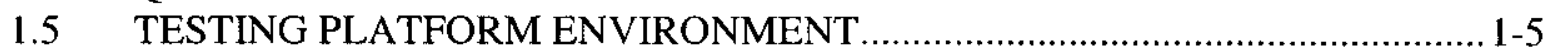

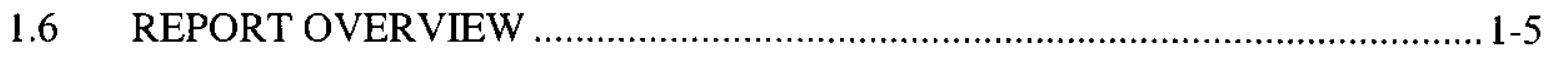

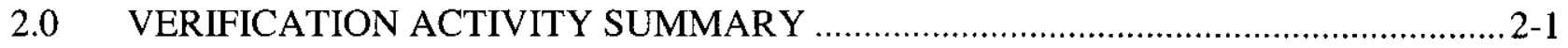

2.1 VERIFICATION TASK MATRIX FOR RESOLVE VERSION 2.5 ................. 2-3

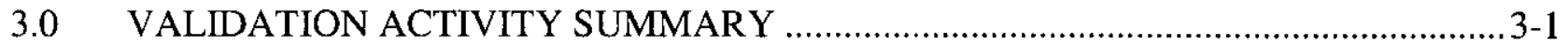

3.1 VALIDATION TASK MATRIX FOR RESOLVE VERSION $2.5 \ldots \ldots \ldots \ldots \ldots \ldots . . . . . . . .3$

4.0 VERIFICATION AND VALIDATION ACTIVITY DESCRIPTIONS .........................4-1

4.1 VERIFICATION: TRACEABILITY OF PROJECT DOCUMENTS ..................4-1

4.2 VERIFICATION: AFE CODE INSPECTION-RESOLVE 1.92 .....................4-2

4.3 VERIFICATION: AFE CODE INSPECTION-RESOLVE 2.16 AND 2.5 ........4-3

4.4 VERIFICATION: HEADSPACE MIXING MODEL .....................................4-7

4.5 VERIFICATION: CONSEQUENCE MODEL .........................................4-10

4.6 VERIFICATION: UNITS CHECKING ...................................................4-15

4.7 VERIFICATION: SOFTWARE REQUIREMENTS SPECIFICATION DATA TRANSFER REQUIREMENTS .................................................... 4- 16

4.8 VERIFICATION: SOFTWARE REQUIREMENTS SPECIFICATION STATISTICAL ANALYSIS AND LHS SAMPLING CHECK ....................... 4-22

4.9 VERIFICATION: SOFTWARE REQUIREMENTS SPECIFICATION GRAPHICAL USER INTERFACE REQUIREMENTS CHECK

4.10 VERIFICATION: SOFTWARE REQUIREMENTS SPECIFICATION MISCELLANEOUS REQUIREMENTS .................................................. 4-27

4.11 VERIFICATION: USER GUIDE REVIEW ….........................................4-28

4.12 VERIFICATION: USER GUIDE IMPLEMENTATION TESTING ................4-29

4.13 VERIFICATION: REFINED SAFETY ANALYSIS PROJECT QUALITY ASSURANCE AUDIT ....................................................................4-30

4.14 VERIFICATION: DATA TRANSFER FROM EXCEL ${ }^{\circledR}$ DATABASES TO ACCESS RELATIONAL DATABASE (PROCESS CHECK) ........................4-31

4.15 VERIFICATION: RESOLVE RELATIONAL, DATABASE CHANGES .........4-34

4.16 VERIFICATION: REDERIVATION OF ANALYSIS FRAMEWORK EQUATIONS. 


\section{TABLE OF CONTENTS (cont'd)}

4.17 VERIFICATION: REDERIVATION OF IMPLEMENTATION DETAILS EQUATIONS

4.18 VERIFICATION: MODEL COMPARISON TESTING .....................................4-36

4.19 VERIFICATION: BENCHMARK TANK TESTING

4.20 VALIDATION: BUOYANT DISPLACEMENT GAS RELEASE EVENT MODEL

4.21 VALIDATION: NON-BUOYANT DISPLACEMENT GAS RELEASE EVENT MODEL-HEADSACE HYDROGEN CONCENTRATION AND MIMIMUM DURATION

4.22 VALIDATION: NON-BUOYANT DISPLACEMENT GAS RELEASE EVENT MODEL-RELEASE FREQUENCY.

4.23 VALIDATION: STRATIFIED LAYER TIME-AT-RISK …….....................4-52

4.24 VALIDATION: SALT WELL PUMPING MODEL …………........................4-56

4.25 VALIDATION: AMMONIA RELEASES DURING BUOYANT DISPLACEMENT GAS RELEASE EVENTS.

4.26 VALIDATION: AMMONIA RELEASES DURING STEADY-STATE OPERATION

4.27 VALIDATION: AMMONIA RELEASES DURING MIXER PUMP OPERATION

4.28 VALIDATION: AMMONIA RELEASE DURING WASTE TRANSFERS .....4-64

4.29 VALIDATION: COMBUSTION MODEL OUTPUT COMPARISON TO EXPERIMENTAL DATA

4.30 VALIDATION: PANEL-BASED UNCERTAINTY DISTRIBUTION VALIDATION

4.31 VALIDATION: DOUBLE-SHELL TANK STEADY-STATE

4.32 HEADSPACE GAS CONCENTRATIONS ................................... CONSEQUENCES COMPARISON TO AUTHORIZATION BASIS.

4.33 VALIDATION: RISK MODEL-FREQUENCY OF HEPA FAILURES OR WORSE

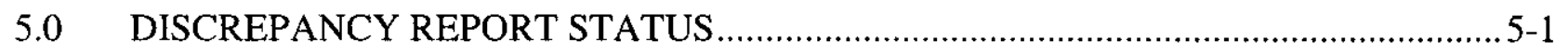

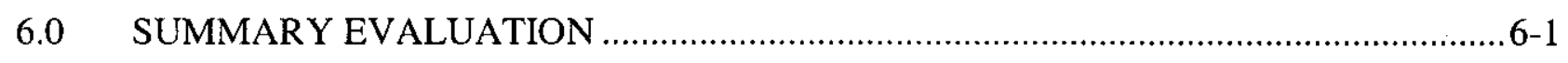

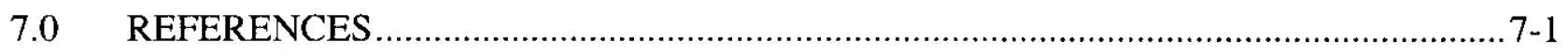

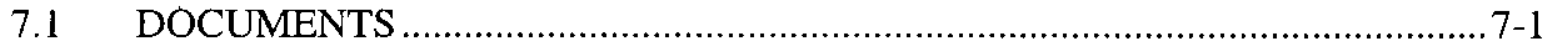

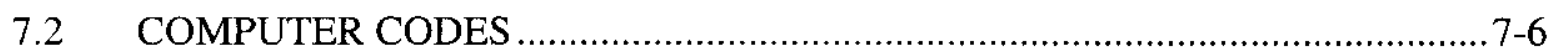

7.3 E-MAIL COMMUNICATIONS, INFORMAL DOCUMENTS ............................ $7-6$ 
RPP-6873 REV 0

\section{LIST OF FIGURES}

Figure 4-1. Peak Headspace Hydrogen Concentrations in Tank 241-U-105-Comparison Results.

Figure 4-2. Non-Buoyant Displacement GRE Minimum Release Duration-Comparison Results.

Figure 4-3. Peak Pressure for Burns of Mixture $29\left(29 \% \mathrm{H}_{2}, 24 \% \mathrm{~N}_{2} \mathrm{O}, 35 \% \mathrm{~N}_{2}, 1 \% \mathrm{CH}_{4}\right.$, $11 \% \mathrm{NH}_{3}$ )-Comparison Results.

Figure 4-4. Detonation Model Case 1: Stoichiometric $\mathrm{H}_{2}-\mathrm{N}_{2} \mathrm{O}$ in Varying \% Air.

Figure 4-5. Detonation Model Case 2: Stoichiometric $\mathrm{H}_{2}-\mathrm{N}_{2} \mathrm{O}$ in Varying $\% \mathrm{~N}_{2}$.

Figure 4-6. Detonation Model Cases 3 and 4: Varying $\% \mathrm{H}_{2}$ in $\mathrm{N}_{2} \mathrm{O}$ and Varying $\% \mathrm{H}_{2}$ in $\mathrm{N}_{2} \mathrm{O}$ with Constant $30 \%$ Dilution with $\mathrm{N}_{2}$.

Figure 4-7. Detonation Model Case 5: Varying $\% \mathrm{H}_{2}$ in Air. 


\section{LIST OF TABLES}

Table 1-1. Major Resolve Releases and Pertinent V\&V Documentation.................................... 1-6

Table 2-1. Significant Products from Resolve Life Cycle Phases............................................... 2-2

Table 2-2. Verification Task Matrix for Resolve Version 2.5 ...................................................... 2-3

Table 3-1. Validation Task Matrix for Resolve Version 2.5. .................................................... 3-3

Table 4-1. Headspace Mixing Model-Test Case Descriptions. ..................................................... 4-9

Table 4-2. Radiological Consequences Verification-Comparison Results................................ 4-13

Table 4-3. Toxicological Consequences Verification-Comparison Results............................... 4-14

Table 4-4. Data Transfer-Test Cases. ................................................................................... 4-20

Table 4-5. Data Transfer-Test Matrix................................................................................ 4-21

Table 4-6. LHS Sampling Check-Test Case Descriptions........................................................ 4-24

Table 4-7. Statistics Validation-Test Case Organization............................................................ 4-25

Table 4-8. Areas Covered and Relevant Contacts for Refined Safety Analysis Project Quality Assurance Audit....................................................................................... 4-31

Table 4-9. Mixer Pump-Test Case Input................................................................................ 4-42

Table 4-10. Buoyant Displacement GRE Potential-Comparison Results..................................... 4-43

Table 4-11. Average Volume of Buoyant Displacement GREs-Comparison Results.................. 4-44

Table 4-12. Average Buoyant Displacement GRE Period-Comparison Results.......................... 4-45

Table 4-13. Average Peak Headspace Hydrogen Concentration for Buoyant Displacement GREs-Comparison Results.

Table 4-14. Frequency and Size of Mixer Pump-Induced Buoyant Displacement GREsComparison Results.

Table 4-15. Peak Headspace Hydrogen Concentration During Non-Buoyant Displacement GREs-Comparison Results.

Table 4-16. Non-Buoyant Displacement GRE Frequencies in 100 Series TanksComparison Results. 


\section{LIST OF TABLES (cont'd)}

Table 4-17. Stratified Layer Time-at-Risk Validation-Test Case Setup.......................................4-54

Table 4-18. Stratified Layer Time-at-Risk Validation-Comparison Results. ............................... 4-55

Table 4-19. Salt Well Pumping Hydrogen Concentration-Test Case Setup...............................4-58

Table 4-20. Salt Well Pumping Flammable Gas Release Rate-Test Case Setup.........................4-58

Table 4-21. Salt Well Pumping Hydrogen Gas Concentration-Comparison Results. ..................4-60

Table 4-22. Salt Well Pumping Flammable Gas Release Rate-Comparison Results. ................. 4-60

Table 4-23. Peak Ammonia Concentrations During Buoyant Displacement Releases-

Comparison Results.

Table 4-24. Steady-State Headspace Ammonia Concentration in Tanks 241-AW-101 and 241-SY-101-Inputs and Intermediate Calculation Values.

Table 4-25. Steady-State Headspace Ammonia Concentration in Tanks 241-AW-101 and 241-SY-101-Comparison Results.

Table 4-26. Ammonia Releases During Mixer Operation-Inputs and Intermediate

Calculation Values.

Table 4-27. Ammonia Headspace Concentrations in the Receiver Tank During Waste Transfers-Comparison Results.

Table 4-28. Peak Pressure for Burns of Mixture $29\left(29 \% \mathrm{H}_{2}, 24 \% \mathrm{~N}_{2} \mathrm{O}, 35 \% \mathrm{~N}_{2}, 1 \% \mathrm{CH}_{4}\right.$, $11 \% \mathrm{NH}_{3}$ )-Comparison Results.

Table 4-29. Lean Flammability Limit Test-Experimental Mixture Compositions. 4-70

Table 4-30. Lean Flammability Limits-Comparison Results. $4-70$

Table 4-31. Mass of Respirable Waste Suspended/Released-Comparison Results. 4-75

Table 4-32. Steady-State Headspace Ammonia Concentration for Tanks with RGS Data. $4-78$

Table 4-33. Steady-State Headspace Methane Concentration Ratio for Tanks with RGS Data. $4-78$

Table 4-34. Steady-State Headspace Nitrogen Concentration for Tanks with RGS Data. 4-78 
RPP-6873 REV 0

\section{LIST OF TABLES (cont'd)}

Table 4-35. Steady-State Headspace Nitrous Oxide Concentration Ratio for Tanks with RGS Data. ................................................................................................... 4-78

Table 5-1. Discrepancy Report Severity Levels. ……............................................................ 5-1

Table 5-1. Status and Severity of Discrepancy Reports. ......................................................... 5-2 


\section{ACRONYMS}

$\begin{array}{ll}\text { AF } & \text { Analysis Framework } \\ \text { AFE } & \text { Analysis Framework Engine } \\ \text { afi } & \text { analysis framework input } \\ \text { afo } & \text { analysis framework output } \\ \text { AT } & \text { Analysis Tool } \\ \text { BD } & \text { Buoyant Displacement } \\ \text { CDF } & \text { Cumulative Distribution Function } \\ \text { CCDF } & \text { Complementary Cumulative Distribution Function } \\ \text { CEDE } & \text { Committed Effective Dose Equivalent } \\ \text { CPU } & \text { Central Processing Unit } \\ \text { CS1 } & \text { Control Set 1 } \\ \text { CS2 } & \text { Control Set 2 } \\ \text { DOE } & \text { U.S. Department of Energy } \\ \text { DR } & \text { Discrepancy Report } \\ \text { DST } & \text { Double-Shell Tank } \\ \text { EDB } & \text { Elicited Database } \\ \text { FG } & \text { Facility Group } \\ \text { FY } & \text { Fiscal Year } \\ \text { GRE } & \text { Gas Release Event } \\ \text { GUI } & \text { Graphical User Interface } \\ \text { I\&R } & \text { Equipment Insertion or Removal Operation } \\ \text { HEPA } & \text { High-Efficiency Particulate Air } \\ \text { HRPP } & \text { Hanford River Protection Project } \\ \text { LANL } & \text { Los Alamos National Laboratories } \\ \text { LFL } & \text { Lower Flammability Limit } \\ \text { LHS } & \text { Latin Hypercube Sampling } \\ \text { ICS } & \text { Ignition Control Strategy } \\ \text { IEEE } & \text { Institute of Electrical and Electronics Engineers } \\ \text { ITSC } & \text { Innovative Technology Solutions Corporation } \\ \text { MHz } & \text { Megahertz } \\ \text { NTS } & \text { Non-Tank Specific } \\ \text { PDB } & \text { Pedigreed Database } \\ \text { PNNL } & \text { Pacific Northwest National Laboratory } \\ \text { PP } & \text { Past Practices } \\ \text { PQAP } & \text { Project Quality Assurance Plan } \\ \text { QA } & \text { Quality Assurance } \\ \text { QAPP } & \text { Quality Assurance Program Plan } \\ \text { RAM } & \text { Random Access Memory } \\ \text { RDB } & \text { Relational Database } \\ \text { RFL } & \text { Rich Flammability Limit } \\ \text { RMCS } & \text { Rotary Mode Core Sampling } \\ & \end{array}$




\section{ACRONYMS (cont'd)}

$\begin{array}{ll}\text { RSA } & \text { Refined Safety Analysis } \\ \text { RWMP } & \text { Radioactive Waste Management Program } \\ \text { SDD } & \text { Software Design Description } \\ \text { SNL } & \text { Sandia National Laboratories } \\ \text { SRS } & \text { Software Requirements Specification } \\ \text { SMP } & \text { Software Management Plan } \\ \text { SST } & \text { Single-Shell Tank } \\ \text { SSTP } & \text { Software Systems Test Plan } \\ \text { SSTR } & \text { Software Systems Test Report } \\ \text { SVGA } & \text { Super Video Graphics Array } \\ \text { TBD } & \text { To Be Determined } \\ \text { TCS } & \text { Tank Control Strategy } \\ \text { TDS } & \text { Tank Damage State } \\ \text { TIG } & \text { Tank Inventory Group } \\ \text { TS } & \text { Tank Specific } \\ \text { TWRS } & \text { Tank Waste Remediation System } \\ \text { ULD } & \text { Unit Liter Dose } \\ \text { V\&V } & \text { Verification and Validation }\end{array}$




\section{GLOSSARY OF TERMINOLOGY}

Elicited Database The database containing the expert panel-based uncertainty distribution data required by phenomenological models and consequences measures. The content of this database is now incorporated into the Resolve Relational Database.

Expert Database Synonymous with "elicited database."

Expert Elicitation A process that uses experts to estimate uncertainty distributions for parameters whose actual values or distributions are not known. Resolve uses an aggregate uncertainty distribution curve derived from the elicited uncertainty distributions.

Fill Factor

The ratio of tank waste volume divided by tank total volume; the range is between zero and one.

Instance A single pass through the Analysis Framework Engine using a single sample vector.

Ignition Event

The presence of an ignition source in a flammable gas mixture, the composition of which exceeds the Lower Flammability Limit (LFL), causing combustion of the flammable gas mixture.

Ignition Source

A phenomenon capable of igniting a flammable gas mixture; usually sparks or localized hot spots.

Pedigreed Database The database containing tank, tank waste, or safety-control characterization data that are well known. The content of this database is now incorporated into the Resolve Relational Database.

Plume

Plume Gas Release

Plume Waste Release
A plume gas release.

A gas release that results in waste gas going to a localized mixing zone or stratified layer rather than being dispersed into the entire headspace volume.

A hypothetical volume release outside the tank after a burn. This volume is defined by a virtual cylinder with a width equal to the width of the tank and a height such that the resulting volume equals the volume of gas that would have to be vented from the tank in order to return the headspace to atmospheric pressure. 


\section{GLOSSARY OF TERMINOLOGY (cont'd)}

Rad Radiological consequences; measured in sieverts.

Sample Vector The collection of a single sample from each distribution in the analysis input values for a particular tank.

Source Safe

Microsoft ${ }^{\circledast}$ version control tool that allows multiple developers to view or edit code and document files without corrupting each other's work. Only one user at a time is allowed write permission to accessed files.

Additional features include user ability to view change history and a code difference utility for tracing modifications between versions.

Stochastic Data Uncertainty parameters that have a known distribution.

Tool

Resolve Analysis Tool.

Tox

Toxicological consequences; measured in fraction-of-risk guidelines. 


\subsection{INTRODUCTION}

The Refined Safety Analysis Project was initiated as a multi-organizational effort in 1996 to support resolution of the Flammable Gas Safety Issue. As part of this activity, Sandia National Laboratories was tasked to develop a methodology for evaluating flammable gas accidents and control selection in the Hanford waste tanks. This methodology is termed the Analysis Framework (AF) and has been incorporated into a software Analysis Tool (AT), called Resolve.

The broad purpose of the Analysis Framework is to establish a physical basis for consistent evaluation of the impact of proposed flammable gas controls on operational risk. It is used to decompose flammable gas accident scenarios into component submodels. Those submodels identify key parameters that may have significant influence on the analysis results. Many of those parameters can be expressed quantitatively as uncertainty distributions constructed from Hanford Site data. Some of those parameters were quantified in uncertainty distributions developed by an expert panel because no actual tank data were available for these parameters. The expert panel evaluated the available information to estimate the range of uncertainty for the key parameters that could not be quantified directly from tank data.

By quantifying the uncertainty associated with each piece of the analysis and tracking the impact of the uncertainty on the computed accident consequences, the Analysis Tool can estimate the degree of technical confidence that may be assigned to the calculated safety risk for each accident analysis. The Analysis Tool provides the flexibility for the user to evaluate the impact of varying the degree of conservatism in selecting values for key parameters. This allows the user to determine the appropriate level of overall conservatism that should be applied. This flexibility is a natural result of using uncertainty distributions instead of point estimates for many parameters identified in the models. The 95\%-confidence-level result for Analysis Framework risk analyses is the level at which $95 \%$ of all individual runs using randomly selected parameter values result in smaller consequences.

User-supplied parameters, often design criteria such as active ventilation flow rates and tankspecific parameters such as tank dimensions and existing waste conditions, are required in the core model. Therefore, these also constitute part of the Analysis Framework. In general, the Analysis Framework is the physical description used to compute flammable gas accident frequencies and consequences, the net annual risk from flammable gas accidents, and the impact of controls on the risk of a flammable gas accident.

The Analysis Framework has been incorporated into a software Analysis Tool called Resolve. The Resolve software serves as the practical implementation of the AF modeling concept. Resolve is composed of three software components: the Relational Database (RDB), the Graphical User Interface (GUI), and the Analysis Framework Engine (AFE).

The Relational Database (RDB) contains the values of all the parameters needed by the core model to perform the calculations. The RDB architecture supports the storage of parameter values as a variety of distribution types, supports the selection of some parameter values based on the values of other parameters, supports the replacement of panel-based distributions with 
data-based distributions, and supports the tracking of the source of the parameter value (for example, data-based vs. panel-based).

The Graphical User Interface (GUI) retrieves data from the database, collects any data that the user might provide for a controls analysis or sensitivity study, and writes an analysis input file (.afi) for use by the Analysis Framework Engine (AFE). Once the AFE has written an output file of its calculations, the GUI reads in the results for each sample set. The GUI then calculates statistics and rollup numbers for these results, and presents the results and statistics to the user in either a table or a chart.

The Analysis Framework Engine (AFE) is the implementation of the core computational model. It reads in the input file, samples distributions, and calculates frequency and consequences based on the sampled data sets for up to 120,000 gas release events. These results are then written out to the analysis output file (.afo).

Software requirements and design for the Resolve tool are documented in the Software Requirements Specification (SRS) for the Gas Release Event Safety Analysis Tool (Humphreys 1998a) and the Software Design Description (SDD) for the Gas Release Event Safety Analysis Tool, Resolve Version 2.0 (Humphreys 1998b).

\subsection{PURPOSE AND SCOPE}

The purpose of this report is to document all verification and validation (V\&V) activities, results, and findings related to the development of Resolve Version 2.5, as prescribed by the Hanford Gas Release Event Safety Analysis Tool Version 2.0 Software Verification and Validation Plan (Hodges 1998d) and the Hanford Gas Release Event Safety Analysis Tool Version 2.5 Software Verification and Validation Plan (Hodges 1999). This report documents all specific life-cycleproduct V\&V tasks accomplished, and their corresponding results, during the time that Resolve Version 2.5 was under development. This report has been prepared in accordance with the Computer Software Quality Assurance Requirements, HNF-PRO-309 (Grier 1998) document, as implemented in the Refined Safety Analysis Project Quality Assurance Plan, PQAP (SNL 1998c).

\subsection{MEANING OF VERIFICATION AND VALIDATION FOR THE REFINED SAFETY ANALYSIS PROJECT AND THE SOFTWARE DEVELOPMENT LIFE CYCLE CONTEXT}

Both verification and validation seek to establish that the software is useful and accurate for the intended applications. The AT 2.5 V\&V Plan (Hodges 1999) definitions of software Verification and Validation, although more detailed, are consistent with those found in the Computer Software Quality Assurance Requirements (Grier 1998):

"Verification is the process of checking that the product is being built 'right' by determining that products in each life cycle phase adhere to and are traceable to prior life cycle phase requirements. In this way, documentation of each product forms an adequate foundation for the next life cycle phase. 
"Validation consists of checking that the right product is being built. By running test cases and various analyses, assurance is provided that the software system adheres to system and software requirements, produces credible results, and compares reasonably to results of alternate calculations (e.g., hand calculations, analytical solutions, alternative computer codes) or experimental data."

A standard software engineering life cycle, based on Institute of Electrical and Electronics Engineers (IEEE) standards, includes seven distinct phases: (1) concept, (2) requirements, (3) design, (4) implementation, (5) test, (6) installation and checkout, and (7) operation and maintenance. Together, these phases work toward the following common goals:

(a) Transforming the original project concept into verified and validated, usable software that is flexible enough to address changing requirements, and

(b) Incorporating features as the need arises during the expected lifetime of the software.

This idealized software development life cycle is used as a road map to identify work products (for instance, requirements, design, code, database) requiring verification and validation (V\&V). Tables 2-2 and 3-1 summarize V\&V activities performed on the life cycle products of this project.

\subsection{RESOLVE SOFTWARE EVOLUTION AND VERIFICATION AND VALIDATION WORK HISTORY}

Following the initial concept study-completed in September 1996-and development of the initial AF, the first release of the Resolve software was Version 1.0 in September 1997.

The first verification and validation suite of testing was conducted on Resolve Versions 1.0 through 1.51. Involving thousands of individual checks, this effort yielded positive results and, in addition, uncovered some issues in the code implementation of the model. This effort was key to focusing subsequent efforts; for example, increased emphasis was placed on line-by-line code review and units checking. This effort also led to refinements in the V\&V process; for example, the Discrepancy Report process was developed and additional emphasis was placed on using the code implementation to validate models. Documentation for this first cycle of testing can be found in Safety Analysis Tool Acceptance and Validation Report, Resolve Version 1.4 (Barker et al. 1998) and Validation Calculations (Gelbard and Cheng 1998).

Since that time, the software has undergone significant revision and expansion in scope. Software versions prior to Version 1.80 are significantly different in code structure from the software as it exists in Version 2.5. Changes to the code structure were driven by the two-step development of the AF. The initial AF development work was limited to SST behaviors, so AT versions 1.0 to 1.51 were limited to SST analyses. Early in 1998 , the AF was expanded to include buoyant displacement GRE behavior. These BD GRE models were first incorporated into Resolve Version 1.80. Because of the degree of revision, results from testing of Resolve versions prior to 1.80 are only tentatively applicable to Resolve Version 2.5 and, for this reason, are not included in this report. 
Since Resolve Version 1.80, two more V\&V cycles have been carried out. Testing has focused around the releases of Resolve Versions 2.0 and 2.5.

V\&V activities were performed on complete, released versions of the Resolve software. The versions of the components, RDB, GUI, and AFE, of a release version are documented in the project Document Management System. A V\&V cycle typically involved the release of a Beta version (Version 1.90 in the case of Resolve 2.0, and Version 2.20 in the case of Resolve 2.5); testing; filing of Discrepancy Reports as issues are discovered; release of interim Beta versions with bug fixes; regression testing to ensure that any issues identified during initial testing were resolved; and final release of the software.

General goals for the Resolve 2.0 V\&V effort were threefold. First, emphasis was placed on new and altered features to the AT since the previous major evaluations were completed. This goal alone proved to be large in scope, reflecting the significant evolution of the software since the previous major release. Second, efforts were concentrated on assessing traceability between critical requirements, design, and the corresponding code. Finally, the improvement of the V\&V process itself was also identified as a principal goal. This included the AF and AT development teams working more closely with the V\&V team and increasing the scope and usefulness of the Discrepancy Report (DR) issue tracking process.

After the release of Resolve Version 2.0, the software continued to undergo revisions. These revisions were intended to resolve discrepancies identified in the Resolve Version $2.0 \mathrm{~V} \& \mathrm{~V}$ testing effort and to implement new functionality. In addition, a comprehensive review of available data for flammable gas risk assessment was accomplished during the summer of 1999 (Barker et al. 1999). The results of this review became formal requirements for the Analysis Tool, with impacts on all three software elements of the tool (the Relational Database (RDB), the Graphical User Interface (GUI), and the Analysis Framework Engine (AFE)).

Three goals were identified for the Resolve Version 2.5 V\&V effort. First, efforts were concentrated on providing a picture of the validity of the tool by comparing Resolve results to all available tank data, experiment data, alternate code results, and alternate expert judgements. All prior validation to external data was repeated, and some new tests of this type were added. Second, emphasis was placed on verifying new and altered features to the AT since the completion of the V\&V evaluation of Resolve Version 2.0. Third, testing activities focused on the overall robustness of the code by submitting it to tests designed to exercise the code under a broad range of analyses. Examples are the Benchmark and the Model Comparison activities (Sections 4.19 and 4.18 respectively).

Table 1-1 relates the history of major Resolve versions and the corresponding V\&V work that has been done for each. For purposes of brevity, the complete titles of the documents in Table 1-1 are not used; however, they can be found in the list of references in Section 7.0.

\subsection{QUALITY ASSURANCE TENETS}

As stated in the Project Quality Assurance Plan (SNL 1998c), all software V\&V activities were performed by individuals who had no part in the individual development efforts for the AF, Database, or Resolve code. Documentation of software V\&V activities including tasks, methods, results, acceptance criteria, and discrepancies are contained within this document as 
stipulated in the Computer Software Quality Assurance Requirements (Grier 1998). All V\&V related test files and handwritten notes, logs, and information were separately submitted as project Quality Assurance (QA) records.

\subsection{TESTING PLATFORM ENVIRONMENT}

All computing platforms used in completing V\&V activities met the following minimum platform requirements documented in the Software Requirements Specification (Humphreys 1998a):

- Personal Computer with Intel 133 megahertz (MHz) Pentium ${ }^{\circledR}$ Central Processing Unit (CPU)

- 32 megabytes Random Access Memory (RAM)

- 1.44 megabyte floppy disk drive

- 20 megabytes free hard disk space

- Super Video Graphics Array (SVGA) monitor with a resolution of $1024 \times 768$ pixels

- A Microsoft $^{\circledR}$ compatible mouse.

Although the software is designed to run with either Microsoft ${ }^{\circledast}{\text { Windows } 95^{\circledast}}^{\circledR}$ or WindowsNT ${ }^{\circledR}$ operating systems, nearly all V\&V activities were run with the WindowsNT ${ }^{\circledR}$ system.

\subsection{REPORT OVERVIEW}

Section 1.0 provides an introduction to the Refined Safety Analysis Project, the Resolve software, and verification and validation in the context of the project. Sections 2.0 and 3.0 summarize all verification and validation tasks respectively. Section 4.0 presents detailed task descriptions for all $\mathrm{V} \& \mathrm{~V}$ tasks including task abstract, applicable requirements, inputs, methods, acceptance criteria, and results. Each task description also notes if any Discrepancy Reports (DRs) were submitted as a result of that activity. Section 5.0 provides a discussion of the Discrepancy Report process and the current status of outstanding DRs. Section 6.0 presents a discussion of overall software maturity, the impact on the project of the V\&V findings, and recommendations. Section 7.0 provides a complete list of all reference material used in the execution of the V\&V tasks. 


\section{RPP-6873 REV 0}

Table 1-1. Major Resolve Releases and Pertinent V\&V Documentation.

\begin{tabular}{|l|l|l|}
\hline $\begin{array}{c}\text { Release } \\
\text { Date }\end{array}$ & $\begin{array}{l}\text { Resolve } \\
\text { Version }\end{array}$ & \multicolumn{1}{c|}{ V\&V Documentation } \\
\hline Sep. 97 & 1.0 & Software Systems Test Plan, Revision 0 (ITSC 1997a) \\
\hline Dec. 97 & 1.2 & Software Systems Test Plan, Revision 1 (ITSC 1997b) \\
\hline Feb. 98 1.4 & $\begin{array}{l}\text { Software Systems Test Plan Revision 1 Addendum (ITSC 1998a) } \\
\text { Safety Analysis Tool Acceptance and Validation Report (Barker et al. } \\
\text { 1998) } \\
\text { Validation Calculations (Gelbard, Cheng 1998) }\end{array}$ \\
\hline Jun. 98 & 1.51 & $\begin{array}{l}\text { V\&V Review and Action Plan; Rev 1.4 (Hodges 1998a) } \\
\text { V\&V Review Status Report, Rev 1.6 (Hodges 1998b) } \\
\text { V\&V Review Status Report, Rev 1.12 (Hodges 1998c) } \\
\text { Software Systems Test Report (ITSC 1998b) }\end{array}$ \\
\hline Nov. 98 & 2.01 & $\begin{array}{l}\text { Version 2.0 Software V\&VV Plan, Version 1.1 (Hodges 1998d) } \\
\text { AT 2.0 Software V\& V Report (McGlinchey et al. 1999) }\end{array}$ \\
\hline Sep. 99 & 2.5 & $\begin{array}{l}\text { Version 2.5 Software V\&V Vlan, Version 1.2 (Hodges 1999) } \\
\text { AT 2.5 Software V\&V Report (this report) }\end{array}$ \\
\hline
\end{tabular}




\subsection{VERIFICATION ACTIVITY SUMMARY}

As defined in Section 1.2, verification determines that the products from each life cycle phase adhere to, and are traceable to, prior life-cycle-phase requirements. Documentation of each product is intended to form an adequate foundation for the next life cycle phase. Table 2-1 summarizes the significant products for each phase in the Refined Safety Analysis project life cycle. A product may be referenced in more than one life cycle phase if its function and usage overlap multiple phases. For purposes of brevity, the complete titles of the products are not used but can be found in the list of references located in Section 7.0.

Verification tasks were performed for the Requirements, Design, Implementation, and Installation and Checkout phases of the project life cycle. In addition, verification of the Project Quality Assurance Plan (SNL 1998c) as well as the Quality Assurance Program Plan (SNL 1998a) was performed against the Computer Software Quality Assurance Requirements (Grier 1998). The primary goals for each of the verification tasks were to determine whether or not the product did in fact form an adequate foundation for the next life cycle phase and whether the product conformed to requirements laid out in prior life cycle phases. Each verification task has been cross-referenced to the relevant life cycle phase(s) as illustrated in Table 2-2, which summarizes all verification tasks. All verification testing activities described in the Resolve Version 2.0 (Hodges 1998d) and Resolve Version 2.5 (Hodges 1999) V\&V Plans were completed and are documented in this report.

The Resolve Version 2.0 V\&V Plan (Hodges 1998d) called for a task to, "Check that code branches work via virtual tanks." This activity was designed to exercise all branches of the headspace mixing model using actual or averaged tank and waste characteristics. This activity has been superceded by more detailed sensitivity studies (Section 4.18), verification check of headspace mixing model logic branches (Section 4.4), and validation to external data of buoyant displacement gas release behavior (Section 4.20), headspace mixing (Sections 4.20 and 4.23) and combustion pressure consequences (Sections 4.29 and 4.33). Because of redundancy with more detailed checks, this activity was considered moot by the customer, and the activity and its results are not reported here. 
Table 2-1. Significant Products from Resolve Life Cycle Phases.

\begin{tabular}{|l|l|}
\hline \multicolumn{1}{|c|}{ Life Cycle Phase } & \\
\hline All & $\begin{array}{l}\text { Software Management Plan (SNL 1998e) } \\
\text { Project Quality Assurance Plan (SNL 2000) } \\
\text { Quality Assurance Program Plan (SNL 1998a) }\end{array}$ \\
\hline Concept & $\begin{array}{l}\text { Analysis Framework Part 1 (Slezak and Williams 1998), Part 2 (Slezak } \\
\text { et al. 1998) } \\
\text { Analysis Framework Implementation Details (Slezak et al. 1999) }\end{array}$ \\
\hline Requirements & $\begin{array}{l}\text { Software Requirements Specification (Humphreys 1998a) } \\
\text { Analysis Framework Part 1 (Slezak and Williams 1998), Part 2 (Slezak } \\
\text { et al. 1998) } \\
\text { Analysis Framework Implementation Details (Slezak et al. 1999) } \\
\text { Flammable Gas Safety Analysis Data Review (Barker et al. 1999) }\end{array}$ \\
\hline Design & Software Design Description (Humphreys 1998b) \\
\hline Implementation & $\begin{array}{l}\text { Resolve Code (Humphreys and Young 1999) } \\
\text { Resolve Relational Database (Barker et al. 1999) } \\
\text { User Guide (Young, E. R. 1998) }\end{array}$ \\
\hline Test & $\begin{array}{l}\text { Software Systems Test Plan } \\
\text { Software Systems Test Report } \\
\text { V\&V Review and Action Plan (Hodges 1998a) } \\
\text { V\&V Review Status Reports (Hodges 1998b, 1998c) } \\
\text { V\&V Plan (Hodges 1998d, 1999) } \\
\text { V\&V Report (Barker et al. 1998, McGlinchey et al. 1999, this report) } \\
\text { Hanford Acceptance Testing }\end{array}$ \\
\hline $\begin{array}{l}\text { Onstallation and } \\
\text { Maintenance }\end{array}$ & $\begin{array}{l}\text { Installation Tests in User's Guide } \\
\text { Discrepancy Report Process (SNL 1998c) }\end{array}$ \\
\hline & $\begin{array}{l}\text { User Guide (Young, E. R. 1998) } \\
\text { Dion and }\end{array}$ \\
&
\end{tabular}


RPP-6873 REV 0

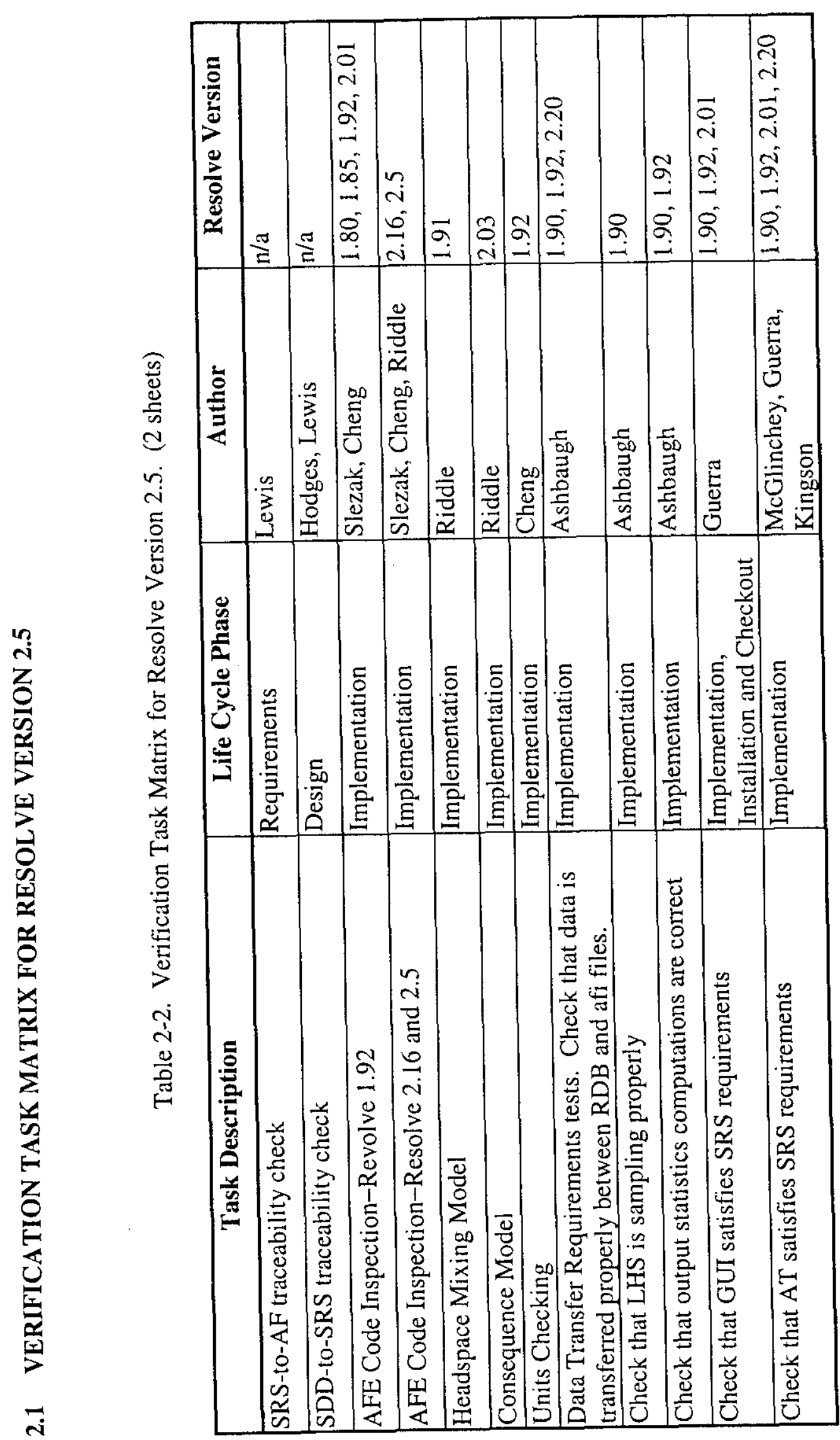


RPP-6873 REV 0

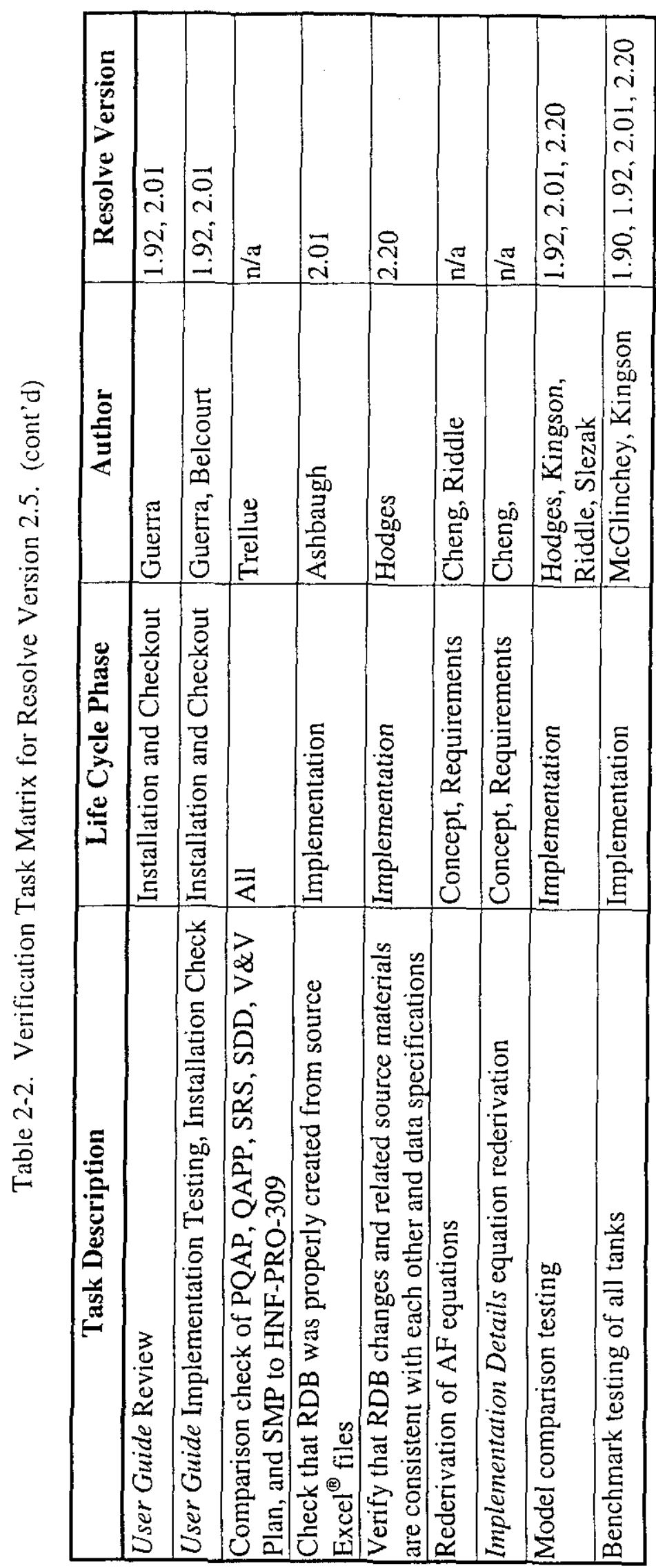




\subsection{VALIDATION ACTIVITY SUMMARY}

The primary goal for each of the validation tasks was to evaluate the correctness of the Analysis Tool (AT). The goal was to ensure that the overall product is usable and capable of yielding credible, defensible results. This was accomplished by comparing AT results to externally accepted data found in previously published sources. This included data generated by other waste behavior computer codes, experimental data, alternate expert judgements and safety assessments, Hanford field reports, or values inferred from field report data. Since such comparisons can never be exact, it was necessary to establish prior ranges around known values within which the model results could be expected to lie. The model was then judged to have met validation expectations if it produced results that were within that range for a given parameter which the model calculated.

All validation testing activities described in the Resolve Version 2.0 (Hodges 1998d) and Resolve Version 2.5 (Hodges 1999) V\&V Plans were completed and are documented in this report. Some additional testing was also performed, as noted in Table 3-1.

For clarity, the terminology used in this report differs slightly from that found in the V\&V plan. Specifically, "SST GRE" is replaced with "non-BD GRE," and "DST GRE" is replaced with "BD GRE." This change reflects the fact that the tool's analysis of Buoyant Displacement and non-Buoyant Displacement releases is irrespective of the type of tank.

The hydrogen release rate during salt well pumping parameter, specified for testing in the Resolve Version 2.5 Plan (Hodges 1999), was not explicitly tested, since validation of the hydrogen concentration during salt well pumping implicitly validates the release rate. Validation of hydrogen concentration during salt well pumping can be found in Section 4.24. Also, the Resolve Version 2.5 V\&V Plan (Hodges 1999) calls for validation of BD GRE duration. Distributions of available data for BD GRE durations were provided by the Data Review Workshop (Barker et al. 1999) and were subsequently incorporated into the relational database. Thus, validation of this model parameter was no longer needed. 


\section{RPP-6873 REV 0}

This page is intentionally left blank. 


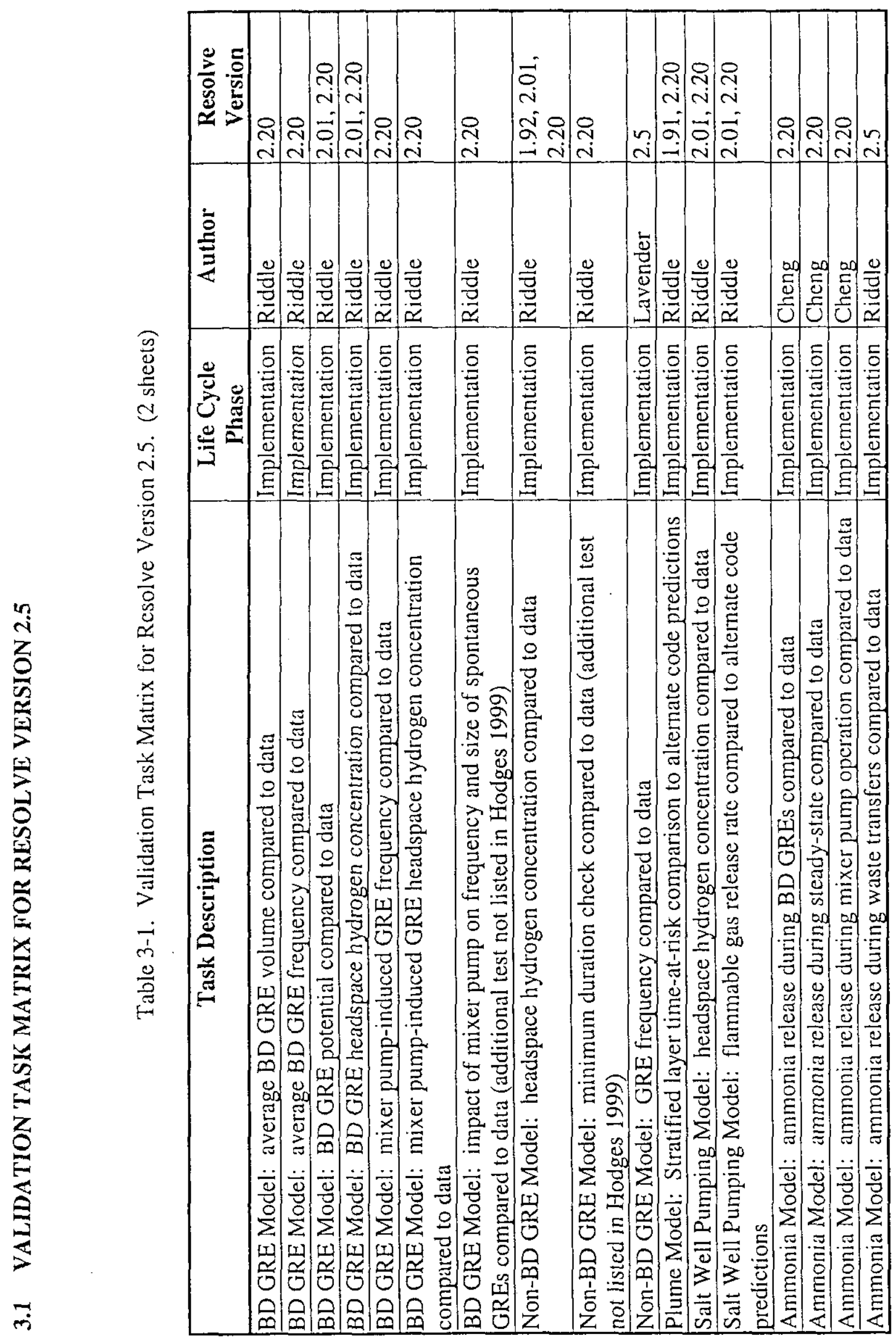




\section{RPP-6873 REV 0}

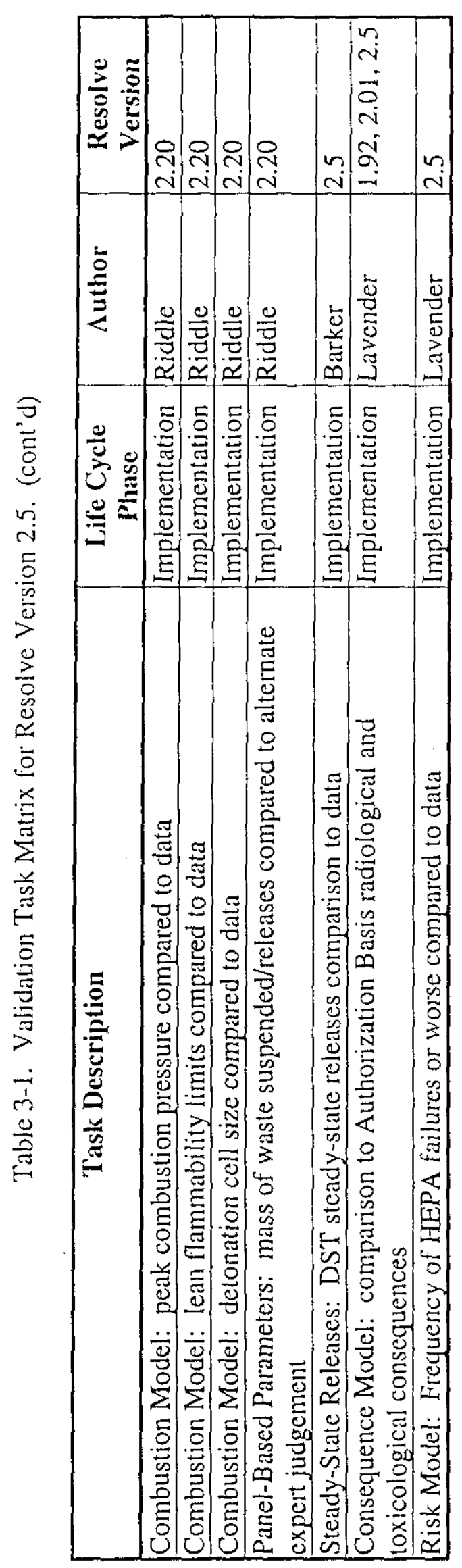




\subsection{VERIFICATION AND VALIDATION ACTIVITY DESCRIPTIONS}

Detailed verification and validation activity descriptions are presented in Sections 4.1 through 4.33 that follow. Each activity description contains a summary abstract, a list of references and input sources, a description of the testing methodology, the acceptance criteria for the activity, and a section detailing results including any Discrepancy Reports that were initiated as a result of the verification and validation activity. All verification and validation activities performed in support of the release of Resolve Version 2.5 are documented here. In some cases, the activity descriptions contain references to external documents or spreadsheets that contain more detailed information on how those particular tests were conducted.

\subsection{VERIFICATION: TRACEABILITY OF PROJECT DOCUMENTS}

Abstract: Part of verification is to ensure that products from prior software development life cycle phases provide adequate foundations for future life-cycle-phase products. Another part of verification is checking that subsequent life-cycle-phase products adhere to requirements laid out in prior life cycle products. See Section 1.2 for a description of the software development cycle concept used in this activity.

To verify these two aspects for the Refined Safety Analysis project documents, requirements were identified and labeled in the Analysis Framework (Slezak and Williams 1998, Slezak et al. 1998) (part of the Concept and Requirements phases), and these requirements were traced to the Software Requirements Specification (Humphreys 1998a) in the Requirements phase and to the Software Design Description (Humphreys 1998b) in the Design phase.

Requirements: Refined Safety Analysis Methodology for Flammable Gas Risk Assessment in the Hanford Site Tanks, Part 1: Analysis Framework for Single-Shell Tanks (Slezak and Williams 1998).

Refined Safety Analysis Methodology for Flammable Gas Risk Assessment in the Hanford Site Tanks, Part 2: Analysis Framework for Double-Shell Tanks (Slezak et al. 1998).

Refined Safety Analysis Methodology for Flammable Gas Risk Assessment in Hanford Site Tanks, Implementation Details for the Analysis Framework (Slezak 1998).

References and Inputs: Above referenced documents as well as the following:

Software Requirements Specification (SRS) for the Gas Release Event Safety Analysis Tool (Humphreys 1998a).

Software Design Description (SDD) for the Gas Release Event Safety Analysis Tool, Resolve Version 2.0 (Humphreys 1998b).

General Test Procedure: The AF was read by several V\&V team members, and requirements (equations, constants, software implementation details, etc.) were identified and given symbolic 
labels. These labels were then placed in a spreadsheet and each one was traced to the section in the SRS (Humphreys 1998a) that covered that specific requirement. Requirements in the SRS were then traced to the relevant sections in the SDD (Humphreys 1998b).

Acceptance Criteria: Project documents were checked to see that requirements were specified clearly enough for implementation. In addition, project documents were checked for coverage of requirements found in prior project documents. Because there was not a one-to-one correspondence between concept, requirement, and design documents, coverage of identified requirements was limited to (1) equations and (2) major software functionality.

Results: Numerous findings were generated, mostly because of unclear requirements or discrepancies between the project documents and the software implementation. These issues were transmitted to the document authors and were dealt with in subsequent versions of these documents.

The symbolic labeling scheme developed for this activity was adopted by the AFE software developer and included in the code comments. Thus, it is possible to trace specific AF requirements relevant to the analysis to their code implementation.

\subsection{VERIFICATION: AFE CODE INSPECTION-RESOLVE 1.92}

Abstract: This phase was designed to validate that the physical models described in the AF and related documents were correctly encoded in the Analysis Framework Engine (AFE) software. The purpose of the inspection was to ensure that (1) the individual equations given in the Analysis Framework (AF) were correctly encoded, (2) the values for the parameters that went into the AF equations were calculated correctly, (3) all parameter values within the model calculations were correctly passed between program functions, (4) all functionality described in the documentation was implemented in the code, and (5) any assumptions, simplifications, or changes made by the software authors, whether explicitly noted in comments or implicit in the code equations, were physically correct, consistent, and compatible with the intent of the Analysis Framework models. An additional check, to ensure that the equations constituting the AF models were correctly derived and documented without analytical or typographical errors, is documented in Sections 4.16 and 4.17.

This phase did not review the input and output data-handling portions of the AFE code.

Requirements: Requirements for the calculational capabilities of the software are given within the following documents:

Refined Safety Analysis Methodology for Flammable Gas Risk Assessment in the Hanford Site Tanks, Part 1: Analysis Framework for Single-Shell Tanks (Slezak and Williams 1998).

Refined Safety Analysis Methodology for Flammable Gas Risk Assessment in the Hanford Site Tanks, Part 2: Analysis Framework for Double-Shell Tanks (Slezak et al. 1998).

Refined Safety Analysis Methodology for Flammable Gas Risk Assessment in Hanford Site Tanks, Implementation Details for the Analysis Framework (Slezak 1998). 
References and Inputs: The Analysis Framework Engine (AFE) software source code, Resolve Version 1.92 (Humphreys and Young 1998), was inspected for this phase. The software was not exercised.

General Test Procedure: The source code for Resolve Version 1.92 was obtained from Source Safe. Electronic versions of all modules of the code were combined into a single WordPerfect ${ }^{\circledR}$ 8.0 file. The file was then printed with line numbers for reference and bound into a record copy. The hard copy was reviewed and notes were documented directly on the printed material as appropriate. To aid this review, the electronic version of the printed copy was used to scan for parameters and character strings to ensure that all uses of a parameter, function, equation, etc. were located and reviewed.

Each function, subroutine, or declaration within the following modules was inspected and compared against the AF (Slezak and Williams 1998, Slezak et al. 1998) and Implementation Details (Slezak 1998) reports: calcCombustion, calcConsequences, calcData, calcFlammabilityLimits, calcHeadspaceComposition, calcIgnitionFrequencies, calcInitialize, calcReleases, calcRisk, calcXq, inputData, physicalConstants, programConstants, release, and unitConversion. As discrepancies between the code and the documentation were noted, formal Discrepancy Reports were issued.

Acceptance Criteria: Acceptance of code was based on (1) functional equivalence between the FORTRAN equations and the analytical models documented in the AF and the Implementation Details, (2) completeness in implementing AF model functionality, (3) compatibility of data values and their use (that is, "units checking"), and (4) compatibility of the code with "the laws of physics and chemistry" and the physical analyses described by text but not explicitly expressed as equations in the AF and Implementation Details.

Results: This review resulted in more than 60 discrepancy reports. Approximately half the reports addressed missing data error checks and readily correctable programming errors, such as incorrect programming of $\mathrm{AF}$ equations or incorrect calculation of values used by $\mathrm{AF}$ equations. The remaining reports largely addressed missing functionality in the code (for instance, the risk from ignition sources in ex-tank-intrusive regions, expected risk from seismic events), and physical inconsistencies in computing the influence of mass balance on the amount and frequency of gas computed to be released by various sources.

All Discrepancy Reports generated as a result of this activity were closed as of Resolve Version 2.5.

\subsection{VERIFICATION: AFE CODE INSPECTION-RESOLVE 2.16 AND 2.5}

Abstract: This phase was designed to validate that the physical models described in the $\mathrm{AF}$ and related documents were correctly encoded in the Analysis Framework Engine (AFE) software. The inspection was to ensure the following:

- The individual equations given in the $\mathrm{AF}$ were correctly encoded.

- The values for the parameters that went into the AF equations were calculated correctly. 


\section{RPP-6873 REV 0}

- All parameter values within the model calculations were correctly passed between program functions.

- All functionality described in the documentation was implemented in the code.

- Any assumptions, simplifications, or changes made by the software authors, whether explicitly noted in comments or implicit in the code equations, were physically correct, consistent, and compatible with the intent of the Analysis Framework models.

An additional check, to ensure that the equations constituting the AF models were correctly derived and documented without analytical or typographical errors, is documented in Sections 4.16 and 4.17 .

This phase did not review the input and output data-handling portions of the AFE code.

Requirements: Requirements for the calculational capabilities of the software are given within the following documents.

Refined Safety Analysis Methodology for Flammable Gas Risk Assessment in the Hanford Site Tanks, Part 1: Analysis Framework for Single-Shell Tanks (Slezak and Williams 1998).

Refined Safety Analysis Methodology for Flammable Gas Risk Assessment in the Hanford Site Tanks, Part 2: Analysis Framework for Double-Shell Tanks (Slezak et al. 1998).

Refined Safety Analysis Methodology for Flammable Gas Risk Assessment in Hanford Site Tanks, Implementation Details for the Analysis Framework (Slezak et al. 1999).

References and Inputs: The Analysis Framework Engine (AFE) software source codes, Resolve Version 2.16 (Humphreys and Young 1999) and Resolve Version 2.50 (Humphreys and Young 1999), were inspected for this phase. The software was not exercised.

General Test Procedure: The source code for Resolve Version 2.16 was obtained from Source Safe. Electronic versions of all modules of the code were combined into a single WordPerfect ${ }^{(}$ 8.0 file. The file was then printed with line numbers for reference and bound into a record copy. The hard copy was reviewed and notes were documented directly on the printed material as appropriate. To aid this review, the electronic version of the printed copy was used to scan for parameters and character strings to ensure that all uses of a parameter, function, equation, etc. were located and reviewed.

Code review was accomplished in two phases: source code for the Resolve Version 2.16 AFE was inspected, and subsequently, the Resolve 2.5 AFE code was reviewed for areas that had changed between the two versions.

Review of the 2.16 AFE covered the following modules and subroutines. The code was inspected and compared against the AF (Slezak and Williams 1998, Slezak et al. 1998) and Implementation Details (Slezak et al. 1999) reports. 
- calcCombustionModule
a. calcCombustion
b. calcMixtureType
c. calcMixtureComposition
d. calcReactionType
e. calcReactionPressure.

- calcConsequencesModule
a. calcConsequences
b. calcTankDamageStates
c. calcMaterialReleased
d. calcDose
e. calcTox.

- calcHeadspaceCompositionModule
a. calcHeadspaceComposition.

- calcIgnitionFrequenciesModule
a. calcIgnitionFrequencies
b. calcHeadspaceTimeAtRisk
c. calcZoneTimeAtRisk
d. calcLayerTimeAtRisk
e. calcWellMixedTimeAtRisk
f. calcSwpTimeAtRisk
g. calcSpontaneousGreIgnition
h. calcLocalGreIgnition
i. calcGlobalGreIgnition
j. calcSeismicGreIgnition
k. calcActionLevelSwp
1. calcWasteIntrusionIngnition (sic).

- calcInitializeModule
a. calcInitialize
b. calcBdAnalysis
c. calcAverageBdGreMoles
d. calcAverageVoidFraction.

- calcOutputsModule
a. calcOutputs. 


\section{RPP-6873 REV 0}

- calcReleasesModule
a. calcReleases
b. calcInitVariables
c. calcWasteGasPressure
d. calcWasteGasTemperature
e. calcVoidFraction
f. calcWasteGasVolume
g. calcWasteGasMoles
h. calcWasteGasComposition
i. calcDefaultGreComposition
j. calcInducedGreComposition
k. calcSpontaneousGreComposition
l. calcSeismicGreComposition
m. calcMixerComposition
n. calcSourceComposition
o. calcContinuousAnsSwpComposition
p. calcMassBalance.

Cursory examinations of calcDataModule and inputDataModule were performed, but no detailed inspections were performed because revisions to these modules were strictly related to FORTRAN data-handling (of which the tester had no expert knowledge) and not related to the Analysis Framework.

Cursory examinations of calcWasteIntrusionBurnModule and calcXqModule were performed, but no detailed inspections were performed. This was because the only revisions to these modules since the previous detailed code review (of AFE Version 1.92) were in correcting comment statements. There were no changes to the calculations in these modules.

Resolve AFE source code was revised between Version 2.16 and Version 2.5. These changes focused primarily on tracking waste-intruding gas mixtures, on the implementation of ammonia releases in the receiver tank during waste transfers, and on fixes to errors identified during testing. Changes to the following modules were inspected in the AFE Version 2.5:

- calcCombustionModule

a. Check added to calcReactionType for waste-intrusive equipment burns.

b. Check added for detonation based on the waste-intrusive equipment diameter if it was a waste-intrusive equipment burn.

- calcIgnitionFrequenciesModule

a. Well-mixed headspace calculation changed so the time-at-risk is equal to the duration of the GRE if the continuous headspace waste gas concentration is above the lean flammability limit. 


\section{RPP-6873 REV 0}

- calcInitializeModule

a. Check added to make sure that the salt well pumping ignition frequencies are used if salt well pumping.

b. Average void fractions in non-BD GRE tanks with significant liquid layers limited to the neutral buoyancy void fraction.

- calcReleasesModule

a. Parameter voidFraction used averageVoidFraction if a void fraction value is not provided.

b. Mixer GRE duration set to the smaller of the duration of operation or the volume disturbed divided by the disturbance rate.

c. Continuous release calculations moved after the mass balance calculations and continuous release calculations added in the mass balance algorithm.

d. Minimum GRE duration and maximum void fraction limits added.

e. Continuous releases and submerged pipe option for waste transfer operations added.

- physicalConstantsModule

a. Ammonia release parameters for waste transfer operations added.

- releaseModule

a. Intrusive flag added to the gasRelease structure to indicate when the release was associated with a waste-intrusive equipment burn.

Some changes between AFE Version 2.16 and Version 2.5 were not inspected, since they did not have a noticeable impact on output. These changes were typically moved and/or renamed parameters.

Acceptance Criteria: Acceptance of code was based on (1) functional equivalence between the FORTRAN equations and the analytical models documented in the $\mathrm{AF}$ and the Implementation Details; (2) completeness in implementing AF model functionality; (3) compatibility of data values and their use (i.e., "units checking"); and (4) compatibility of the code with "the laws of physics and chemistry" and the physical analyses described by text but not explicitly expressed as equations in the $\mathrm{AF}$ and Implementation Details.

Results: The AFE improved significantly with maturity. While more than 60 discrepancies of varying impact and scope were reported during code review of AFE Version 1.92, no errors were noted in either of the AFE Version 2.16 or Version 2.5 code review efforts.

\subsection{VERIFICATION: HEADSPACE MIXING MODEL}

Abstract: Headspace mixing is modeled in the AF as an intermediate step between gas release and burn consequences and frequencies. The mole fraction of source gas in the mixing volume is determined for use in assessing flammability and post-burn headspace pressure. The source gas concentration is also used to calculate a time-at-risk of ignition. This test was designed to verify the tool's implementation of AF logic and equations for calculating mixture type (wellmixed headspace, mixing zone, or stratified layer), flammability, source gas concentration in the 
mixing volume, and time-at-risk, by comparing Resolve interim results to values calculated by a spreadsheet that implemented AF equations (Riddle 1999h). Inerting and steady-state, or continuous source gas releases were not considered. Given the limitations of time and the tester's knowledge of Excel ${ }^{\circledast}$ spreadsheets, the modeling of stratified layers with source gas concentrations greater than the rich flammability limit (RFL), which incorporates an iterative process in the tool, was not tested.

Requirements: Hanford Gas Release Event Safety Analysis Tool Version 2.0 Software Verification and Validation Plan (Hodges 1998d).

Refined Safety Analysis Methodology for Flammable Gas Risk Assessment in the Hanford Site Tanks (Slezak et al. 2000).

References and Inputs: Software Design Folder (Humphreys 1997).

Resolve Version 1.91 (Humphreys and Young 1998); GUI Version 1.92; AFE Version 1.91; RDB Version 2.0.

A spreadsheet, "Plume Model Verification.xls" (Riddle 1999h), was used to design cases, calculate expected results, and collect output data.

General Test Procedure: Nine test cases were used to "hit" all the logic tree end states of the plume model. A graphical representation of this logic tree is presented in Figure 6-4 of Slezak et al. (2000). Note that this tree encompasses the determination of mixture type for not only plumes releases (modeled either as mixing zones or stratified layers), but also for wellmixed headspace releases. The regimes represented by these nine cases are shown in Table 4-1.

A spreadsheet (Riddle 1999h), using AF equations, was created to calculate the mixture type, flammability, source gas concentration in the mixture volume, and time-at-risk for a small (plume_case1) or medium (all other cases) non-buoyant displacement GRE.

Nine cases were designed, using the spreadsheet, to hit all the logic branches in the AF's modeling of headspace mixture. Tank 241-SX-103 was used as a starting point because of its large tank and waste volumes.

For each of the test cases, .afi files were created; the test cases were run using the Resolve GUI Version 1.92 and AFE Version 1.91. AFE Version 1.91 was used because in this version the mass balance could be turned off, which allowed for greater freedom in generating the GRE volumes needed to fully exercise the headspace mixing model. Values used to create the nine .afi's can be found in "Plume Model Verification.xls" (Riddle 1999h); all cases were Tank 241-SX-103 Sensitivity Analyses with a seed number of 123456789 and 1 sample.

Mixture type, flammability, source gas concentration in the mixture volume, and time-at-risk information were obtained from debug output text files (dlevel $=463$ ) and compared with values calculated by the spreadsheet. 
Table 4-1. Headspace Mixing Model Test-Case Descriptions.

\begin{tabular}{|c|c|c|}
\hline Case & Regime & AF Model Mixture Type \\
\hline plume_case 1 & $\begin{array}{l}\text { small GRE with a release rate }<0.05 \mathrm{~m}^{3} / \mathrm{s} \text {, non- } \\
\text { flammable well-mixed headspace }\end{array}$ & $\begin{array}{l}\text { Non-Flammable Well- } \\
\text { Mixed Headspace }\end{array}$ \\
\hline plume_case2 & $\begin{array}{l}\text { medium GRE with a release rate }<0.05 \mathrm{~m}^{3} / \mathrm{s} \text {, } \\
\text { flammable well-mixed headspace }\end{array}$ & $\begin{array}{l}\text { Flammable Well-Mixed } \\
\text { Headspace }\end{array}$ \\
\hline plume_case 3 & $\begin{array}{l}\text { medium GRE with a release rate }>0.05 \mathrm{~m}^{3} / \mathrm{s} \text {, } \\
\text { flammable well-mixed headspace }\end{array}$ & $\begin{array}{l}\text { Flammable Well-Mixed } \\
\text { Headspace }\end{array}$ \\
\hline plume_case4 & $\begin{array}{l}\text { medium GRE with a release rate }>0.05 \mathrm{~m}^{3} / \mathrm{s} \text {, non- } \\
\text { flammable well-mixed headspace, non-flammable } \\
\text { mixing zone, source gas not self-flammable }\end{array}$ & $\begin{array}{l}\text { Non-Flammable Well- } \\
\text { Mixed Headspace }\end{array}$ \\
\hline plume_case 5 & $\begin{array}{l}\text { medium GRE with a release rate }>0.05 \mathrm{~m}^{3} / \mathrm{s} \text {, non- } \\
\text { flammable well-mixed headspace, non-flammable } \\
\text { mixing zone, source gas self-flammable }\end{array}$ & Flammable Mixing Zone \\
\hline plume_case6 & $\begin{array}{l}\text { medium GRE with a release rate }>0.05 \mathrm{~m}^{3} / \mathrm{s} \text {, non- } \\
\text { flammable well-mixed headspace, flammable mixing } \\
\text { zone, non-flammable stratified layer }\end{array}$ & Flammable Mixing Zone \\
\hline plume_case7 & $\begin{array}{l}\text { medium GRE with a release rate }>0.05 \mathrm{~m}^{3} / \mathrm{s} \text {, non- } \\
\text { flammable well-mixed headspace, flammable mixing } \\
\text { zone, flammable stratified layer, unstable stratified } \\
\text { layer }\end{array}$ & Flammable Mixing Zone \\
\hline plume_case 8 & $\begin{array}{l}\text { medium GRE with a release rate }>0.05 \mathrm{~m}^{3} / \mathrm{s} \text {, non- } \\
\text { flammable well-mixed headspace, flammable mixing } \\
\text { zone, flammable stratified layer, stable stratified layer, } \\
\text { stratified layer fuel concentration }<\text { RFL }\end{array}$ & $\begin{array}{l}\text { Flammable Stratified } \\
\text { Layer }\end{array}$ \\
\hline plume_case9 & $\begin{array}{l}\text { medium GRE with a release rate }>0.05 \mathrm{~m}^{3} / \mathrm{s} \text {, non- } \\
\text { flammable well-mixed headspace, flammable mixing } \\
\text { zone, flammable stratified layer, stable stratified layer, } \\
\text { stratified layer fuel concentration }>\text { RFL }\end{array}$ & $\begin{array}{l}\text { Flammable Stratified } \\
\text { Layer or Non-Flammable } \\
\text { Well-Mixed Headspace }\end{array}$ \\
\hline
\end{tabular}

Acceptance Criteria: For logical values (mixture type and flammability), the logical value generated by Resolve had to match the value predicted by the spreadsheet. For numeric values (source gas concentration and time-at-risk), a tolerance limit of $0.1 \%$ difference was used.

Results: Of the nine cases, one case, plume_case9, could not be evaluated because the iterative method used in the AF model for calculating flammable gas concentrations in stratified layers above the RFL could not be computed using an Excel ${ }^{\circledR}$ spreadsheet. For the eight remaining cases evaluated, all the tests on mixture type passed; all the tests on flammability passed; five of the tests on time-at-risk passed; and seven of the tests on source gas concentration passed. All the failed tests were traced to three specific errors found in the Resolve source code, and Discrepancy Reports were issued.

The three issues identified above have been corrected as of Resolve Version 2.5. Regression testing showed Resolve results met acceptance criteria. 
RPP-6873 REV 0

\subsection{VERIFICATION: CONSEQUENCE MODEL}

Abstract: Accurate and appropriate consequence calculations are key to Resolve's usefulness as a safety analysis tool. Often validation testing substantiates the assessment of adequacy for individual cases; a detailed, thorough traceability/implementation check was needed to provide confidence in the full range of results. Consequence model verification was carried out in Resolve Version 2.03. It involved the comparison of Resolve-calculated radiological and toxicological consequences to those calculated by a spreadsheet (Riddle 1999h) constructed from equations and data from the source documents.

Requirements Refined Safety Analysis Methodology for Flammable Gas Risk Assessment in the Hanford Site Tanks, Part 1: Analysis Framework for Single-Shell Tanks, Rev. 2 (Slezak and Williams 1998).

References and Inputs: GXQ 4.0 Program Users' Guide (Hey 1994).

Models and Data for Stochastic Treatment of $X / Q$ (Hey 1998).

Tank Waste Compositions and Atmospheric Dispersion Coefficients for Use in Safety Analysis Consequence Assessment (Van Kueren 1998).

Toxic Chemical Considerations for Tank Farm Releases (Van Kueren 1996).

“Design Review Notes" (Riddle 1999a).

Refined Safety Analysis Methodology for Flammable Gas Risk Assessment in the Hanford Site Tanks, Part 1: Analysis Framework for Single-Shell Tanks, Rev. 2 (Slezak and Williams 1998).

Resolve Version 2.03 (Humphreys and Young 1999).

Spreadsheet "Dose Model Verification.xls" (Riddle 1999h) was used to collect input and output data, perform unit conversions, and calculate expected results.

General Test Procedure: A spreadsheet was designed to calculate expected radiological and toxicological consequences (Riddle 1998h). For calculating X/Q, the spreadsheet primarily used equations and logic from Models and Data for Stochastic Treatment of $X / Q$ (Hey 1998). Data for calculating X/Q were transferred electronically from the Resolve Relational Database and GXQ 4.0 Program Users' Guide (Hey 1994). Toxicological consequences were calculated as specified in SARR-011 (Van Kueren 1996), and radiological consequences were calculated as specified in SARR-016 (Van Kueren 1998).

AF/AT radiological and toxicological consequences were calculated based on a number of accident, waste, and meteorological parameters. Consequence model verification testing described here was designed to provide thorough coverage of these parameters. Thorough coverage provided confidence that no errors were significantly impacting the AT's prediction of consequences for the range of accident scenarios that it analyzes. 


\section{Accident Parameters}

Three accident parameters affect the consequences calculated by the AT. First, the height and width of the right cylinder release volume (calculated as described in AF Part 1, Rev 2, Section 2.1.5 [Slezak and Williams 1998]) are used to compute the initial parameters for an area source correction factor. The cylinder's height dimension is calculated based on peak combustion pressure and the tank's diameter. For the specific accident scenarios tested here, the right cylinder release volumes were calculated by Resolve, collected from debug output, and then used to design similar accident scenarios for which expected consequences were calculated in spreadsheet "Dose Model Verification.xls" (Riddle 1999h).

Second, accident frequency has a direct impact on toxicological fraction-of-guidelines calculations. Risk guidelines are frequency bin dependent, and so the fraction-of-guidelines per unit release values reported in SARR-011 (Van Kueren 1996) are frequency dependent.

Accidents occurring every 1 to 100 years are termed "Likely"; accidents occurring every 100 to 10,000 years are termed "Unlikely"; and accidents occurring every 10,000 to $1,000,000$ years are termed "Extremely Unlikely." The AT treats all accidents with a frequency of less than 1 every $10^{6}$ years as Extremely Unlikely. Three cases were designed to have large, spontaneous GREs in each of the Likely, Unlikely, and Extremely Unlikely frequency bins.

Third, the mass of waste released (both respirable and transportable) impacts the consequence calculations. For a particular accident, the AFE calculates a mass released depending on tank damage state and peak combustion pressurization. For this verification testing, the mass released values for specific accidents calculated by Resolve were collected from debug output and used as input values to the consequence calculations in the "Dose Model Verification.xls" (Riddle 1999h) spreadsheet.

\section{Waste Parameters}

Two waste parameters impact the consequences calculated for a specific scenario. Toxicological fraction-of-guidelines per unit release values are conditioned on waste surface dryness. The AT uses five different waste surface dryness types: SST Liquids, SST Slurry, SST Solids, DST Liquids, and DST Solids. SST Slurry fraction-of-guideline values are simple averages of the corresponding SST Solids and SST Liquids values. Five test cases were created, one for each of the five waste types.

Unit Liter Dose (ULD), the radiological exposure from inhaling one liter of respirable waste, is, by default, defined as a distribution in the AT. For each test case, the ULD value was set to a point value, the mean of the ULD distribution for the tank/waste tested.

\section{Meteorological Parameters}

As part of the best-estimate approach used in the AF, consequence calculations are based on observed meteorological frequencies rather than $99^{\text {th }}$ percentile meteorology. The X/Q calculation performed in the AT requires both an atmospheric stability class and a wind speed. There are 52 stability class/wind speed pairs that have some observed frequency of occurrence at the Hanford Site. In order to provide a verification of the stochastic meteorological parameters used in the AT, eight cases were designed to touch all seven of the atmospheric stability classes as well as all eight of the wind speeds that have been observed. 


\section{General}

Eight test cases were designed and used to create afi files. A description of the parameters that were changed from their defaults to create these cases can be found in "Dose Model Verification.xls" (Riddle 1999h). All cases were run in Resolve 2.03 and used one sample.

Debug output from these cases was collected. For the first five cases, a burn was selected at random. For the last three cases, the large, spontaneous GRE with controlled frequency was selected. The right cylinder release volume's height and the masses of respirable and transportable waste were used in conjunction with parameters defined in the test case descriptions to calculate expected results.

For the first five cases where accident frequency was not controlled as part of test design, expected values were calculated for all three frequency bins and the value closest to that calculated by Resolve was used for comparison. For the last three cases where the ignition frequencies of the large spontaneous GREs were controlled, expected values were calculated for the relevant frequency bins.

Acceptance Criteria: Verification testing using spreadsheet calculations provides for stringent acceptance criteria. A tolerance of $0.1 \%$ was used.

Results: Tables 4-2 and 4-3 summarize the results of this test. Of the 32 cases evaluated, 27 passed and 5 failed. Two discrepancies were discovered, and discrepancy reports were issued. These issues were corrected in Resolve Version 2.04 and regression testing indicated that Resolve results were within the acceptable range. 
Table 4-2. Radiological Consequences Verification-Comparison Results.

\begin{tabular}{|c|c|c|c|c|c|}
\hline Case ID & $\begin{array}{l}\text { Receptor } \\
\text { Distance }\end{array}$ & $\begin{array}{l}\text { Expected } \\
\text { Result }\end{array}$ & $\begin{array}{l}\text { Resolve- } \\
\text { Calculated } \\
\text { Result }\end{array}$ & $\begin{array}{l}\text { Ratio (Resolve/ } \\
\text { Expected Value) }\end{array}$ & Pass/Fail \\
\hline $\begin{array}{l}\text { Consequence } \\
\text { Verification } 1\end{array}$ & Onsite & $4.98 \mathrm{E}-02$ & $4.97 \mathrm{E}-02$ & 1.000 & Pass \\
\hline $\begin{array}{l}\text { Consequence } \\
\text { Verification } 1\end{array}$ & Offsite & $5.08 \mathrm{E}-04$ & $5.08 \mathrm{E}-04$ & 1.000 & Pass \\
\hline $\begin{array}{l}\text { Consequence } \\
\text { Verification } 2\end{array}$ & Onsite & $7.46 \mathrm{E}-04$ & $7.46 \mathrm{E}-04$ & 1.000 & Pass \\
\hline $\begin{array}{l}\text { Consequence } \\
\text { Verification } 2\end{array}$ & Offsite & $2.32 \mathrm{E}-06$ & $2.32 \mathrm{E}-06$ & 1.000 & Pass \\
\hline $\begin{array}{l}\text { Consequence } \\
\text { Verification } 3\end{array}$ & Onsite & $5.54 \mathrm{E}-04$ & $5.54 \mathrm{E}-04$ & 1.000 & Pass \\
\hline $\begin{array}{l}\text { Consequence } \\
\text { Verification } 3\end{array}$ & Offsite & $5.58 \mathrm{E}-07$ & $5.58 \mathrm{E}-07$ & 1.000 & Pass \\
\hline $\begin{array}{l}\text { Consequence } \\
\text { Verification } 4\end{array}$ & Onsite & $2.56 \mathrm{E}-05$ & $2.56 \mathrm{E}-05$ & 1.000 & Pass \\
\hline $\begin{array}{l}\text { Consequence } \\
\text { Verification } 4\end{array}$ & Offsite & $8.44 \mathrm{E}-09$ & $8.44 \mathrm{E}-09$ & 1.000 & Pass \\
\hline $\begin{array}{l}\text { Consequence } \\
\text { Verification } 5\end{array}$ & Onsite & $1.95 \mathrm{E}-05$ & $1.95 \mathrm{E}-05$ & 1.000 & Pass \\
\hline $\begin{array}{l}\text { Consequence } \\
\text { Verification } 5\end{array}$ & Offsite & $8.09 \mathrm{E}-10$ & $8.09 \mathrm{E}-10$ & 1.000 & Pass \\
\hline $\begin{array}{l}\text { Consequence } \\
\text { Verification } 6\end{array}$ & Onsite & $2.80 \mathrm{E}-07$ & $2.96 \mathrm{E}-07$ & 1.057 & Fail \\
\hline $\begin{array}{l}\text { Consequence } \\
\text { Verification } 6\end{array}$ & Offsite & $4.45 \mathrm{E}-13$ & $4.45 \mathrm{E}-13$ & 1.000 & Pass \\
\hline $\begin{array}{l}\text { Consequence } \\
\text { Verification } 7\end{array}$ & Onsite & $3.69 \mathrm{E}-03$ & $3.69 \mathrm{E}-03$ & 1.000 & Pass \\
\hline $\begin{array}{l}\text { Consequence } \\
\text { Verification } 7\end{array}$ & Offsite & $7.86 \mathrm{E}-08$ & $7.86 \mathrm{E}-08$ & 1.000 & Pass \\
\hline $\begin{array}{l}\text { Consequence } \\
\text { Verification } 8\end{array}$ & Onsite & $4.69 \mathrm{E}-04$ & $4.69 \mathrm{E}-04$ & 1.000 & Pass \\
\hline $\begin{array}{l}\text { Consequence } \\
\text { Verification } 8\end{array}$ & Offsite & $1.46 \mathrm{E}-08$ & $1.46 \mathrm{E}-08$ & 1.000 & Pass \\
\hline
\end{tabular}


Table 4-3. Toxicological Consequences Verification-Comparison Results.

\begin{tabular}{|c|c|c|c|c|c|}
\hline Case ID & $\begin{array}{l}\text { Receptor } \\
\text { Distance }\end{array}$ & $\begin{array}{c}\text { Expected } \\
\text { Result }\end{array}$ & $\begin{array}{c}\text { Resolve- } \\
\text { Calculated } \\
\text { Result } \\
\end{array}$ & $\begin{array}{c}\text { Ratio } \\
\begin{array}{c}\text { (Resolve/Expected } \\
\text { Value) }\end{array} \\
\end{array}$ & Pass/Fail \\
\hline $\begin{array}{l}\text { Consequence } \\
\text { Verification 1 }\end{array}$ & Onsite & $4.90 \mathrm{E}+00$ & $4.90 \mathrm{E}+00$ & 1.000 & Pass \\
\hline $\begin{array}{l}\text { Consequence } \\
\text { Verification } 1\end{array}$ & Offsite & $1.02 \mathrm{E}+00$ & $1.02 \mathrm{E}+00$ & 1.000 & Pass \\
\hline $\begin{array}{l}\text { Consequence } \\
\text { Verification } 2\end{array}$ & Onsite & $1.20 \mathrm{E}+02$ & $1.20 \mathrm{E}+02$ & 1.000 & Pass \\
\hline $\begin{array}{l}\text { Consequence } \\
\text { Verification } 2\end{array}$ & Offsite & $6.60 \mathrm{E}+00$ & $6.60 \mathrm{E}+00$ & 1.000 & Pass \\
\hline $\begin{array}{l}\text { Consequence } \\
\text { Verification } 3\end{array}$ & Onsite & $7.60 \mathrm{E}+00$ & $7.60 \mathrm{E}+00$ & 1.000 & Pass \\
\hline $\begin{array}{l}\text { Consequence } \\
\text { Verification } 3\end{array}$ & Offsite & $2.86 \mathrm{E}-02$ & $2.86 \mathrm{E}-02$ & 1.000 & Pass \\
\hline $\begin{array}{l}\text { Consequence } \\
\text { Verification } 4\end{array}$ & Onsite & $7.66 \mathrm{E}-01$ & $7.66 \mathrm{E}-01$ & 1.000 & Pass \\
\hline $\begin{array}{l}\text { Consequence } \\
\text { Verification } 4\end{array}$ & Offsite & $1.35 \mathrm{E}-03$ & $1.35 \mathrm{E}-03$ & 1.000 & Pass \\
\hline $\begin{array}{l}\text { Consequence } \\
\text { Verification } 5\end{array}$ & Onsite & $1.95 \mathrm{E}-01$ & $1.95 \mathrm{E}-01$ & 1.000 & Pass \\
\hline $\begin{array}{l}\text { Consequence } \\
\text { Verification } 5\end{array}$ & Offsite & $2.88 \mathrm{E}-05$ & $2.88 \mathrm{E}-05$ & 1.000 & Pass \\
\hline $\begin{array}{l}\text { Consequence } \\
\text { Verification } 6\end{array}$ & Onsite & $1.84 \mathrm{E}-02$ & $4.85 \mathrm{E}-04$ & 0.003 & Fail \\
\hline $\begin{array}{l}\text { Consequence } \\
\text { Verification } 6\end{array}$ & Offsite & $8.28 \mathrm{E}-08$ & $1.50 \mathrm{E}-08$ & 0.018 & Fail \\
\hline $\begin{array}{l}\text { Consequence } \\
\text { Verification } 7\end{array}$ & Onsite & $2.41 \mathrm{E}+02$ & $1.15 \mathrm{E}+01$ & 0.005 & Fail \\
\hline $\begin{array}{l}\text { Consequence } \\
\text { Verification } 7\end{array}$ & Offsite & $9.71 \mathrm{E}-03$ & $5.00 \mathrm{E}-03$ & 0.0515 & Fail \\
\hline $\begin{array}{l}\text { Consequence } \\
\text { Verification } 8 \\
\end{array}$ & Onsite & $4.67 \mathrm{E}+00$ & $4.67 \mathrm{E}+00$ & 1.000 & Pass \\
\hline \begin{tabular}{|l|} 
Consequence \\
Verification 8 \\
\end{tabular} & Offsite & $2.97 \mathrm{E}-03$ & $2.97 \mathrm{E}-03$ & 1.000 & Pass \\
\hline
\end{tabular}




\subsection{VERIFICATION: UNITS CHECKING}

Abstract: The use of correct units throughout the code is essential to obtaining a correct answer. Many of the parameters from the databases were provided in English units. The programmer converted the parameter values to metric units in one module. When different units for the same variable were required-for example, as in the universal gas constant when used for calculating gas volumes versus calculating heat capacity at constant volume from heat capacity at constant pressure-conversion was done locally.

Units checking was conducted using two different methods. The first method made use of the program module for unit conversion and verified that metric units were used for the analysis. Since metric units are consistent unto themselves, this gives one level of confidence in the units checking. The second method involved checking the debug output to determine if the numbers were within a reasonable range of values for the given metric units. For example, the expected pressure in $\mathrm{Pa}$ is on the order of $10^{5}$ and pre-combustion temperature in $\mathrm{K}$ is in the range of 300 . The most thorough method would involve tracing all of the variables throughout the program to make sure that the units were converted when required. However, that is also the most timeconsuming method and was done for a few variables; the remainder were checked during the line-by-line inspection of the AFE code (Sections 4.2 and 4.3).

Requirements: Hanford Gas Release Event Safety Analysis Tool Version 2.0 Software Verification and Validation Plan (Hodges 1998d).

References and Inputs: Resolve Version 1.92 (Humphreys and Young 1998).

Perry's Chemical Engineers' Handbook (Green, Sixth Edition).

General Test Procedure: Two methods of units checking were used. They were as follows:

- The conversion factors in the conversion module were checked for correctness.

- The ranges of interim calculation values for the parameters were checked for correctness.

The following conversion factors were checked:

- FtoKFactor

- FtoKOffset

- InWaterToPaFactor

- PsiToPaFactor

- GalToM3Factor

- ft3ToM3Factor

- LbFt3ToKgM3Factor

- CfmToM3Sfactor

- GmlToKgM3Factor

- YrToSecFactor

- DayToSecFactor 
The following is a list of the calculated values that were checked:

- Release\%X\%ammonia

- Release\%X\%hydrogen

- Release\%X\%methane

- Release\%X\%nitrogen

- Release\%X\%nitrousOxide

- Release\%N\%total

- Release\%pressure

- Rease\%temperature

- Release\%volume

- Release\%duration

- WsolidStress

- WliquidDense

- WsolidDense

- WcrustThick

- TheadPressure

- WcrustThick

- WliquidThick

- WsolidThick

Acceptance Criteria: Conversion factors must be correct, and sample calculated values must be within a reasonable range.

$\underline{\text { Results: }}$ All of the conversion factors in unitConversion Module were correct. All calculated values also were of a reasonable magnitude.

\subsection{VERIFICATION: SOFTWARE REQUIREMENTS SPECIFICATION DATA TRANSFER REQUIREMENTS}

Abstract: The accuracy of data transfer between the components of the Resolve software was a key aspect of software verification. The Resolve data transfer verification testing was designed to ensure that data were (a) correctly transferred between the database and the analysis framework input (.afi) file and (b) correctly transferred between the database and the Resolve GUI. This effort did not include explicit testing of data transfer in the following processes:

- From the Analysis Framework input (.afi) file to the AFE

- From the AFE to the Analysis Framework output (.afo) file

- To and from the Latin Hypercube Sampling (LHS) routine (although success can be implicitly inferred by successful completion of the statistical validation tests documented in Section 4.8)

- From the GUI (for modified parameters) to the AFE.

Requirements: Requirements for the database are described in Section 3.8.1 of the SRS (Humphreys 1998a). No specific requirements are spelled out for data transfer. 


\section{RPP-6873 REV 0}

References and Inputs: Resolve Analysis Framework input (.afi) files created by executing several different runs were used. The different runs are specifically identified in the "General Test Procedure." The Relational Database (corresponding to the code version used) was also used as input.

General Test Procedure: Eight executions of Resolve were required to force transfer of all parameters dependent on the values of other parameters. These runs are defined in Table 4-4.

Data transfer verification was then performed using the following process:

1. For each of the five benchmark runs, data-based parameter values from the RDB were compared by hand to values listed in the Analysis Framework input (.afi) file.

2. For each of the five benchmark runs, panel-based parameter values (for 53 data pairs) and the distribution type from the RDB were compared to values listed in the Analysis Framework input (.afi) file. In addition to comparing the values in the distribution, each run was examined to ensure that the proper distributions were passed to the Analysis Framework input (.afi) file. For example, for run S101dtrn1, it was confirmed that all distributions that were tank classification-dependent were for Facility Group 2.

The panel-based parameter value comparison involved a sufficient number of values that hand comparisons were not possible. Instead, an Excel ${ }^{\circledR}$ spreadsheet was used for comparison. The values for each panel-based distribution were copied electronically from the RDB to a unique worksheet in the Excel $^{\circledR}$ spreadsheet. For each of the five benchmark runs, each panel-based distribution passed to the Analysis Framework input (.afi) file was then copied to the appropriate worksheet. An Excel ${ }^{\circledR}$ formula was then used to compare the data. An example of the formula used is shown below. This formula results in an "ERROR" message if the values do not compare within the specified tolerance. Otherwise, it leaves the cell blank.

$$
=\mathrm{IF}(\mathrm{J} 3-\$ \mathrm{G} 3=0, \text {,",IF(ABS(J3-\$G3)/\$G3<0.001,"'","ERROR")) }
$$

where column "G" contains the database values and column " $\mathrm{J}$ " contains the Analysis Framework input (.afi) file values.

3. The benchmark runs were examined to determine which parameters, if any, were not passed to the Analysis Framework input (.afi) file in any of the five runs. Three sensitivity runs were then prepared with input shown in Table 4-4 to ensure that each of the parameters that had not been checked previously would be passed to the Analysis Framework input (.afi) file. Steps 1 and 2 were then repeated for these parameters only.

4. To ensure the accuracy of data transfer between the RDB and the Resolve GUI, data run SY101dtrn5 was used. For data-based parameters, the following items from the RDB were compared by hand to those read into the GUI:

- Parameter name

- Unit of measure 
- Value

- Data source.

For panel-based parameters, the following items from the RDB were compared by hand to those read into the GUI:

- Distribution description

- Distribution type

- Data source (that is, the distribution number).

In addition, the graphical distribution representations in the GUI were examined to ensure that the titles on the graphs matched the distribution descriptions. The actual values contained in the distributions were not checked because of the enormous number of values that would have required examination. However, since the AFE takes the distribution values from the Analysis Framework input (.afi) file, this omission was not considered important.

\section{Waste Transfer Analysis Data Transfer}

To ensure the accuracy of data transfer for a waste transfer analysis, data run SY101dtrn9 was used. All data-based parameters shown on the waste transfer screen were examined. This includes "during transfer" parameters and "after transfer" parameters for both the source and receiver tanks. The set of data items listed above under point 4 was verified for each parameter.

In addition to transfer of data from the RDB to the GUI, a waste transfer analysis allows the user to write afi files for the source and receiver tanks, both during and after transfer. The data values written to these files were examined to ensure that they were properly transferred from the GUI to the afi files.

Some software errors identified by "Failed" tests from testing of Resolve Versions 1.90 and 1.92 were corrected prior to the release of Version 2.0. These tests were repeated as regression tests to ensure that the software modification resulted in proper data transfer. No additional failed test occurred during subsequent testing.

\section{Testing for Updated Version (Resolve 2.20 Beta)}

Normally, testing for updated versions of software would be performed as regression testing. That is, tests would be selected randomly for retesting with a new software version to ensure that the software was still functioning appropriately. However, given the number of changes to the $\mathrm{RDB}$, it was decided to repeat a large number of tests for Resolve Version 2.20 (Beta). The first test was a repeat of the benchmark tests described in Table 4-4 for Tanks 241-C-103 and 241-SY-101. These tests were repeated to examine data transfer from the RDB to the afi file for the entire list of RDB parameters. A number of tests were then performed to ensure that the afi file was properly updated by the GUI when the user changed tank control strategies or other parameters in the GUI. Tests were performed to check a parameter (wasteVoidFraction) that was changed in the RDB for five individual tanks since the previous data transfer testing was performed. 


\section{RPP-6873 REV 0}

The data transfer tests that resulted from the processes outlined above are categorized in Table 4-5. Note that tests 1 through 464, as defined for Resolve versions prior to Version 1.90, were deleted and replaced because of changes in the database parameters.

Acceptance Criteria: Successful data transfer for each data-based value, parameter name, unit of measure, and data source, as well as each panel-based distribution description and distribution type was defined as exact transfer from the database (within four significant figures in scientific notation for numeric values) to the Analysis Framework input (.afi) file. For the electronic panel-based distribution check, a tolerance limit of $0.1 \%$ was used.

Results: As shown in Table 4-5, approximately 2300 data transfer tests were performed with Resolve Versions 1.90 and 1.92 . Only 40 errors were identified that were directly related to transfer of data within the software for analyses not related to waste transfer. (Three other discrepancies related to deficiencies in supporting documentation were reported.) For testing of data transfer during waste transfer analyses, 20 errors were identified. For testing of Resolve Version 2.20 (Beta), five discrepancies were found and reported.

All discrepancies were logged in the Discrepancy Report resolution system. All discrepancies were corrected and closed as of Resolve Version 2.5 . 
Table 4-4. Data Transfer-Test Cases.

\begin{tabular}{|c|c|c|c|c|}
\hline Run ID & S101dtrn1 & BX107dtrn2 & C103dtrn3 & BY112dtrn4 \\
\hline Tank & $S-101$ & BX-107 & C- 103 & BY-112 \\
\hline Run Type & Benchmark & Benchmark & Benchmark & Benchmark \\
\hline Tank Type & SST & SST & SST & SST \\
\hline $\begin{array}{l}\text { Tank } \\
\text { Classification }\end{array}$ & Facility Group 2 & Facility Group 2 & Facility Group 3 & Facility Group 3 \\
\hline $\begin{array}{l}\text { Salt Well } \\
\text { Pumping Status }\end{array}$ & Never Pumped & Pumped Previous & Never Pumped & Pumped Previous \\
\hline Pumping ICS ${ }^{1}$ & $\mathrm{n} / \mathrm{a}$ & $\mathrm{n} / \mathrm{a}$ & $\mathrm{n} / \mathrm{a}$ & $\mathrm{n} / \mathrm{a}$ \\
\hline $\begin{array}{l}\text { Equipment } \\
\text { Insertion or } \\
\text { Removal } \\
\text { Operation ICS }\end{array}$ & Control Strategy 2 & Control Strategy 2 & $\begin{array}{c}\text { Control Strategy } 2, \\
\text { Past Practices } \\
\text { Control Strategy }\end{array}$ & $\begin{array}{c}\text { Control Strategy 2, } \\
\text { Past Practices } \\
\text { Control Strategy }\end{array}$ \\
\hline $\begin{array}{l}\text { Short Term } \\
\text { Equipment } \\
\text { Operation ICS }{ }^{1}\end{array}$ & Control Strategy 2 & Control Strategy 2 & $\begin{array}{c}\text { Control Strategy } 2, \\
\text { Past Practices } \\
\text { Control Strategy }\end{array}$ & $\begin{array}{c}\text { Control Strategy } 2, \\
\text { Past Practices } \\
\text { Control Strategy }\end{array}$ \\
\hline $\begin{array}{l}\text { Headspace } \\
\text { Purging Status }\end{array}$ & Not Purged & Not Purged & Not Purged & Not Purged \\
\hline
\end{tabular}

\begin{tabular}{|l|c|c|c|c|}
\hline \multicolumn{1}{|c|}{ Run ID } & SY101dtrn5 & S101dtrn6 & S101dtrn7 & S101dtrn8 \\
\hline Tank & SY-101 & S-101 & S-101 & S-101 \\
\hline Run Type & Benchmark & Sensitivity & Sensitivity & Sensitivity \\
\hline Tank Type & DST & SST & SST & SST \\
\hline $\begin{array}{l}\text { Tank } \\
\text { Classification }\end{array}$ & Facility Group 1 & Facility Group 2 & Facility Group 2 & Facility Group 2 \\
\hline $\begin{array}{l}\text { Salt Well } \\
\text { Pumping Status }\end{array}$ & Never Pumped & Currently Pumping & Currently & Currently \\
\hline Pumping ICS & & Pumping & Pumping \\
\hline $\begin{array}{l}\text { Equipment } \\
\text { Insertion or } \\
\text { Removal } \\
\text { Operation ICS }\end{array}$ & Control Strategy 2 & $\begin{array}{l}\text { Control Strategy 1, } \\
\text { Control Strategy 2 }\end{array}$ & Control Strategy 2 & Control Strategy 2 \\
\hline $\begin{array}{l}\text { Short Term } \\
\text { Equipment } \\
\text { Operation ICS }\end{array}$ & Control Strategy 2 & $\begin{array}{l}\text { Control Strategy 1, } \\
\text { Control Strategy 2, } \\
\text { Past Practices } \\
\text { Control Strategy }\end{array}$ & Control Strategy 2 & Control Strategy 2 \\
\hline $\begin{array}{l}\text { Headspace } \\
\text { Purging Status }\end{array}$ & & Not Purged & Not Purged & Purging \\
\hline
\end{tabular}

${ }^{1}$ ICS - Ignition Control Strategy 
Table 4-5. Data Transfer-Test Matrix.

\begin{tabular}{|c|c|c|c|c|c|c|c|}
\hline $\begin{array}{c}\text { Test } \\
\text { Number }\end{array}$ & $\begin{array}{l}\text { Resolve } \\
\text { Version }\end{array}$ & Run ID & Regression & $\begin{array}{c}\text { Data- } \\
\text { Based } \\
\text { Parameter } \\
\text { Value }\end{array}$ & $\begin{array}{c}\text { Panel- } \\
\text { Based } \\
\text { Parameter } \\
\text { Value }\end{array}$ & $\begin{array}{l}\text { From } \\
\text { RDB } \\
\text { to .afi }\end{array}$ & $\begin{array}{c}\text { From } \\
\text { RDB } \\
\text { to } \\
\text { GUI }\end{array}$ \\
\hline $1-464$ & Deleted $^{1}$ & Deleted $^{1}$ & Deleted $^{\prime}$ & Deleted $^{1}$ & Deleted $^{\prime}$ & Deleted $^{\prime}$ & Deleted' \\
\hline $465-558$ & 1.90 & SY101dtrn 1 & No & $\mathrm{X}$ & & $X$ & \\
\hline $559-713$ & 1.90 & SY101dtrn 1 & No & & $X$ & $\mathrm{X}$ & \\
\hline 714 & 1.90 & S101dtrn6 & No & & $\mathrm{X}$ & $X$ & \\
\hline 715 & 1.90 & S101dtrn7 & No & & $\mathrm{X}$ & $\mathrm{X}$ & \\
\hline 716 & 1.90 & S101dtrn 8 & No & & $\mathrm{X}$ & $\mathrm{X}$ & \\
\hline $717-719$ & 1.90 & S101dtrn6 & No & & $X$ & $\mathrm{X}$ & \\
\hline 720 & 1.90 & S101dtrn8 & No & & $\mathrm{X}$ & $\mathrm{X}$ & \\
\hline $721-814$ & 1.90 & BX107dtrn2 & No & $\mathrm{X}$ & & $\mathrm{X}$ & \\
\hline $815-969$ & 1.90 & BX107dtrn2 & No & & $\mathrm{X}$ & $X$ & \\
\hline $970-1062$ & 1.90 & C103dtm 3 & No & $\mathrm{X}$ & & $\mathrm{X}$ & \\
\hline $1063-1217$ & 1.90 & C103dtrn3 & No & & $X$ & $\mathrm{X}$ & \\
\hline $1218-1372$ & 1.90 & BY112dtm4 & No & & $\mathrm{X}$ & $\mathrm{X}$ & \\
\hline $1373-1480$ & 1.90 & SY101dtrn5 & No & $\mathrm{X}$ & & $\mathrm{X}$ & \\
\hline $1481-1635$ & 1.90 & SY101dtrn5 & No & & $\mathrm{X}$ & $\mathrm{X}$ & \\
\hline $1636-2099$ & 1.90 & SY101dtrn5 & No & $\mathrm{X}$ & & & $\mathrm{X}$ \\
\hline $2100-2411$ & 1.90 & SY101dtrn5 & No & & $\mathrm{X}$ & & $\mathrm{X}$ \\
\hline $2412-2505$ & 1.90 & BY112dtrn4 & No & $X$ & & $\mathrm{X}$ & \\
\hline $2506-2691^{2}$ & 1.92 & SY101dtrn9 & No & $\mathrm{X}$ & & & $\mathrm{X}$ \\
\hline $2692-2753^{2}$ & 1.92 & SY101dtrn 9 & No & $X$ & & $\mathrm{X}$ & \\
\hline $2754-2759$ & 2.08 & $\mathrm{n} / \mathrm{a}$ & No & $X$ & & $\mathrm{X}$ & \\
\hline $2760-2986^{3}$ & 2.20 & $\mathrm{C} 103$ & No & $\mathrm{X}$ & $\mathrm{X}$ & $\mathrm{X}$ & \\
\hline $2987-3213^{3}$ & 2.20 & SY101 & No & $X$ & $\mathrm{X}$ & $\mathrm{X}$ & \\
\hline $3214-3282^{3}$ & 2.20 & C103A & No & $\mathrm{X}$ & $\mathrm{X}$ & $X$ & \\
\hline $3283^{3}$ & 2.20 & AN103 & No & $X$ & & $\mathrm{X}$ & \\
\hline $3284^{3}$ & 2.20 & AN104 & No & $\mathrm{X}$ & & $\mathrm{X}$ & \\
\hline $3285^{3}$ & 2.20 & AN105 & No & $\mathrm{X}$ & & $\mathrm{X}$ & \\
\hline $3286^{3}$ & 2.20 & AW-101 & No & $\mathrm{X}$ & & $\mathrm{X}$ & \\
\hline $3287^{3}$ & 2.20 & SY-103 & No & $\mathrm{X}$ & & $\mathrm{X}$ & \\
\hline
\end{tabular}

\footnotetext{
${ }^{1}$ Tests DTRN-1 through DTRN-464, as defined for Resolve versions prior to Version 1.90, have been deleted and replaced because of changes in the database parameters.

${ }^{2}$ Tests 2506 through 2753 were for a waste transfer analysis. Tests 2692 through 2753 tested the passing of data from the GUI to the afi file for waste transfer analyses.

${ }^{3}$ The RDB was reorganized so that testing of data-based and panel-based parameters was not performed separately for tests after 2759 .
} 
RPP-6873 REV 0

\subsection{VERIFICATION: SOFTWARE REQUIREMENTS SPECIFICATION STATISTICAL ANALYSIS AND LHS SAMPLING CHECK}

Abstract: Tests in this phase were designed to verify the statistical analysis mode of Resolve. Tests were divided into two areas: (1) testing the sampling of input distributions by the Latin Hypercube Sampling (LHS) algorithm and (2) testing the computation of output statistics for consequences and frequencies of interest.

verification

Requirements: Requirements for statistical analysis capabilities are defined in Section 2.2.3 and Section 3.1.2 of the Software Requirements Specification (SRS) for the Gas Release Event Safety Analysis Tool (Humphreys 1998a).

References and Inputs: A separate Resolve benchmark run for Tank 241-A-101 was performed for each of the two test types.

\section{Testing Input Distribution Sampling}

- A benchmark Resolve run (stat1) was performed to create LHS output for testing input distribution sampling.

- The relational database (corresponding to the code version used) was used as the basis for comparison to determine whether LHS input distribution sampling was performed properly.

- The sampled output was obtained from the LHS/Resolve output file stat 1.lho.

- An Excel ${ }^{\circledR}$ spreadsheet,"stat1.xls" (Ashbaugh 1998a), was created to compare the original data (from the relational database) and the sampled output generated during the Resolve run.

\section{Testing Output Distributions Statistics Computation}

- A benchmark Resolve run (stat2) was performed to generate the required output. The calculated output for each instance was obtained from the Resolve output file stat2.afo.

- An Excel ${ }^{\circledR}$ spreadsheet, "stat2.xls" (Ashbaugh 1998b), was created to compare statistical characteristics of output data to Resolve-calculated statistics.

General Test Procedure: A Resolve benchmark calculation was performed for each type of testing using Tank 241-A-101. Table 4-6 summarizes the test cases executed for the LSH sampling check task.

\section{Testing Input Distribution Sampling}

A cumulative distribution function, rather than a point value, describes each of the panel-based parameters used within Resolve. For ten panel-based parameters, output samples from each cycle of the LHS routine were copied from the stat 1 .lho file into the spreadsheet stat $1 . x$ ls. For each parameter, the following procedure was applied to validate proper LHS sampling.

The (approximate) entire range of sampled values was determined for the sampled values. The range was divided into 25 equal bins (on a log scale). For each input distribution, 601 samples were generated. For each of the bin boundary values, the number of samples with a 
value of less than or equal to the bin boundary was divided by the total number of samples. This approximates the value of the cumulative distribution function for that input distribution.

These calculated points were then plotted in $\operatorname{Excel}^{\circledR}$ against the original relational database distribution.

Note that LHS sampling may be repeated during AFE execution. However, results were processed for only the final LHS execution. Therefore, the values in the stat 1 .lho file were from the final LHS execution for Run stat1.

\section{Testing Output Distributions Statistics Computation}

A Resolve benchmark calculation was initiated with an initial sample size of 1500 for Tank 241-A-101. The final Resolve output contained 10,790 values for each output parameter. Tests in this group consisted of confirmation of mean, median, $5^{\text {th }}$, and $95^{\text {th }}$ percentiles for each of the following output parameters:

- On-Site Radiological Consequences

- Off-Site Radiological Consequences

- On-Site Toxicological Consequences

- Off-Site Toxicological Consequences

- Small, Spontaneous GRE Ignition Frequency with No Tank Damage

- Medium, Spontaneous GRE Ignition Frequency with No Tank Damage

- Large, Spontaneous GRE Ignition Frequency with Dome Failure.

Resolve-calculated output was read from the stat2.afo file into the spreadsheet stat2.xls. The mean, median, and percentile values for each of the listed output parameters were computed separately using an Excel $^{\circledR}$ spreadsheet. These values were compared to values listed in the Resolve GUI Output Summary display.

The entire suite of tests for validation of output distribution statistical computation was subjected to regression testing with Resolve Version 1.92. This was due to an uncertainty in the requirements for which results should be included in the statistical analysis. Prior to release of Version 1.92, it was clarified that statistical analysis should include only those instances that resulted in GRE ignition. Regression tests were performed to ensure that this was the case for Version 1.92 statistical analyses. In some cases, where a parameter was dropped from the database or renamed, a new parameter was randomly selected to replace it.

The statistics validation tests that resulted from the processes outlined above are categorized in Table 4-7.

\section{Acceptance Criteria:}

\section{Testing Input Distributions Sampling}

Test acceptance of the LHS sampling was based on whether or not the values for the cumulative distribution function that were based on the LHS output and calculated in the stat 1.xls spreadsheet compared well (visually) with the original source distributions. This visual comparison confirmed that the calculated points lay on the relational database curve when simultaneously plotted. 


\section{Testing Output Distributions Statistics Computation}

Test acceptance of output distribution statistics was based on whether or not the independently computed means, medians, and percentiles matched those generated by Resolve. Agreement was required to be exact with the precision of four significant figures in scientific notation (that is, $x . x x x E+x x)$.

Results: Thirty-eight total tests were performed to validate statistical functions in Resolve. Errors related to calculation of $95^{\text {th }}$ percentile values for output data were noted in initial testing. The developers revisited the method for calculation of output statistics for Version 1.92. Therefore, the entire suite of tests related to validation of output statistics was subjected to regression testing. No errors were noted. Fifth $\left(5^{\text {th }}\right)$ percentile values for output data were no longer included in the GUI (at the request of the customer).

Table 4-6. LHS Sampling Check-Test Case Descriptions.

\begin{tabular}{|l|l|}
\hline Test & \multicolumn{1}{|c|}{ Description } \\
\hline 1 & $\begin{array}{l}\text { Confirm LHS Sampling: Spontaneous GRE, Small (WGREFREQUENCYS) 601 } \\
\text { Samples }\end{array}$ \\
\hline 2 & $\begin{array}{l}\text { Confirm LHS Sampling: Probability of Medium GRE Induced by Local WDO } \\
\text { (CGREPROBML) 601 Samples }\end{array}$ \\
\hline 3 & $\begin{array}{l}\text { Confirm LHS Sampling: Probability of Large GRE Induced by Global WDO } \\
\text { (CGREPROBLG) 601 Samples }\end{array}$ \\
\hline 4 & Confirm LHS Sampling: Frequency of Random Ignition Sources 601 Samples \\
\hline 5 & Confirm LHS Sampling: Duration of GRE, Small (WGREDURATIONS) 601 Samples \\
\hline 6 & Confirm LHS Sampling: Duration of GRE, Large (WGREDURATIONL) 601 Samples \\
\hline 7 & Confirm LHS sampling: (WRESSST_FAIL) 601 samples \\
\hline 8 & Confirm LHS sampling: (WIGNITIONQUAKEY3) 601 samples \\
\hline 9 & Confirm LHS sampling: (WRESSST_NONE) 601 samples \\
\hline 10 & Confirm LHS sampling: (WGREQUAKESY2) 601 samples \\
\hline
\end{tabular}


Table 4-7. Statistics Validation-Test Case Organization.

\begin{tabular}{|l|l|l|c|c|c|}
\hline $\begin{array}{c}\text { Test } \\
\text { Number }\end{array}$ & $\begin{array}{l}\text { Resolve } \\
\text { Version }\end{array}$ & Run ID & Regression & $\begin{array}{c}\text { Input } \\
\text { Distribution } \\
\text { Sampling }\end{array}$ & $\begin{array}{c}\text { Output Distribution } \\
\text { Statistical Computation }\end{array}$ \\
\hline 1 & 1.90 & Stat1 & NO & X & \\
\hline $3-5$ & 1.90 & Stat1 & NO & X & \\
\hline $9-10$ & 1.90 & Stat1 & NO & X & \\
\hline $11-38$ & 1.90 & Stat2 & NO & & X \\
\hline $39-42$ & 1.90 & Stat1 & NO & X & X \\
\hline $11-38$ & 1.92 & Stat3 & YES & & \\
\hline
\end{tabular}

\subsection{VERIFICATION: SOFTWARE REQUIREMENTS SPECIFICATION GRAPHICAL USER INTERFACE REQUIREMENTS CHECK}

Abstract: GUI testing verified that each of the GUI requirements specified in the Software Requirements Specification (Humphreys 1998a) was satisfied. General functionality of the GUI was noted, including considerations of user convenience and general "look and feel" of the interface.

Requirements: Software Requirements Specification (SRS) for the Gas Release Event Safety Analysis Tool (Humphreys 1998a).

References and Inputs: Resolve Versions 1.90, 1.92 (Humphreys and Young 1998).

General Test Procedure: Twenty-three individual user interface requirements are set forth in Section 3.2.1 of the SRS (Humphreys 1998a). These requirements were grouped into seven functional areas as follows:

\section{Data Fields}

- Each data field will be labeled and will describe the required data contents.

- The format of data fields will be consistent from one screen to the next.

- Default values will be provided.

\section{Form Layout}

- Logical groups will be separated by spaces, lines, borders, or other visual cues.

- Grouping of data items will be consistent from one screen to the next.

- Position of navigational aids will be consistent from one screen to the next.

- There will be an obvious way to exit or quit the Analysis Tool.

\section{General}

- The Analysis Tool will allow the user to specify a name to identify the run. 


\section{RPP-6873 REV 0}

\section{File Manipulation and File Menu Features}

- The Analysis Tool will allow the user to select a previously saved input file to perform an analysis.

- The Analysis Tool will allow the user to save the new set of parameters to a different file name.

- The Analysis Tool will require the user to specify a file name for the output.

- The Analysis Tool will save detailed scenario calculation results to the output file.

- The Analysis Tool will save the name used to identify the run and write it to the output file.

- The Analysis Tool will display the current file name for reference during the use of the Analysis Tool.

\section{Analysis Tool Database Access and Manipulation}

- The Analysis Tool will not allow the user to manipulate the AT relational database.

- The Analysis Tool will allow the user to display the value and units of any parameter in the relational database.

- The Analysis Tool will allow the user to change a parameter's value within the user interface to model the effects of possible decisions.

- The Analysis Tool will visually distinguish the changed parameter values from the default values.

\section{Analysis}

- The Analysis Tool will allow the user to perform a statistical analysis using a default or user-defined number of Latin Hypercube samples.

\section{Final Output and Summary Data Displays}

- The Analysis Tool will allow the user to graphically display the results and metrics of each scenario.

- The Analysis Tool will allow the user to view the frequencies and consequences of the damage states defined for each scenario.

- The Analysis Tool will include the following tank damage states:

a. Burn with no HEPA failure

b. Burn with HEPA failure but no dome cracking or tank failure

c. Burn with HEPA failure and dome cracking but no tank failure

d. Burn with HEPA failure, dome cracking, and tank failure.

- The Analysis Tool will display the following metrics:

a. Means, medians, and percentiles of the on-site (100-m) CEDE

b. Means, medians, and percentiles of the site boundary CEDE

c. Means, medians, and percentiles of the on-site $(100-\mathrm{m})$ fraction of toxicological risk guidelines

d. Means, medians, and percentiles of the site boundary fraction of toxicological risk guidelines.

Single runs of Resolve were done to complete tests within this phase. 
RPP-6873 REV 0

The Resolve software was initiated and loaded with data from the relational database. Checks were made to confirm that the GUI functioned properly in response to each of the 23

requirements tested. Two hundred forty-five checks were performed to verify that requirements were met.

Acceptance Criteria: Each requirement was worded in such a way that the acceptance criteria were implicit within the description of the requirement itself. Failure of the GUI to meet any requirement was noted in the form of a Discrepancy Report (DR). DRs were also issued to note Alook and feela or Aease of use@ observation.

Results: Version 1.90 Graphical User Interface (GUI) testing of Resolve was initiated by downloading the zipped software from the Document Management System to a personal computer operating on a WindowsNT ${ }^{\circledR} 4.0$ platform. The software tool was then unzipped, installed, and launched.

Actual GUI testing was accomplished by conducting 245 individual tests that compared "look and feel" results against requirements contained in Section 3.2.1.2 of the SRS. The rigor of testing activities spanned basic data field configuration to conducting complex multi-tank analyses.

During the GUI test period, 36 DRs were issued documenting problems that were encountered. The majority of GUI DRs that were written addressed "look and feel" issues. A few DRs identified operational issues.

Overall, anticipated software performance and results, based upon SRS requirements, were realized.

Resolve Version 1.92 was acquired and installed in the same fashion as 1.90 . Version 1.92 focused on significant software changes made to Waste Transfer options that resulted in a complete redesign of the Waste Transfer screen. Because of the limited scope of changes, the level GUI testing was also confined to Waste Transfer issues. Test results yielded two DRs that address operational problems.

Overall, as with version 1.90 , anticipated software performance and results were realized. All DRs generated as a result of this activity were closed out as of Resolve Version 2.5.

\subsection{VERIFICATION: SOFTWARE REQUIREMENTS SPECIFICATION MISCELLANEOUS REQUIREMENTS}

Abstract: The Software Requirements Specification (SRS) (Humphreys 1998a) contains various general and specific requirements addressing a myriad of subjects. This section explains the process used to capture the requirements, perform the appropriate tests, and document the tests.

Requirements: Sofiware Requirements Specification (SRS) for the Gas Release Event Safety Analysis Tool (Humphreys 1998a).

References and Inputs: "Table B-20" (Guerra and Kingson 1998). 
General Test Procedure: The Software Requirements Specification was reviewed to locate miscellaneous requirements; these requirements ranged in type from very specific to general in nature. Results of some requirements are dependent upon the execution of other specific tests; other requirements are merely overview statements that are actually tested via other sections in this report. For instance, one requirement states that "The AT will allow the user to select all of the calculated frequency-consequence pairs for display or subsets of pairs based on consequence, GRE size, tank damage state, and GRE source." This requirement is historically subjected to testing in other sections of this report (for instance, Section 4.18 Model Comparison Testing.).

The SRS miscellaneous requirements were captured as line items and placed in a table using Microsoft ${ }^{\circledR}$ Word (see "Table B-20" (Guerra and Kingson 1998) in References). Each line item was then tested comparing expected results to actual results. Where a test matched expectations, the test passed. Where the test failed, a Discrepancy Report was generated. All results are documented on "Table B-20" (Guerra and Kingson 1998)

Acceptance Criteria: The software must meet the identified requirements.

Results: Because the Resolve software has undergone substantial revision since the SRS was revised in May 1998, some of the requirements contained in the SRS were no longer applicable as written. This resulted in two minor discrepancy reports. Additionally, because some requirements were general in nature, suggestions were provided to the author for rewording those particular requirements to reference specific related tests. The two discrepancies dealt with documentation issues that did not impact the results of the software. These two DRs were deferred.

\subsection{VERIFICATION: USER GUIDE REVIEW}

Abstract: An effective user-friendly user guide is both essential and critical for installing, operating, and updating software programs. In keeping with that theme and accepted industry standards, a user's guide was developed for Version 2.0 and subsequent versions of the AT. Review of the User Guide was conducted to ensure that it was both useful and correct.

Requirements: Hanford Gas Release Event Safety Analysis Tool Version 2.0 Software Verification and Validation Plan (Hodges 1998d).

References and Inputs: Refined Safety Analysis Tool Resolve Version 2.0 User Guide Draft (Young, E. R. 1998).

General Procedures: The central thought maintained while developing the User Guide was to design the document from the user's perspective. In other words, "What does the user need to know in order to easily install, operate, and update the software?"

As draft versions of the User Guide were developed, they were circulated to Resolve Team members for critique of implementation, effectiveness, and overall usability. The drafts were then "red-lined" with comments and recommendations and returned to the developer for review 
of comments and consideration of implementation. This round of iterations was repeated four times in order to bring the User Guide to its final state.

Acceptance Criteria: Acceptance criteria included the ease and ability of the tester to understand the purpose and correct use of the software. Because this was a subjective task in nature, no formal DRs were issued.

Results: The published version of the User Guide is reflective of the iterative review and redlining of draft versions. New users of the software have found the guide to be easily understood and useful for learning how to utilize the tool.

\subsection{VERIFICATION: USER GUIDE IMPLEMENTATION TESTING}

Abstract: The Resolve V\&V team wanted assurance that the User Guide provided adequate instruction and direction to software end-users. To accomplish this task, a plan was devised to provide an independent non-team member with a computer workstation that was void of any previous Resolve software installation, an up-to-date copy of the User Guide, and a source from which to acquire the latest version of the software. The tester was asked to provide documented feedback to the $V \& V$ team regarding the following aspects of the guide:

- Overall User Guide and software friendliness

- User Guide effectiveness

- Problems and errors arising from software installation and operation

- Recommendations to improve the User Guide and software.

To further ensure total dependency on the tools provided, testing would be performed in an unmonitored environment with no support other than information provided in the User Guide and software.

Requirements: Hanford Gas Release Event Safety Analysis Tool Version 2.0 Software Verification and Validation Plan (Hodges 1998d).

References and Inputs: Resolve Version 2.01 (Humphreys and Young 1998).

Refined Safety Analysis Tool, Resolve Version 2.0, User Guide Draft (Young, E. R. 1998).

General Test Procedures: The test procedure consisted of providing an objective, non-team member with a computer workstation that was void of any previous Resolve software installation, an up-to-date copy of the User Guide, and a source from which to acquire the latest version of the tool.

The workstation used to perform the test was configured as follows:

- Personal Computer with an Intel $166 \mathrm{MHz}$ Pentium ${ }^{\circledR} \mathrm{CPU}$

- 64 megabytes RAM

- 1.44 megabyte floppy disk drive 
- Over 20 megabytes of free hard disk space

- Super VGA monitor with a resolution of $1024 \times 768$ pixels

- A Microsof ${ }^{\circledR}$ mouse and compatible keyboard

- Microsoft $^{\circledR}$ Windows $95^{\circledR}$.

Acceptance Criteria: Acceptance criteria included the ability of the tester to install the software and perform sample runs as defined in the User Guide and the ease with which the tester was able to accomplish this.

Results: The findings and results were summarized by the users and related to the User Guide author. Revisions were made to the documents to further improve usefulness.

\subsection{VERIFICATION: REFINED SAFETY ANALYSIS PROJECT QUALITY ASSURANCE AUDIT}

Abstract: The purpose of this audit was to assess the adequacy, status, and effectiveness of the Radioactive Waste Management Program (RWMP) Quality Assurance Program Plan (SNL 1998a) as it applies to the Refined Safety Analysis Project.

Requirements: The following documents contain quality requirements that apply to this audit. Refined Safety Analysis Project (RSAP) Process Descriptions (PD) are addenda to the Refined Safety Analysis Project, Project Quality Assurance Plan (PQAP) (SNL 1998c). Radioactive Waste Management Program (RWMP) Process Descriptions (PD) are addenda to the Radioactive Waste Management Program, Quality Assurance Program Plan (SNL 1998a).

- HNF-PRO-309, Rev. 0, Computer Software Quality Assurance Requirements (Grier 1998)

- RSAP PD 3-2 Discrepancy Management

- RWMP PD 1-1 Quality Level Requirements

- RWMP PD 2-1 Training Effectiveness

- RWMP PD 3-1 Deficiency Reporting

- RWMP PD 4-1 Preparation \& Format of PDs

- RWMP PD 4-2 Peer Review

- RWMP PD 4-3 Document Control

- RWMP PD 4-4 Records Management

- RWMP PD 5-1 Software Control

- RWMP PD 5-2 Tests, Experiments, and Scientific Investigation

- RWMP PD 9-1 Management Assessment Process

- RWMP PD 10-1 Qualification of Auditors, Lead Auditors, \& Surveillance Personnel

- RWMP PD 10-2 Audits

- SNL-000147 Rev. 2, Refined Safety Analysis Project, Project Quality Assurance Plan (SNL 1998c)

- SNL-000148 Rev. 2, Radioactive Waste Management Program, Quality Assurance Program Plan (SNL 1998a). 
References and Inputs: The audit team consisted of Patty Trellue (SNL Org. 12326) as Lead Auditor. Chris Saavedra (SNL Org. 6805) supported the audit to the extent possible within the requirements of RWMP process description PD 10-2 Audits.

General Test Procedure: Areas of the PQAP covered by the audit are listed in Table 4-8 along with the primary point(s) of contact for that area. In addition, all findings from the audit performed by HRPP on 11/13/97 were reaudited.

Table 4-8. Areas Covered and Relevant Contacts for Refined Safety Analysis Project Quality Assurance Audit.

\begin{tabular}{|c|c|}
\hline Areas of PQAP to be covered & Primary Point(s) of Contact \\
\hline $\begin{array}{l}\text { RWMP Quality Assurance Program Plan } \\
\text { Applicability }\end{array}$ & Chris Saavedra \\
\hline QA Records and Storage Location & Chris Saavedra \\
\hline \multicolumn{2}{|c|}{ Software Quality Assurance Requirements } \\
\hline Software Planning & Steve Humphreys, Eunice Young \\
\hline Verification and Validation & Ann Hodges \\
\hline Documentation & Steve Humphreys, Eunice Young \\
\hline Configuration Management & Steve Humphreys, Eunice Young \\
\hline Defect Reporting and Resolution & Jaye Bullington \\
\hline
\end{tabular}

Results: The audit was performed as scheduled. All audit findings were of minor consequence with respect to the overall quality effort of the Refined Safety Analysis Project. The Refined Safety Analysis Project used quality methods and procedures to manage and produce their products. The interest and efforts in continuous improvement of Refined Safety Analysis Project processes and their products were evident to the auditors.

All Discrepancy Reports generated as a result of this activity were closed out as of Resolve Version 2.5.

\subsection{VERIFICATION: DATA TRANSFER FROM EXCEL ${ }^{\circledR}$ DATABASES TO ACCESS RELATIONAL DATABASE (PROCESS CHECK)}

Abstract: The database architecture for both the pedigreed database (PDB) and the elicited database (EDB) was converted from an Excel $^{\circledR}$ spreadsheet to an Access Relational Database (RDB) for Resolve Version 1.85. The accuracy with which the data were transferred to the RDB is the subject of these tests. 
Requirements: Hanford Gas Release Event Safety Analysis Tool Version 2.5 Software Verification and Validation Plan (Hodges 1999).

References and Inputs: The following files were used for comparison:

- Excel $^{\circledR}$ PDB: PDB v2.0a 980901.xls

$(1,845 \mathrm{~KB})$

- Excel $^{(}$EDB: Edb20.xls

- Access RDB: resolve1_85.mdb

These files are maintained in the project Document Management System.

General Test Procedure: Requirements for the databases are described in Section 3.8.1 of the SRS (Humphreys 1998a). No specific requirements are spelled out for ensuring appropriate transfer of data during the architecture modification. Therefore, the following requirements were assumed.

In general, all entries checked were expected to match exactly between the Excel ${ }^{\circledR}$ file and the Access file. The following exceptions were noted:

- For some pedigreed data values, the Excel $^{\circledR}$ spreadsheet contained numbers with more than ten significant figures. For values that were not transferred exactly, a requirement of agreement within $0.001 \%$ was assumed. This was to ensure that that values agreed within the five most significant digits and any discrepancies could be attributed to roundoff in the different software systems.

- For some pedigreed parameter names, slight differences were observed. It was assumed that preservation of meaning was the requirement for these cases. For example, if the parameter name in Excel ${ }^{\circledR}$ contained the text "Tank Control Strategy," it was considered acceptable for this to appear as "TCS" in the Access parameter name (since this is a welldefined acronym in Resolve documentation).

For the EDB, the following information was examined for each of the 155 panel-based distributions:

- variableName

- tankGroup

- distributionNumber

- parameterName

- distributionType

- unitMeasure

- "X" and "Y" values for each of 53 data pairs.

The data migration process check was then performed using the following process:

These data were compared by using the Windows ${ }^{\circledR}$ clipboard to electronically copy and paste information from the original Excel ${ }^{\circledR}$ EDB and the Access RDB to a separate Excel ${ }^{\circledR}$ spreadsheet. This comparison involved a sufficient number of values that hand comparisons were not possible. Instead, the entries were compared using an Excel ${ }^{\circledR}$ formula. An example of 
the formula used is shown below. This formula results in an "ERROR" message if the values do not compare exactly. Otherwise, it leaves the cell blank.

$=\mathrm{F}(\mathrm{J} 3=\mathrm{G} 3, "$ ","ERROR")

Where column "G" contains the original Excel ${ }^{\circledR}$ EDB entries, and column " $\mathrm{J}$ " contains the Access RDB entries.

For the PDB, the following information was checked:

- Parameter Variable Names (variableName)

- Parameter Names (parameterName)

- Parameter Units (unitMeasure)

- Pedigreed Tank-Specific (PTS) Values for all parameters, all tanks

- PTS Record Initiation date entries for all parameters, all tanks

- PTS Point of Contact entries for all parameters, all tanks

- PTS Last Update date entries for all parameters, all tanks

- PTS Justification Choice entries for all parameters, all tanks

- PTS Data Source entries for all parameters, all tanks

- Pedigreed Non-Tank-Specific (PNTS) Variable Names

- PNTS Data Value entries

- PNTS Data Source entries

- PNTS Record Initiation entries

- PNTS Last Update entries

- PNTS Point of Contact entries

- Pedigreed Distribution Types

- Pedigreed Distribution Coefficients

- Pedigreed Default Variable Names

- Pedigreed Default Data Value entries

- Pedigreed Default Data Source entries

- Pedigreed Default Record Initiation entries

- Pedigreed Default Last Update entries

- Pedigreed Default Point of Contact entries

- Key for Definition of Tank Groups

- Key for Definition of Distribution IDs

- Key for Definition of Data Source Ids.

Acceptance Criteria: Successful data transfer was defined as compliance with the requirements listed above.

Results: 1337 data transfer checks were performed. In reality, many more checks were performed because most tests were checks of data for "all tanks" or "all parameters." Twenty discrepancy reports were prepared as a result of 226 test failures. All DRs except one were closed as of Resolve Version 2.5. The single exception was a low-severity issue with regard to 
lack of documentation of the panel-based parameter variable names in the Software Design Description (Humphreys 1998b).

\subsection{VERIFICATION: RESOLVE RELATIONAL DATABASE CHANGES}

Abstract: This activity checked the consistency between the Resolve Relational Database (RDB) changes and related source materials.

Requirements: Flammable Gas Safety Analysis Data Review (Barker et al. 1999).

References: Flammable Gas Safety Analysis Data Review (Barker et al. 1999).

“New RDB Distributions 990831 (sab).xls” (Barker 1999b), a spreadsheet containing analysis for distributions.

Proposed Data Review Workshop Changes to the Refined Safety Analysis Tool, Resolve Version 2.50 (Humphreys 1999).

"RDB input waste form 990819.xls" (Barker 1999c), a spreadsheet containing updates to tank waste form classification.

General Testing Procedure: Several aspects of RDB version 2.25 were verified.

- The waste form identified by tank in Table 2.2 of Flammable Gas Safety Analysis Data Review (Barker et al. 1999) was checked in the classification field in the TSValues table.

- Distributions and related lower and upper bounds (if applicable) specified in Flammable Gas Safety Analysis Data Review (Barker et al. 1999) were checked against the entries in the RDB. Tank average void fraction, waste form average void fraction distributions, duration and frequency of releases, and BD release duration entries in the RDB were verified.

- The RDB entries were also checked for consistency with "New RDB Distributions 990831 (sab).xIs" (Barker 1999b). RDB entries were based on SHMS and RGS data represented in spreadsheets contained in this Excel ${ }^{\circledR}$ file.

Acceptance:

- Curves fit to data were visually inspected. Subjective judgement was used to determine adequacy.

- RDB entries had to be consistent with "New RDB Distributions 990831 (sab).xls" (Barker 1999b) and with Flammable Gas Safety Analysis Data Review (Barker et al. 1999).

Results: The only verification problems noted were captured in two discrepancy reports. The first discrepancy report was a medium-severity problem. The tank waste form grouping for Tank 241-SX-106 should have been SC/SS-NL, but was listed as SC/SS-LIQ in the classification variable in the TSValues table. Additionally, Steve Barker had noted Tank 241-AN-103 should have been changed from SC/SS-LIQ to SC/SS-NL in "RDB input waste form 990819.xIs" (Barker 1999c), "Compare_rslts" sheet, but this was not reflected in the tank's waste form grouping. The second discrepancy report was a low-severity problem. A parameter description 
was incorrect in the RDB Parameters Table. In verifying the distributions in the "DepWasteForm" table, there were some incorrect/missing Parameter Description entries. Suggestions for descriptions were provided in the DR.

The waste form grouping for Tank 241-SX-106 and Tank 241-AN-103 were corrected. The labeling issue identified in DR \#295 was deferred since it had no impact on results computed by Resolve.

\subsection{VERIFICATION: REDERIVATION OF ANALYSIS FRAMEWORK EQUATIONS}

Abstract: The objective of this activity was to determine if there were any errors made in the derivation of the AF equations. Errors could consist of sign errors, coefficient errors, logic errors, or typos. Of primary concern was whether or not the logic used in the derivations was clearly stated.

Requirements: Hanford Gas Release Event Safety Analysis Tool Version 2.0 Software Verification and Validation Plan (Hodges 1998d).

References and Inputs: Refined Safety Analysis Methodology for Flammable Gas Risk Assessment in the Hanford Site Tanks, Part 1: Analysis Framework for Single-Shell Tanks, (Slezak and Williams 1998).

Refined Safety Analysis Methodology for Flammable Gas Risk Assessment in the Hanford Site Tanks, Part 2: Analysis Framework for Double-Shell Tanks (Slezak et al. 1998).

General Test Procedure: The procedure consisted of following the derivations given in the AF. Where algebraic steps had been left out, they were filled in as per rules of algebra and calculus. Equations were also checked for consistency of physical units. Where clarification was required regarding sources or derivation steps, the author was consulted and text was revised accordingly for the final AF report (Slezak et al. 2000). Sample numerical calculations were done to confirm values shown in tables of the AF, with the exception of Tables 7 through 12 of AF Part II.

Acceptance Criteria: Each equation must be traceable to either a basic scientific principle, an accepted model, or an empirical correlation. References for models or correlations must be documented. Units of equations must be consistent.

Results: Comments and findings were provided the author of the AF and implemented as appropriate. Only four errors of substance were detected in the rederivation, involving the following equations:

- Part I, Eqns. 57 and 62

- Part I, Eqn. 95

- Part II, Eqns. 37, 43, and 44

- Part II, Eqn. 130. 
RPP-6873 REV 0

The correct equations were immediately transmitted to the software programmer to ensure that the code was revised to implement the correct expressions. The correct expressions were incorporated in the final AF report (Slezak et al. 2000).

\subsection{VERIFICATION: REDERIVATION OF IMPLEMENTATION DETAILS EQUATIONS}

Abstract: The objective of this activity was to ensure the correctness of equations found in the Implementation Details (Slezak et al. 1999). Equations in the Implementation Details revision released on January 15, 1999, were rederived from basic scientific principles or from published relationships. In addition, the equations were inspected for logic errors, typos, and clarity of symbology.

Requirements: Hanford Gas Release Event Safety Analysis Tool Version 2.5 Software Verification and Validation Plan (Hodges 1999).

References and Inputs: Refined Safety Analysis Methodology for Flammable Gas Risk Assessment in the Hanford Site Tanks: Implementation Details for the Analysis Framework (Slezak et al. 1/15/99).

General Test Procedure: Equations in the Implementation Details revision (Slezak et al.) released on January 15, 1999, were rederived from basic scientific principles or from published relationships. In addition, the equations were inspected for logic errors, typos, and clarity of symbology.

Acceptance Criteria: No errors should be found in logic, equation derivation, or symbology. Symbols employed should be consistent.

Results: No errors were discovered in the equation derivations. The rederivation effort resulted primarily in recommendations that would simplify and unify the notation. Some of the recommendations were incorporated at the discretion of the author. Changes as a result of these recommendations were incorporated into the final AF report (Slezak et al. 2000).

\subsection{VERIFICATION: MODEL COMPARISON TESTING}

Abstract: Tests in this area provided a validation check on the models by checking that the results were credible. Specific Relational Database parameter values were varied for each test case, and results were compared between runs. Observed trends were compared against expected behaviors. Verification occurred simultaneously in the sense that models were evaluated for proper implementation of the Analysis Framework (AF) and for having the required features.

Requirements: Refined Safety Analysis Methodology for Flammable Gas Risk Assessment in the Hanford Site Tanks, Part 1: Analysis Framework for Single-Shell Tanks (Slezak and Williams 1998).

Refined Safety Analysis Methodology for Flammable Gas Risk Assessment in the Hanford Site Tanks, Part 2: Analysis Framework for Double-Shell Tanks (Slezak et al. 1998). 
Refined Safety Analysis Methodology for Flammable Gas Risk Assessment in Hanford Site Tanks, Implementation Details for the Analysis Framework (Slezak 1998).

Software Requirements Specification (SRS) for the Gas Release Event Safety Analysis Tool (Humphreys 1998a).

$\underline{\text { References and Inputs: }}$ Microsoft ${ }^{\circledR}$ Windows $98^{\circledR}$ Resource Kit.

"Comparison_Test_Cases_2.20.xls" (Riddle and Hodges 1998), a spreadsheet containing the details of each input file required for individual test construction for each test case. The worksheet titled "guide for .afi file creation" provided input specification and the worksheet titled "output parameters table" contained parameters to be observed for each test. Hodges (1998d), Appendix B contained the comparison test design specification. The expected output and pass/fail criteria were listed for each test case.

General Test Procedure: Test cases were listed by model. By listing cases according to each model, regression testing was facilitated-if a model changed, only the set of test cases indicated needed to be rerun. Scripts were created to facilitate automated execution of test cases. A comparison test consisted of multiple runs, where one or more input parameters were modified between runs, and output was checked for expected trends. Tank 241-SY-101 was the tank used for DST test cases, and Tank 241-A-101 was used for SST tests. There were several models that had test cases for both SSTs and DSTs. For these models, DSTs were used in all cases with the exception of test cases involving salt well pumping. The defaults for the indicated tanks were used unless otherwise noted. Test cases were designed to cover the major phenomenological models in the tool. The following models were specifically targeted:

- Radiological and toxicological consequences

- Deflagration combustion

- Detonation combustion

- Frequency of burns

- Global headspace mixing

- Plume headspace mixing

- Buoyant displacement GREs

- Engineered GREs

- Risk

- Salt well pumping

- Waste-disturbing operation in DSTs

- Waste transfers

- Steady-state releases

- DST ammonia releases. 
Parameter values were modified and output from the above models was checked for expected trends. The following is a list of the parameters or ratios that were varied for individual test cases during this activity:

- Fill factor

- Mixer pump radius of influence

- Mixer pump frequency of operations

- Mixer pump settled solids disturbance rate

- Liquids-to-solids ratio (with BD GREs)

- Liquids-to-solids ratio (without BD GREs)

- Ignition control set

- Ignition control location (in-tank, ex-tank)

- Salt well pumping rate

- Tank failure pressure

- Ventilation rate

- Waste-intruding equipment inerting status

- Headspace inerting efficiency

- Void fraction

- Ventilation duct diameter

- Waste-intruding equipment internal diameter

- Liquid-to-solid density ratio

- Gas generation rate

- Settled solids yield strength

- Facility group classification

- Mixer pump waste-disturbing window

- Waste transfer rate

- Waste transfer volume.

Acceptance Criteria: Appendix B of Hodges (1998d) contained the evaluation criteria for each test. "Comparison_Test_Cases_2.20.xls" (Riddle and Hodges 1998), worksheet output parameters table, contained the specific values observed for each test.

Results: All of the comparison tests identified for the Resolve Version 2.20 -xcept those tests requiring debug output (four tests)-were executed. Tests requiring evaluation of debug output were not performed because of time constraints.

Sensitivity testing on a variety of parameters indicated that output from all key models in Resolve trended as expected. No test case failures were noted.

This testing noted that the calculated expected risk has a certain degree of statistical instability. That is, changes in calculated risk may result from sampling wide uncertainty distributions and not from actual change in the flammable gas risk. Specifically, instability is associated with (1) a low number of non-zero consequence events (few samples to generate population statistics) and/or (2) performing a sensitivity study on a parameter that impacts the mass balance equation (equivalent to using different seeds). 
While this observation may cast doubt on the significance of calculated risk values when the set of non-zero consequence events is too small $(<100)$ for statistical stability, the ratio of zero to non-zero consequence cases is quite stable. This is because the overall analysis performs sufficient sampling $(=>1000)$ to achieve a reasonable degree of stability in the partitioning between burns and non-burns. Thus, while an analysis with few non-zero consequence "hits" may generate suspect risk numbers, the analysis still yields significant information about the flammable gas risk in terms of the number of sample passes that did not burn.

In addition, there are a number of methods that an analyst may employ to minimize the instability in his or her results. First, increasing the number of samples can improve stability. Second, when appropriate, distributions can be replaced with point values to perform deterministic or semi-deterministic analyses (results indicate that uncertainty in ignition frequency is the primary driver for variability in risk). Third, attention should be focused on model outputs that specifically target the area of investigation. For example, if doing a study of the effect of ventilation rate, \% LFL values can be examined in addition to risk and consequences; or, for example, if the risk associated with an operation is under investigation, the risk from induced sources should be specifically looked at. It should be noted that risk is the product of two independent systems (consequence and frequency), both of which have high degrees of uncertainty.

\subsection{VERIFICATION: BENCHMARK TANK TESTING}

Abstract: Tests in this area verified whether or not the AT could successfully run each of the 177 Hanford Site tanks as benchmark tests. Each test was also used to check the Resolve performance requirements. As a side benefit, a subset of output parameters for each tank was tracked for comparison purposes between Resolve versions. For Resolve Version 2.20, benchmark tests were run for all 177 tanks.

Requirements: Hanford Gas Release Event Safety Analysis Tool Version 2.0 Software Verification and Validation Plan (Hodges 1998d).

Software Requirements Specification (SRS) for the Gas Release Event Safety Analysis Tool (Hurnphreys 1998a).

References and Inputs: Resolve Version 2.20 (Humphreys and Young 1998).

General Test Procedure: Each individual test comprised a unique tank run as benchmark. Interaction with the GUI was limited to selection of a tank and input of an analysis name followed by a run request. No changes were made to any database parameters or run options.

All tests used the default sample size of 1000 for the first pass through the LHS. AFE run times were noted and checked against the run time maximum limit of five minutes (Humphreys 1998a). During AFE execution, the LHS distribution count and re-sample size were also noted. 
The following AFE output parameters were additionally tracked separately for comparison purposes between each of the Resolve versions:

- Mean GRE Frequency

- Mean On-Site Radiological Consequences

- Mean On-Site Toxicological Consequences

- Mean Accident Frequency

- Expected Radiological Risk

- Expected Toxicological Risk

- Number of Outputs

- Number of Deflagrations

- Number of Non-Burns

- Number of Detonations.

These outputs were noted where possible and were used as bellwether indicators of the overall status of the models encoded within the AFE.

Acceptance Criteria: Software Requirements Specification (Humphreys 1998a), Section 2.2 provides an overview of what the tool is expected to do; it was logically inferred that these expectations were for every tank covered within the database. Section 3.3 gives the time limit of five minutes for analyses using 1000 samples. This requirement was interpreted to mean five minutes of Analysis Framework Engine (AFE) run time since time spent by the user while interacting with the Graphical User Interface (GUI) is dependent on user actions.

The criteria were based on whether or not the tool executed cleanly, completely, and within the five-minute run time limit. Any GUI or AFE errors noted would have resulted in nonacceptance. The additional tracked output parameters were not used in any way to determine acceptance.

Results: For benchmark testing of Resolve Version 2.20, all tanks completed the analysis within the time limit, and no GUI or AFE errors were encountered.

\subsection{VALIDATION: BUOYANT DISPLACEMENT GAS RELEASE EVENT MODEL}

Abstract: The frequency and amount of gas released during buoyant displacement GREs is an important intermediate step in the AF's determination of flammable gas risk. Historical monitoring data or values inferred from monitoring data are available for the BD GRE behavior of some tanks. These data include the following:

- Duration of release

- Volume of release

- Period between releases

- Peak hydrogen concentration in the headspace during a BD GRE.

Available data on BD GRE durations were used to construct data-based distributions and these distributions were incorporated into the Relational Database. Thus, BD GRE duration as used by 
the tool is valid by construction. The tool has the capability to allow replacement of panel-based distributions with data-based distributions when the available data are deemed adequate.

Model predictions for average BD GRE volume, the average peak hydrogen concentration after a release, and average period between BD GREs were compared against the monitoring data (Meyer et al. 1997, Stewart 1998) for double-shell tanks (DSTs) in which BD GRE behavior has historically been observed. In addition, the AT's evaluation of BD GRE potential — whether BD behavior will or will not occur in a tank-was compared to the list of tanks in which BD GRE behavior has historically been observed.

The model also predicts the impact of waste-disturbing flammable gas controls on the frequency and size of spontaneous releases as well as the frequency and size of releases induced by the control. These model predictions were compared to field observations and SHMS monitoring data (Conner and Koreske 1998) for mixer pump operations in Tank 241-SY-101.

Requirements: Refined Safety Analysis Methodology for Flammable Gas Risk Assessment in the Hanford Site Tanks (Slezak et al. 2000).

Flammable Gas Safety Analysis Data Review (Barker et al. July 1999).

References and Inputs: Gas Retention and Release Behavior in Hanford Double-Shell Waste Tanks (Meyer et al. 1997),

"Quarterly Review of 241-SY-101 Mixer Pump Date: April-June, 1998" (Conner and Koreske 1998).

"shmsgred.xls" (Stewart 1998), a spreadsheet containing monitoring data and derivation of peak hydrogen concentration for tanks with observed buoyant displacement GRE behavior.

Resolve Version 2.20 (Humphreys and Young 1999).

"FilterResolveResults.sh," Version 1.2 (McCornak 1999).

Spreadsheet "BD GRE Volume, Duration, and Period Validation.xls" (Riddle 1999b) was used to collect input and output data as well as to perform unit conversions and calculations.

General Test Procedure: Benchmark cases were created for the six tanks with historically observed BD GRE behavior (241-AN-103, 241-AN-104, 241-AN-105, 241-AW-101, 241-SY-101, and 241-SY-103). A sample size of 200 and a seed of 123456789 were used. Benchmark analyses were also run for all the DSTs in order to evaluate BD GRE potential. For these test cases, a sample size of 1000 and a random seed were used.

Average BD GRE volumes for the six BD positive tanks are reported in Meyer et al. (1997). These values were compared with the mean (average) of the spontaneous BD GRE release . volumes calculated for 200 trials in Resolve. These values were removed electronically from the debug output file using the "FilterResolveResults.sh" (McCornak 1999) filter tool. 
Spreadsheet "shmsgred.xls" (Stewart 1998) contains average values for monitoring data of peak headspace hydrogen concentrations during BD GREs. These values were compared to the average of the peak headspace hydrogen concentrations (mole fraction) calculated by Resolve for spontaneous BD GREs on 200 trials. These values were removed electronically from the debug output file using the "FilterResolveResults.sh" (McCornak 1999) filter tool.

Meyer et al. (1997) reports average BD GRE periods as well. These were compared to the spontaneous BD GRE frequencies reported in the GUI calculated statistics.

For testing of the waste-disturbing operation model, a test case was created to simulate mixer pump operation in Tank 241-SY-101 (Table 4-9).

Spontaneous and mixer pump-induced GRE frequencies were taken from the output statistic reported in the GUI. Headspace hydrogen concentrations were removed from the debug output using the "FilterResolveResults.sh" (McCornak 1999) filter tool. These values were compared to monitoring data in Conner and Koreske (1998).

Table 4-9. Mixer Pump Test-Case Input.

\begin{tabular}{|c|c|c|c|c|c|c|c|}
\hline Run ID & Tank ID & $\begin{array}{c}\text { Mixer } \\
\text { Pump } \\
\text { Radius of } \\
\text { Influence } \\
\text { (ft) }\end{array}$ & $\begin{array}{c}\text { Post- } \\
\text { Equipment- } \\
\text { Operation } \\
\text { Void } \\
\text { Fraction } \\
(\boldsymbol{\%})\end{array}$ & $\begin{array}{c}\text { Mixer } \\
\text { Pump } \\
\text { Status }\end{array}$ & $\begin{array}{c}\text { Mixer } \\
\text { Pump } \\
\text { Operation } \\
\text { Duration }\end{array}$ & $\begin{array}{c}\text { Mixer Pump } \\
\text { GRE/Waste- } \\
\text { Disturbing } \\
\text { Window }\end{array}$ & $\begin{array}{c}\text { Mixer } \\
\text { Pump } \\
\text { Operations } \\
\text { Frequency }\end{array}$ \\
\hline $\begin{array}{c}\text { SY-101 } \\
\text { with mixer } \\
\text { pump.afi }\end{array}$ & SY-101 & 37.5 & 4.5 & $\begin{array}{c}\text { Equip- } \\
\text { ment } \\
\text { Avail- } \\
\text { able }\end{array}$ & 5.5 & 30 & 12 \\
\hline
\end{tabular}

Acceptance Criteria: For comparisons of point values, the AT was considered to have passed the test if it was no more than a factor of 3 conservative and a factor of 2 non-conservative. For the BD GRE potential, the set of BD GRE positive tanks determined by the tool must contain the entire set of tanks that have displayed BD behavior. For mixer pump-induced releases, the general acceptance criterion of no more than 2 orders of magnitude conservative or 1 order of magnitude non-conservative was applied.

\section{Results:}

\section{BD GRE Potential}

Resolve accurately predicted BD GRE behavior in all the tanks that historically have displayed BD GRE behavior (241-AN-103, 241-AN-104, 241-AN-105, 241-AW-101, 241-SY-101, and 241-SY-103). It also predicted BD GRE behavior in Tank 241-AN-102 and Tank 241-AN-107. 
Tanks 241-AN-102 and 241-AN-107 had significant liquid layers and relatively thin settled solids layers. These conditions were similar to those found in tanks where BD GRE behavior historically has been observed. It is possible that low-level BD activity occurred undetected in these tanks.

Since the waste configurations where BD GRE behavior has been observed are a subset of the waste configurations for which the model predicts BD GRE behavior, there is some confidence that future or hypothetical waste configurations in which BD GREs would occur will be trapped by the model. As noted in the Analysis Framework, evaluating additional tanks to be BD GRE positive even though no BD GRE events have been observed in them is conservative on the side of safety; this is because a greater flammable gas risk is associated with BD-type releases and because it is possible for a tank to experience BD GRE events without the event being detected.

Table 4-10. Buoyant Displacement GRE Potential-Comparison Results.

\begin{tabular}{|c|c|c|c|c|c|}
\hline Case ID & Tank ID & $\begin{array}{c}\text { BD GREs Historically } \\
\text { Observed? }\end{array}$ & $\begin{array}{l}\text { Slezak et al. (2000) } \\
\text { Predict BD GREs? }\end{array}$ & $\begin{array}{c}\text { Resolve Predict } \\
\text { BD GREs? }\end{array}$ & $\begin{array}{l}\text { Pass/ } \\
\text { Fail }\end{array}$ \\
\hline AN101bmrk644 & AN-101 & no & no & no & PASS \\
\hline an 102bmrk645 & $\mathrm{AN}-102$ & no & yes & yes & PASS \\
\hline an 103 bmrk646 & $\mathrm{AN}-103$ & yes & yes & yes & PASS \\
\hline an 104bmrk647 & AN-104 & yes & yes & yes & PASS \\
\hline an 105bmrk648 & AN-105 & yes & yes & yes & PASS \\
\hline an 106bmrk649 & AN-106 & no & no & no & PASS \\
\hline an $107 \mathrm{bmrk650}$ & AN-107 & no & yes & yes & PASS \\
\hline ap 101 bmrk651 & AP-101 & no & no & no & PASS \\
\hline ap 102bmrk652 & AP-102 & no & no & no & PASS \\
\hline ap 103bmrk653 & $\mathrm{AP}-103$ & no & no & no & PASS \\
\hline ap 104bmrk654 & AP-104 & no & no & no & PASS \\
\hline apl05bmrk655 & AP-105 & no & yes & no & PASS \\
\hline ap 106bmrk656 & $\mathrm{AP}-106$ & no & no & no & PASS \\
\hline ap 107bmrk657 & AP- 107 & no & no & no & PASS \\
\hline ap 108bmrk658 & $\mathrm{AP}-108$ & no & no & no & PASS \\
\hline aw 101bmrk659 & AW-101 & yes & yes & yes & PASS \\
\hline aw 102 bmrk660 & $\mathrm{AW}-102$ & no & no & no & PASS \\
\hline aw 103 bmrk661 & AW-103 & no & no & no & PASS \\
\hline aw 104bmrk662 & $\mathrm{AW}-104$ & no & no & no & PASS \\
\hline aw 105 bmrk663 & AW-105 & no & no & no & PASS \\
\hline aw 106bmrk664 & AW-106 & no & no & no & PASS \\
\hline ay 101 bmrk669 & $\mathrm{AY}-101$ & no & no & no & PASS \\
\hline ay 102 bmrk670 & $\mathrm{AY}-102$ & no & no & no & PASS \\
\hline az101bmrk671 & AZ-101 & no & no & no & PASS \\
\hline azlo2bmrk672 & $\mathrm{AZ}-102$ & no & no & no & PASS \\
\hline sy 101 bmrk 756 & SY-101 & yes & yes & yes & PASS \\
\hline sy 102 bmrk757 & SY-102 & no & no & no & PASS \\
\hline sy 103 bmrk758 & SY-103 & yes & yes & yes & PASS \\
\hline
\end{tabular}




\section{BD GRE Volume}

Except for the Tank 241-SY-101 analysis, the average of Resolve-calculated BD GRE release volumes for a tank vary from the average of BD GRE volumes inferred from headspace hydrogen measurement histories for the same tank (Meyer et al. 1997) by no more than a factor of 2 (Table 4-11). This is within the acceptable range for this comparison.

In the case of Tank 241-SY-101 (pre-mixer-pump conditions), the average of the calculated releases is approximately one third of the average for the inferred volumes, outside the acceptance range for BD GRE releases. A Tank 241-SY-101 analysis was run with the data values in the Analysis Framework (Slezak et al. 2000) and the results compared acceptably to the predicted values in the AF and to the monitoring data. This indicates that (1) for this analysis, the Buoyant Displacement model is correctly implemented in the AFE, and (2) that the discrepancy is caused by differences between the Tank 241-SY-101 data in the database an the data in the AF. In particular, the biggest driver of the divergent results was found to be the liquid layer density values.

The discrepancy arises from the incompatibility of sparse existing data with the assumption of the model that liquid density in the tanks is constant. Because of the unique safety concerns regarding flammable gas releases in Tank 241-SY-101, data on waste configuration were collected soon after $\mathrm{BD}$ events had occurred when the likelihood of a release during sampling was believed to be low. For some time following a BD, the liquid portion of the waste contains suspended particulate or soluants that increase its density. The equations in the AF for calculating frequency and size of BD releases, however, assume steady-state values for the densities of the liquid and solids layers. The effect in the model of higher liquid layer densities is that neutral buoyancy is reached during a shorter period of void growth, so releases are predicted to be smaller and more frequent than those that are actually experienced.

Table 4-11. Average Volume of Buoyant Displacement GREs-Comparison Results.

\begin{tabular}{|c|c|c|c|c|}
\hline Tank ID & $\begin{array}{c}\text { Resolve Average } \\
\text { BD GRE } \\
\text { Volume } \\
\text { (standard-m }\end{array}$ & $\begin{array}{c}\text { Meyer et al. (1997), } \\
\text { Average BD GRE } \\
\text { Volume (standard-m }\end{array}$ & $\begin{array}{c}\text { Ratio (Resolve/ } \\
\text { Meyer et al.) }\end{array}$ & $\begin{array}{c}\text { Pass/ } \\
\text { Fail }\end{array}$ \\
\hline AN103 & 16.1 & $14 \pm 4$ & 1.1 & PASS \\
\hline AN104 & 14.9 & $23 \pm 16$ & 0.6 & PASS \\
\hline AN105 & 32.4 & $26 \pm 11$ & 1.2 & PASS \\
\hline AW101 & 20.4 & $14 \pm 10$ & 1.5 & PASS \\
\hline SY101 & 43.8 & $131 \pm 47$ & 0.3 & FAIL \\
\hline SY103 & 6.4 & $13 \pm 6$ & 0.5 & PASS \\
\hline
\end{tabular}




\section{BD GRE Period}

Except for the Tank 241-SY-101 analysis, the average period between BD GREs calculated for a tank by Resolve are within a factor of 2 of the average historically observed BD GRE period for the same tank reported by Meyer et al. (1997) (Table 4-12). This is within the acceptable range for this comparison. The historical data on BD GRE periods indicate a high degree of variability; even so, the Resolve-calculated average BD periods for a tank are within the one sigma band of the observed periods in that tank.

In the case of Tank 241-SY-101 (pre-mixer-pump conditions), the average of the calculated release periods is approximately one third of the average of the historical data, outside the acceptance range for BD GRE releases. This difference arises from the incompatibility of sparse existing data with the assumption of the model that liquid density in the tanks is constant. The effect is that releases are predicted to be smaller and more frequent than those that are actually experienced, as noted above in the discussion of BD GRE release volume.

Table 4-12. Average Buoyant Displacement GRE Period-Comparison Results.

\begin{tabular}{|l|c|c|c|c|}
\hline Tank ID & $\begin{array}{c}\text { Resolve Average BD } \\
\text { GRE Period } \\
\text { (days/event) }\end{array}$ & $\begin{array}{c}\text { Meyer et al. (1997), } \\
\text { Average BD GRE Period } \\
\text { (days/event) }\end{array}$ & $\begin{array}{c}\text { Ratio } \\
\text { (Resolve/ } \\
\text { Meyer et al.) }\end{array}$ & Pass/ Fail \\
\hline AN-103 & 236 & $160 \pm 120$ & 1.5 & PASS \\
\hline AN-104 & 73 & $120 \pm 90$ & 0.6 & PASS \\
\hline AN-105 & 228 & $160 \pm 130$ & 1.4 & PASS \\
\hline AW-101 & 100 & $220 \pm 230$ & 0.5 & PASS \\
\hline SY-101 & 29 & $110 \pm 24$ & 0.3 & FAIL \\
\hline SY-103 & 34 & $90 \pm 70$ & 0.4 & PASS \\
\hline
\end{tabular}

\section{BD GRE Average Peak Hydrogen Concentration}

Except for the Tank 241-SY-101 analysis, the average peak BD GRE hydrogen concentration calculated for a tank by Resolve are within a factor of 2 of the monitoring data for the same tank (Stewart 1998) (Table 4-13). This is within the acceptable range for this comparison.

In the case of Tank 241-SY-101 (pre-mixer-pump conditions), the average of the peak hydrogen concentrations is approximately one sixth of the average of the monitoring data, outside the acceptance range for $\mathrm{BD}$ GRE releases. This difference arises from the incompatibility of sparse existing data with the assumption of the model that liquid density in the tanks is constant. The effect is that releases are predicted to be smaller and more frequent than those that are actually experienced, as noted above in the discussion of BD GRE release volume. The smaller release volumes yield lower predicted headspace hydrogen concentrations.

Tank 241-AN-103 has only one reported peak hydrogen concentration. It is not possible to determine where this release might fall relative to a representative set of historic or future 
releases from the current waste configuration; therefore, the Tank 241-AN-103 results are reported here for informational purposes only.

Table 4-13. Average Peak Headspace Hydrogen Concentration for Buoyant Displacement GREs-Comparison Results.

\begin{tabular}{|c|c|c|c|c|}
\hline Tank ID & $\begin{array}{c}\text { Resolve Average, Well- } \\
\text { Mixed BD GRE Peak } \\
\text { H }_{\mathbf{2}} \text { Concentration } \\
\text { (ppm) }\end{array}$ & $\begin{array}{c}\text { Stewart (1998) Average } \\
\text { Peak H2 Concentration } \\
\text { (ppm } \pm \text { sigma) }\end{array}$ & $\begin{array}{c}\text { Ratio (Resolve } \\
\text { Stewart) }\end{array}$ & Pass/ Fail \\
\hline AN-103 & 4873 & 1600 & 3.05 & PASS \\
\hline AN-104 & 4038 & $2399 \pm 1841$ & 1.68 & PASS \\
\hline AN-105 & 14820 & $7417 \pm 6875$ & 2.00 & PASS \\
\hline AW-101 & 4219 & $2814 \pm 1521$ & 1.50 & PASS \\
\hline SY-101 & 6060 & $36080 \pm 16182$ & 0.17 & FAIL \\
\hline SY-103 & 1058 & $1969 \pm 1275$ & 0.54 & PASS \\
\hline
\end{tabular}

\section{Mixer Pump-Induced BD GREs}

The frequency of mixer pump induced releases as calculated by Resolve is approximately an order of magnitude less, and the size of the induced release is approximately an order of magnitude more, than the monitoring data for frequency and size of mixer pump-induced releases (Conner and Koreske 1998). This result is observed because Resolve sums up, into a single modeled pump operation, all the pump operations required to sweep a full circle in the tank. This abstraction is used to model the void growth in the total volume of waste disturbed by pump operations. Thus, each Resolve modeled pump operation represents the effects of several smaller and more frequent actual pump operations. Since both the monitoring data and the model results show all releases to be below the LFL, a reduction in the frequency is not nonconservative (one large, infrequent release with consequences represents more risk than small, frequent events with no consequences). Resolve conservatively predicts larger mixer pumpinduced releases, but as noted before, these releases are well below the flammability limit.

\section{Mixer Pump Impact on Spontaneous BD GREs}

Field observations indicate the mitigation of large BD GREs in Tank 241-SY-101 since the installation of a mixer pump. Conner and Koreske (1998) also report spontaneous gas releases, releases not coincident to pump operations, during the period when mixer pump operations were taking place. Approximately 20 of these releases occurred every year, with an average measured hydrogen concentration of $0.5 \%$ of the LFL ( $200 \mathrm{ppm})$.

Resolve results indicate that with the mixer pump control in place, (1) there are no large, spontaneous releases, and (2) the remaining releases generate headspace concentration with an average \%LFL of 6.5 and a frequency of four per year (Table 4-14). 
The Resolve results are conservative by approximately an order of magnitude, which is within the acceptance range. Despite the conservatism, it should be noted that Resolve results correctly reflect the gross effects of mixer pump operation (complete mitigation of large releases).

Table 4-14. Frequency and Size of Mixer Pump-Induced Buoyant Displacement GREsComparison Results.

\begin{tabular}{|c|c|c|c|c|}
\hline & $\begin{array}{c}\text { Conner and Koreske } \\
\text { (1998) }\end{array}$ & Resolve & $\begin{array}{c}\text { Ratio (Resolve/ } \\
\text { Conner and Koreske) }\end{array}$ & Pass/ Fail \\
\hline $\begin{array}{c}\text { Average Frequency } \\
\text { (GREs/year) }\end{array}$ & 116 & 12 & 0.10 & PASS \\
\hline $\begin{array}{c}\text { Average Headspace } \\
\text { Hydrogen Concentration } \\
\text { (mole fraction) }\end{array}$ & $1.90 \mathrm{E}-04 \pm 6.84 \mathrm{E}-05$ & $3.33 \mathrm{E}-03$ & 17.53 & PASS \\
\hline
\end{tabular}

\subsection{VALIDATION: NON-BUOYANT DISPLACEMENT GAS RELEASE EVENT MODEL-HEADSACE HYDROGEN CONCENTRATION AND MIMIMUM DURATION}

Abstract: Data exist for peak headspace hydrogen concentrations during non-BD GREs (Barker 1999a). In addition, the duration of these releases was inferred from headspace hydrogen histories (Barker 1999a).

The AF model prediction of headspace hydrogen concentrations was validated against the monitoring data, and the minimum release duration calculated by the model was checked to ensure that it was less than any inferred release duration. Shorter durations are conservative from a flammable gas risk perspective, because they lead to higher flammable gas headspace concentrations and a higher probability of computing a combustion.

Requirements: Hanford Gas Release Event Safety Analysis Tool Version 2.5 Software Verification and Validation Plan (Hodges 1999).

Flammable Gas Safety Analysis Data Review (Barker et al. 1999).

Refined Safety Analysis Methodology for Flammable Gas Risk Assessment in the Hanford Site Tanks, Part 1: Analysis Framework for Single-Shell Tanks (Slezak and Williams 1998).

References and Inputs: "NonBD_GRE - Sum2C_Shms 0819.xls" (Barker 1999a).

Resolve Version 2.20 (Humphreys and Young 1999).

"FilterResolveResults.sh," Version 1.2 (McCornak 1999).

"NON-BD GRE minDuration Validation.xls" (Riddle 1999b). 
A spreadsheet, "Peak H2 (\%LFL) during a Small GRE.xls" (Riddle 1999c), was used to collect input and output data as well as to perform unit conversions.

General Test Procedure: “NonBD_GRE - Sum2C_Shms 0819.xls" (Barker 1999a) contains the set of GRE data used in the Data Analysis Workshops (Barker et al. 1999). For the headspace hydrogen test, a subset of tanks, each of which had three or more non-BD releases, was selected. Benchmark analysis cases were created for each of these tanks with a sample size of 200 and a seed of 123456789 .

The monitoring data for Tank 241-SY-102 indicated a larger waste volume $(910,166$ gallons average) than the value in the RDB database version $2.25(733,100 \mathrm{gal})$. The value in the monitoring data was used so that waste configuration and headspace volume would more closely match the conditions under which the monitoring data were taken. The additional waste was assumed to be all liquid and no changes were made to density values. (When the configuration of multiple waste layers is specified, as in Tank 241-SY-102, the Waste Average Bulk Density is not used by the model; the densities of the different waste layers are used instead.)

The test cases were run in Resolve 2.20, and the calculated headspace hydrogen concentrations for small, spontaneous non-BD releases were removed from the debug output using the "FilterResolveResults.sh" (McCornak 1999) tool. The averages of these values were compared to the average values for the monitoring data.

"NonBD_GRE - Sum2C_Shms 0819.xls" (Barker 1999a) also contains the set of non-BD GRE release duration data used in the Data Analysis Workshops (Barker et al. 1999).

An AFE input file was created using Tank 241-B-203 and a waste density of $1.224 \mathrm{~g} / \mathrm{ml}$, since these conditions represent the bounds of current field data that "maximize" the calculated minimum duration. See "NON-BD GRE minDuration Validation.xls" (Riddle 1999b) for more information on how the input file was created.

Debug parameters release\%duration, release $\%$ N\%waste, and release $\%$ \%total were removed from debug output using the "FilterResolveResults.sh" (McCornak 1999) tool.

Acceptance Criteria: Resolve results must be no more than 1 order of magnitude nonconservative, and no more than 2 orders of magnitude conservative. For the model determination of minimum release duration, all inferred release durations should be longer than the corresponding minimum durations calculated by Resolve. This ensures that the minimum release duration calculation is conservative relative to experience.

\section{Results:}

\section{Average Peak Headspace Hydrogen Concentration}

Table 4-15 provides a summary of the results for the peak headspace hydrogen concentration test. The average of Resolve-calculated values for peak headspace hydrogen concentrations during non-BD GREs are, in general, lower than the average of the monitoring data values (Barker 1999). Except for the case of Tank 241-SY-102, Resolve-calculated values are lower, 
on average, by a factor of 0.5 with a maximum deviation of a factor of 4 . This is within the acceptable range for this comparison.

Tank 241-SY-102 generates an anomalous result because of its unique waste configuration relative to the other tanks tested, all of which are SSTs. As noted in Table 4-15, Tank 241-SY-102 failed the acceptance criteria, and a Discrepancy report was issued.

It should be noted that, even though Resolve underpredicts the headspace hydrogen concentration after a non-BD GRE, all of the non-BD releases to date have been well below the LFL. The fact that the mean of the monitoring data and the calculated mean diverge raises the question of whether Resolve underpredicts the largest (and most risk-significant) non-BD releases. To address this question, the distribution of peak hydrogen concentration measured in Tank 241-U-105 (this tank has the most measured non-BD releases) was compared to the benchmark Tank 241-U-105 results from Resolve. This comparison (Figure 4-1) showed good agreement between the two distributions; it also showed that Resolve does indeed simulate releases larger than the largest measured Tank $241-\mathrm{U}-105$ releases.

\section{Minimum Release Duration}

Resolve's calculated minimum release durations were always shorter than inferred non-BD release durations by at least an order of magnitude (Barker 1999d) (Figure 4-2). This means that only overly conservative, short-duration values are being trimmed from the relevant uncertainty distributions. Resolve is still conservative in this case, because shorter release durations lead to higher flammable gas headspace concentrations and a higher probability of computing a combustion.

Table 4-15. Peak Headspace Hydrogen Concentration During Non-Buoyant Displacement GREs-Comparison Results.

\begin{tabular}{|c|c|c|c|c|c|}
\hline Tank & $\begin{array}{c}\text { Number of } \\
\text { GREs, } \\
\text { Barker } \\
(1999 a)\end{array}$ & $\begin{array}{c}\text { Barker (1999a) } \\
\text { Average of Peak } \\
\text { Hydrogen } \\
\text { Concentrations } \\
\text { (ppm) } \\
\end{array}$ & \begin{tabular}{|c|} 
Resolve Average of \\
Peak Hydrogen \\
Concentrations \\
(ppm)
\end{tabular} & $\begin{array}{c}\text { Ratio } \\
\text { (Resolve/ } \\
\text { Barker) }\end{array}$ & $\begin{array}{c}\text { Pass/ } \\
\text { Fail }\end{array}$ \\
\hline S-102 & 3 & 4,140 & 1014 & 0.24 & Pass \\
\hline SX-103 & 3 & 1,797 & 692 & 0.39 & Pass \\
\hline $\mathrm{SX}-105$ & 3 & 527 & 669 & 1.27 & Pass \\
\hline SX-109 & 3 & 187 & 49 & 0.26 & Pass \\
\hline SY-102 & 11 & 171 & 8 & 0.05 & Fail \\
\hline $\mathrm{U}-103$ & 4 & 950 & 467 & 0.49 & Pass \\
\hline $\mathrm{U}-105$ & 8 & 1,058 & 684 & 0.65 & Pass \\
\hline U-107 & 7 & 1,599 & 788 & 0.49 & Pass \\
\hline U-108 & 4 & 1,259 & 878 & 0.70 & Pass \\
\hline U-109 & 3 & 1,600 & 528 & 0.33 & Pass \\
\hline
\end{tabular}


Figure 4-1. Peak Headspace Hydrogen Concentrations in Tank 241-U-105-Comparison Results.

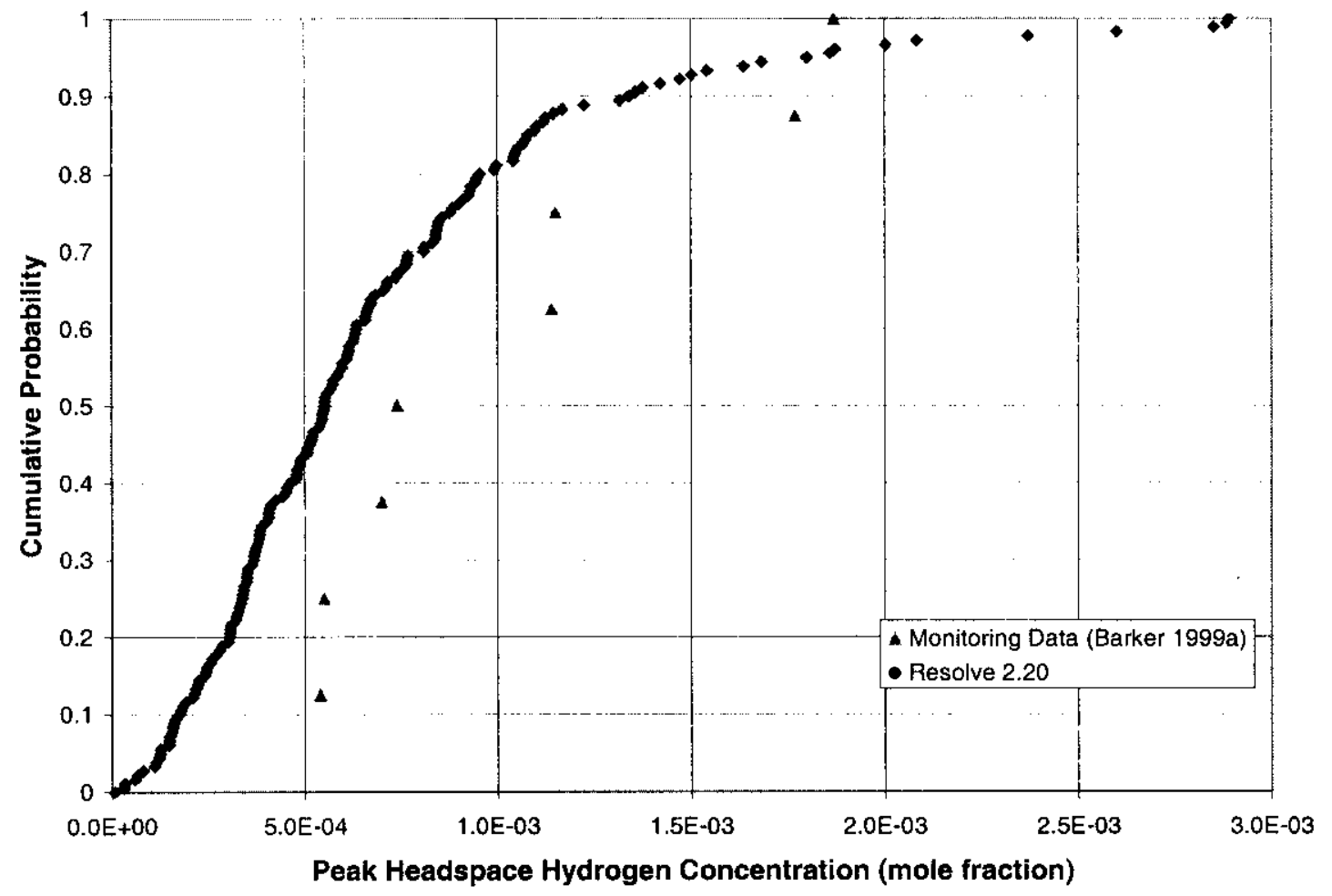

Figure 4-2. Non-Buoyant Displacement GRE Minimum Release Duration-Comparison Results.

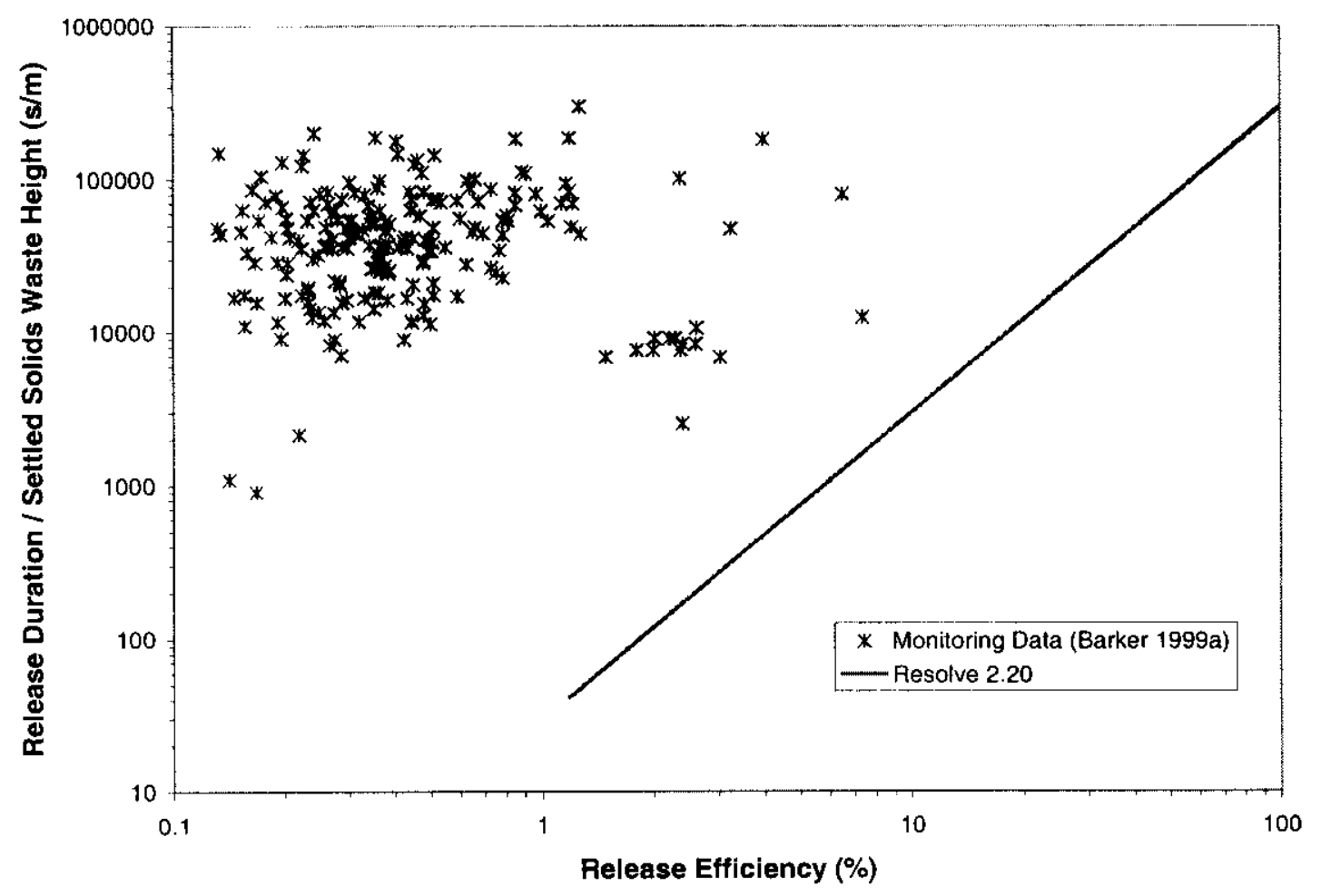




\subsection{VALIDATION: NON-BUOYANT DISPLACEMENT GAS RELEASE EVENT MODEL-RELEASE FREQUENCY}

Abstract: A validation test was performed to compare the calculated frequencies of small GREs in SSTs to the Hanford Site tank waste behavior for frequency of observed GREs. The relational database currently implemented by Resolve Version 2.5 contains the observed GRE frequency data. As described in the database, there are-based on the characteristics of the waste (solids, slurry, liquid, or a combination of two or more)-seven waste classifications. Of the seven, four waste classifications represent all SSTs. Therefore, the evaluation compared the calculated GRE frequency (calculated using Resolve Version 2.5) to the data contained in the relational database. This evaluation was conducted to ensure that the calculation models and mass balance checks within Resolve Version 2.5 generate results (that is, GRE frequencies) that reflect observed behavior.

Requirements: Hanford Gas Release Event Safety Analysis Tool Version 2.5 Software Verification and Validation Plan (Hodges 1999).

References and Inputs: Resolve Version 2.20 (Humphreys and Young 1999).

General Test Procedure: The four waste classifications that represent all SST waste are as follows: Class (1) saltcake/settled solids and no liquid; Class (2) saltcake/settled solids and liquid; Class (3) slurry and no liquid; and Class (5) mix of saltcake, solids, and slurry with no liquid. The observed GRE behavior or GRE frequency for each of the waste classes is summarized in Table 4-16.

The Analysis Tool Resolve Version 2.5 was run for each of the 100 Series single-shell tanks. The analyses had the frequencies of all waste disturbing operations set to 0 events per year. In addition, the Salt Well Pumping Status parameter was set to "Never Pumped" for those tanks that were being salt well pumped. The Analysis Framework gives priority to induced releases when determining if a sample vector would violate mass balance, so operation frequencies were set to 0 to avoid suppression of spontaneous GREs.

Output was collected for the X mean for all small, spontaneous events (\%LFL data set). This analysis reports the frequency of all GREs (including GREs that did not deflagrate or detonate as well as those that did). For each waste class, the average as well as the minimum and maximum values have been calculated for the comparative evaluation.

Acceptance Criteria: Resolve results must be no more than 1 order of magnitude nonconservative, and no more than 2 orders of magnitude conservative to be acceptable.

Results: Table 4-16 summarizes and compares the calculated GRE frequencies to the observed GRE frequency ranges contained in the relational database. The Resolve calculated values are within roughly a factor of 3 of the observed GRE frequencies, which is within the acceptable range for this test. 
RPP-6873 REV 0

Table 4-16. Non-Buoyant Displacement GRE Frequencies in 100 Series Tanks-Comparison Results.

\begin{tabular}{|c|c|c|c|c|c|c|c|}
\hline \multirow{2}{*}{$\begin{array}{c}\text { Waste } \\
\text { Class }\end{array}$} & \multicolumn{3}{|c|}{$\begin{array}{c}\text { GRE Frequency Values Contained in } \\
\text { Relational Database }\end{array}$} & \multicolumn{3}{c|}{$\begin{array}{c}\text { Calculated Values Using } \\
\text { Resolve Version 2.5 }\end{array}$} \\
\cline { 2 - 8 } & mean & $\begin{array}{c}\text { std. } \\
\text { deviation }\end{array}$ & $\begin{array}{c}\text { min. } \\
\text { value }\end{array}$ & $\begin{array}{c}\text { max. } \\
\text { value }\end{array}$ & average & $\begin{array}{c}\text { min. } \\
\text { value }\end{array}$ & $\begin{array}{c}\text { max. } \\
\text { value }\end{array}$ \\
\hline 1 & 0.95844 & 0.79576 & 0.0001 & 3.3951 & 0.318 & 0.16 & 0.653 \\
\hline 2 & 0.95844 & 0.79576 & 0.0001 & 3.3951 & $0.345^{*}$ & 0.345 & 0.345 \\
\hline 3 & 0.82152 & 0.80998 & 0.0001 & 3.22948 & 0.8434 & 0.174 & 1.05 \\
\hline 5 & 0.82152 & 0.80998 & 0.0001 & 3.22948 & 0.264 & 0.208 & 0.372 \\
\hline
\end{tabular}

* There was only one SST in this waste classification.

\subsection{VALIDATION: STRATIFIED LAYER TIME-AT-RISK}

Abstract: A buoyant flammable gas release could potentially form a stable stratified layer at a tank's dome. The flammable gas would then be "confined" to a smaller volume, and smaller releases (smaller than those needed to yield a globally flammable headspace) could potentially create flammable mixtures. Some degree of technical uncertainty surrounds plume behavior in tanks and there are limitations to the complexity of a model that could be effectively implemented within the modified Monte Carlo approach of the AF/AT. It is important to know if the AF's stratified layer model is reasonable, given the best-estimate approach that was adopted. The stratified layer time-at-risk validation testing was designed to gauge the AF model against other computer codes (Antoniak and Recknagle 1997, Zerkel et al. 1997) that calculate values for similar gas release behavior and headspace mixing.

Requirements: Refined Safety Analysis Methodology for Flammable Gas Risk Assessment in the Hanford Site Tanks, Part 1: Analysis Framework for Single-Shell Tanks (Slezak and Williams 1998).

Refined Safety Analysis Methodology for Flammable Gas Risk Assessment in the Hanford Site Tanks: Implementation Details for the Analysis Framework (Slezak et al. 4/30/1999).

Hanford Gas Release Event Safety Analysis Tool Version 2.5 Software Verification and Validation Plan (Hodges 1999).

References and Inputs: Resolve Version 2.20 (Humphreys and Young 1998).

Refined Safety Analysis Methodology for Flammable Gas Risk Assessment in Hanford Site Tanks: Implementation Details for the Analysis Framework (Slezak et al. 4/30/99).

Validation Calculations for the Enhanced Safety Analysis Methodology for Flammable Gas Risk Assessment in Hanford Site Tanks Analysis Framework (Gelbard and Cheng 1998). 
RPP-6873 REV 0

Initial Parametric Study of the Flammability of Plume Releases in Hanford Waste Tanks (Antoniak and Recknagle 1997).

Final Report: Plume Dispersion in Hanford Waste Tanks (Zerkel et al. 1997).

"FilterResolveResults.sh," Version 1.2 (McCornak 1999).

A spreadsheet, "Plume Time-at-Risk Validation.xls" (Riddle 1999e), was used to collect input and output data as well as to perform unit conversions.

General Test Procedure: Data from Zerkel et al. (1997) and Antoniak and Recknagle (1997) as summarized in the Validation Calculations (Gelbard and Cheng 1998) were used to compare to Resolve-calculated stratified layer times-at-risk. The Validation Calculations compared AF model output against 11 runs though the other computer codes, 5 test cases using PNNL's TEMPEST code (Antoniak and Recknagle 1997) and 6 test cases using LANL's FLUENT/UNS code (Zerkel et al. 1997). The case descriptions for the 11 cases are shown in Table 4-17.

Since the publication of the Validation Calculations, the AF's plume model has undergone significant revisions. These revisions incorporated the latest experimental laboratory observations into the plume model. Experimental data indicate that there are minimum release volumes and durations below which plumes will not form. These observations were incorporated into the AF plume model as a minimum release rate of $0.05 \mathrm{~m}^{3} / \mathrm{s}\left(\sim 106 \mathrm{ft}^{3} / \mathrm{min}\right)$. Cases $1,2,5$, and 6 all have release rates slower than $0.05 \mathrm{~m}^{3} / \mathrm{s}$. In addition, given the headspace volumes, release durations, and ventilation rates in the case descriptions, none of these cases are flammable on a well-mixed basis. This means that, for these cases, the AF model would not calculate any time-at-risk. Therefore, cases $1,2,5$, and 6 can not be used as meaningful validation cases for the AF plume model.

In addition, test case 7 does not represent a valid test case since flammable "unvented" conditions do not represent operational conditions in the waste tanks. Even if ventilation systems fail, the tanks passively ventilate. Cases 3, 4, and 8-11 were used to validate the AF's plume model using Resolve Version 2.20.

The following assumptions were made in order to allow for comparison between the various models:

- There are several physical parameters that the AF uses to calculate plume time-at-risk that are not specified in the test case descriptions (Table 4-17). For those parameters it was assumed that Tank 241-A-101 default values would be adequate. 
- The test case descriptions for the PNNL test runs describe the "GRE hydrogen concentration" as $40 \%$ hydrogen in air. It is unclear whether this mixture composition applies to the source gas or the stratified layer mixture. It was assumed that a source gas composition of $40 \%$ hydrogen and $60 \%$ nitrous oxide would provide an adequate comparison (it is not possible to model air as a source gas component in the AF/AT model).

- For some of the cases, the total hydrogen gas generation rate was increased. This was done to ensure that single sample test cases pass the mass balance test. A check was made to ensure that increasing the gas generation rate did not impact the calculated timeat-risk.

Seven test cases were designed using the assumptions referred to above and the test case descriptions in Table 4-17. Input .afi files were created for each of the test cases, and the test cases were run using Resolve 2.20. Values used to create the seven .afi's can be found in "Plume Time-at-Risk Validation.xls" (Riddle 1999e). All cases were Tank 241-A-101 Sensitivity Analyses with seed numbers of 123456789 and 1 sample.

Time-at-risk, mixture type, and flammability information were removed from debug output text files-by hand or by using the "FilterResolveResults.sh" (McCornak 1999)-and compared with values from the alternate models.

Table 4-17. Stratified Layer Time-at-Risk Validation-Test Case Setup.

\begin{tabular}{|c|c|c|c|c|c|c|c|c|}
\hline Case ID & $\begin{array}{c}\text { Alternate } \\
\text { Model }\end{array}$ & $\begin{array}{c}\text { GRE } \\
\text { Amount } \\
\left(\mathrm{ft}^{3}\right)\end{array}$ & $\begin{array}{c}\text { GRE H } \text { H}_{2} \\
\text { Conc. }(\%)\end{array}$ & $\begin{array}{c}\text { GRE } \\
\text { Duration } \\
\text { (min) }\end{array}$ & $\begin{array}{c}\text { Headspace } \\
\text { Volume } \\
\left(\mathrm{ft}^{\mathbf{3}}\right)\end{array}$ & $\begin{array}{l}\text { Vent } \\
\text { Rate } \\
\text { (cfm) }\end{array}$ & $\begin{array}{c}\text { Tank } \\
\text { Diameter } \\
\text { (ft) }\end{array}$ & $\begin{array}{c}\text { Height of } \\
\text { Dome above } \\
\text { Waste (ft) }\end{array}$ \\
\hline 1/PNNL & TEMPEST & 100 & 40 (in air) & 10 & 80000 & passive & 75 & 18.1 \\
\hline $2 / \mathrm{PNNL}$ & TEMPEST & 400 & 40 (in air) & 10 & 80000 & passive & 75 & 18.1 \\
\hline 3/PNNL & TEMPEST & 1600 & 40 (in air) & 10 & 80000 & passive & 75 & 18.1 \\
\hline 4/PNNL & TEMPEST & 6400 & 40 (in air) & 10 & 80000 & passive & 75 & 18.1 \\
\hline $5 / \mathrm{PNNL}$ & TEMPEST & 6400 & 40 (in air) & 100 & 80000 & passive & 75 & 18.1 \\
\hline 6/LANL & $\begin{array}{c}\text { FLUENT/ } \\
\text { UNS }\end{array}$ & 1000 & $50\left(\right.$ in $\left.\mathrm{N}_{2} \mathrm{O}\right)$ & 10 & 52000 & unvented & 75 & 11.8 \\
\hline 7/LANL & $\begin{array}{c}\text { FLUENT/ } \\
\text { UNS }\end{array}$ & 1000 & $50\left(\right.$ in $\left.\mathrm{N}_{2} \mathrm{O}\right)$ & 2 & 52000 & unvented & 75 & 11.8 \\
\hline 8/LANL & $\begin{array}{c}\text { FLUENT/ } \\
\text { UNS }\end{array}$ & 1000 & $50\left(\right.$ in $\left.\mathrm{N}_{2} \mathrm{O}\right)$ & 2 & 52000 & 200 & 75 & 11.8 \\
\hline 9/LANL & $\begin{array}{c}\text { FLUENT/ } \\
\text { UNS }\end{array}$ & 1000 & $50\left(\overline{\text { in }} \mathrm{N}_{2} \mathrm{O}\right)$ & 1 & 52000 & 200 & 75 & 11.8 \\
\hline $10 / \mathrm{LANL}$ & $\begin{array}{c}\text { FLUENT/ } \\
\text { UNS } \\
\end{array}$ & 2250 & $50\left(\right.$ in $\left.\mathrm{N}_{2} \mathrm{O}\right)$ & 2 & 52000 & 200 & 75 & 11.8 \\
\hline $11 / \mathrm{LANL}$ & $\begin{array}{c}\text { FLUENT/ } \\
\text { UNS }\end{array}$ & 5000 & $50\left(\right.$ in $\left._{2} \mathrm{O}\right)$ & 10 & 52000 & 500 & 75 & 11.8 \\
\hline
\end{tabular}


Acceptance Criteria: Resolve results must be no more than 1 order of magnitude nonconservative, and no more than 2 orders of magnitude conservative to be acceptable.

Results: Table 4-18 provides a summary of the results for the stratified layer time-at-risk validation test. The times-at-risk calculated using the simple parametric plume dilution and stratified layer dissipation models in the AF/AT compare well with those calculated by more complicated, finite element models. For the test cases run, the AF/AT results were, on average, conservative by a factor of 15 compared to the results from the FLUENT/UNS (Zerkel et al. 1997) and TEMPEST (Antoniak and Recknagle 1997) codes. The maximum deviation was by a factor of 28 . These results are within the acceptability range.

Table 4-18. Stratified Layer Time-at-Risk Validation-Comparison Results.

\begin{tabular}{|c|c|c|c|c|c|c|}
\hline Case ID: & $\begin{array}{c}\text { Alternate } \\
\text { model used for } \\
\text { comparison }\end{array}$ & $\begin{array}{c}\text { Alternate } \\
\text { model } \\
\text { Time-at-Risk } \\
\text { (sec) }\end{array}$ & $\begin{array}{c}\text { Resolve } \\
\text { Time-at-Risk } \\
\text { (sec) }\end{array}$ & $\begin{array}{c}\text { Ratio } \\
\text { (Resolve/ } \\
\text { Alternate } \\
\text { model) }\end{array}$ & $\begin{array}{c}\text { Pass/ } \\
\text { Fail }\end{array}$ & $\begin{array}{c}\text { Resolve } \\
\text { modeled this } \\
\text { case as }\end{array}$ \\
\hline Plume.Trsk.3 & TEMPEST $^{1}$ & 600 & 4560 & 7.6 & Pass & $\begin{array}{c}\text { Flammable } \\
\text { stratified layer }\end{array}$ \\
\hline Plume.Trsk.4 & TEMPEST $^{1}$ & 7980 & 8863 & 1.1 & Pass & $\begin{array}{c}\text { Flammable } \\
\text { well-mixed }\end{array}$ \\
\hline Plume.Trsk.8 & FLUENT/UNS & 127.2 & 2069 & 16.3 & Pass & $\begin{array}{c}\text { Flammable } \\
\text { stratified layer }\end{array}$ \\
\hline Plume.Trsk.9 & FLUENT/UNS & 75 & 2069 & 27.6 & Pass & $\begin{array}{c}\text { Flammable } \\
\text { stratified layer }\end{array}$ \\
\hline Plume.Trsk.10 & FLUENT/UNS & 136.2 & 2997 & 22 & Pass & $\begin{array}{c}\text { Flammable } \\
\text { stratified layer }\end{array}$ \\
\hline Plume.Trsk.11 & FLUENT/UNS & 433.2 & 2852 & 6.6 & Pass & $\begin{array}{c}\text { Flammable } \\
\text { well-mixed }\end{array}$ \\
\hline
\end{tabular}

'Antoniak and Recknagle (1997).

${ }^{2}$ Zerkel et al. (1997). 


\section{RPP-6873 REV 0}

\subsection{VALIDATION: SALT WELL PUMPING MODEL}

Abstract: Salt well pumping is an operation used to interim-stabilize single-shell tanks. Flammable gas release during salt well pumping is a safety concern; it is therefore important that the lumped-parameter salt well pumping gas release model in the AF/AT calculate valid results as part of the overall analysis package for flammable gas risk.

Monitoring data for hydrogen releases during salt well pumping are available (Caley et al. 1996), as are altemate calculation results for total flammable gas release rate (LANL 1996c, 1997a, b, c, and $d$ ). The AF/AT model was validated by comparing it to these data.

Requirements: Refined Safety Analysis Methodology for Flammable Gas Risk Assessment in the Hanford Site Tanks, Part 1: Analysis Framework for Single-Shell Tanks (Slezak and Williams 1998).

Refined Safety Analysis Methodology for Flammable Gas Risk Assessment in the Hanford Site Tanks: Implementation Details for the Analysis Framework (Slezak et al. 4/30/1999).

Hanford Gas Release Event Safety Analysis Tool Version 2.5 Software Verification and Validation Plan (Hodges 1999).

References and Inputs: Summary of Tank Information Relating Salt Well Pumping to Flammable Gas Issues (Caley et al.1996).

A Safety Assessment for Salt Well Pumping in Tank 241-A-101: Hanford Site, Richland, Washington (LANL 1996c).

Checklist Evaluation Report for Salt Well Pumping Single Transfer Operations in Tank 241-S-109, Hanford Site, Richland, Washington (LANL 1997a).

Checklist Evaluation Report for Salt Well Pumping Single Transfer Operations in Tank 241-SX-103, Hanford Site, Richland, Washington (LANL 1997b).

Checklist Evaluation Report for Salt Well Pumping Single Transfer Operations in Tank 24I-BY-105, Hanford Site, Richland, Washington (LANL 1997c).

Checklist Evaluation Report for Salt Well Pumping Single Transfer Operations in Tank 241-S-102, Hanford Site, Richland, Washington (LANL 1997d).

Validation Calculations for the Enhanced Safety Analysis Methodology for Flammable Gas Risk Assessment in Hanford Site Tanks-Analysis Framework (Gelbard and Cheng 1998).

"FilterResolveResults.sh," Version 1.2 (McCornak 1999).

Resolve Version 2.21 (Humphreys and Young 1998). 
RPP-6873 REV 0

A spreadsheet, "Salt Well Pumping Validation.xls" (Riddle 1999f), was used to collect input and output data as well as to perform unit conversions and calculations.

\section{General Test Procedure:}

\section{Salt Well Pumping Headspace Hydrogen Concentration}

Caley et al. (1996) reports hydrogen gas release rate and concentration monitoring data for six single-shell tanks taken during salt well pumping operations. Input files were created using 500 samples and a seed of 793239936. Salt well pumping rates were set to values estimated from Caley et al. (1996) as reported in Validation Calculations (Gelbard and Cheng 1998); in addition, the salt well pumping action level control was disabled by setting the Maximum Fraction of LFL parameter to 100 (unitless). Database defaults were used for tank and waste configurations. Refer to Table 4-19 for test case setup. After running the test cases, the release\%X\%hydrogen parameter was removed from debug output using the "FilterResolveResults.sh" (McCornak 1999) tool.

\section{Salt Well Pumping Flammable Gas Release Rate}

LANL (1996c, 1997a, b, c, and d) also reports the results of salt well pumping model calculations using the DRAIN code. These results include a total flammable gas release rate. Resolve does not calculate a flammable gas release rate in a way that is comparable to the results from the DRAIN model. In order to compare Resolve-calculated values to the output from the DRAIN code, the results from the DRAIN code were converted from flammable gas release rates to flammable gas concentrations using the steady-state, mass balance Equation 66 in the Implementation Details (Slezak et al. 4/30/1999). The flammable gas concentrations calculated from the DRAIN results were then compared with the flammable gas concentrations calculated by Resolve.

Input files were created with a seed of 88007040,100 samples, and the data values shown in Table 4-20. For all input tanks, that input file was created with the Pumping Status as "Currently Pumping," with the Salt Well Pumping Tank Control Strategy as "Past Practices," and with the Maximum LFL Fraction set to 100 (unitless). After running the test cases, release\%X\%ammonia and release\%X\%hydrogen were removed from debug output using the "FilterResolveResults.sh" (McCornak 1999) tool.

Acceptance Criteria: For validation testing comparing a point value to a point value, the Resolve-calculated point value must be within the range of no more than 2 orders of magnitude conservative and 1 order of magnitude non-conservative to be acceptable. 
Table 4-19. Salt Well Pumping Hydrogen Concentration-Test Case Setup.

\begin{tabular}{|c|c|c|c|c|}
\hline Case ID & Tank ID & $\begin{array}{c}\text { Salt Well Pumping } \\
\text { Status }\end{array}$ & $\begin{array}{c}\text { Salt Well } \\
\text { Pump Rate (cfm) }\end{array}$ & $\begin{array}{c}\text { Salt Well Pumping } \\
\text { Tank Control Strategy }\end{array}$ \\
\hline SwpH2Rel.1 & S-108 & Currently Pumping & 0.025 & Past Practices \\
\hline SwpH2Rel.2 & T-104 & Currently Pumping & 0.053 & Past Practices \\
\hline SwpH2Rel.3 & BY-103 & Currently Pumping & 0.016 & Past Practices \\
\hline SwpH2Rel.4 & BY-106 & Currently Pumping & 0.056 & Past Practices \\
\hline SwpH2Rel.5 & BY-109 & Currently Pumping & 0.014 & Past Practices \\
\hline SwpH2Rel.6 & S-110 & Currently Pumping & 0.032 & Past Practices \\
\hline
\end{tabular}

Table 4-20. Salt Well Pumping Flammable Gas Release Rate-Test Case Setup.

\begin{tabular}{|c|c|c|c|c|}
\hline Run ID & Tank ID & $\begin{array}{l}\text { Salt Well Pump } \\
\text { Rate (cfm) }\end{array}$ & $\begin{array}{c}\text { Ventilation Rate } \\
\text { (cfm) }\end{array}$ & $\begin{array}{c}\text { Headspace Pressure } \\
\text { (inwg) }\end{array}$ \\
\hline SwpFlamRel.1 & A-101 & 0.668 & not changed & not changed \\
\hline SwpFlamRel.2 & A-101 & 0.134 & not changed & not changed \\
\hline SwpFlamRel.1 & A-101 & 0.668 & not changed & not changed \\
\hline SwpFlamRel.1 & A-101 & 0.668 & not changed & not changed \\
\hline SwpFlamRel.2 & A-101 & 0.134 & not changed & not changed \\
\hline SwpFlamRel.1 & A-101 & 0.668 & not changed & not changed \\
\hline SwpFlamRel.3 & S-109 & 0.668 & not changed & not changed \\
\hline SwpFlamRel.4 & S-109 & 0.134 & not changed & not changed \\
\hline SwpFlamRel.5 & S-109 & 0.067 & not changed & not changed \\
\hline SwpFlamRel.6 & S-109 & 0.027 & not changed & not changed \\
\hline SwpFlamRel.7 & SX-103 & 0.668 & 50 & -1 \\
\hline SwpFlamRel.8 & $\mathrm{SX}-103$ & 0.134 & 50 & -1 \\
\hline SwpFlamRel.9 & SX-103 & 0.067 & 50 & -1 \\
\hline SwpFlamRel.10 & SX-103 & 0.027 & 50 & -1 \\
\hline SwpFlamRel.11 & $\mathrm{BY}-105$ & 0.668 & not changed & not changed \\
\hline SwpFlamRel.12 & $\mathrm{BY}-105$ & 0.134 & not changed & not changed \\
\hline SwpFlamRel.13 & $\mathrm{BY}-105$ & 0.067 & not changed & not changed \\
\hline SwpFlamRel.14 & BY -105 & 0.027 & not changed & not changed \\
\hline SwpFlamRel.15 & S-102 & 0.668 & not changed & not changed \\
\hline SwpFlamRel.16 & S-102 & 0.134 & not changed & not changed \\
\hline SwpFlamRel.17 & S-102 & 0.067 & not changed & not changed \\
\hline SwpFlamRel.18 & S-102 & 0.027 & not changed & not changed \\
\hline
\end{tabular}




\section{Results:}

\section{Headspace Hydrogen Concentration}

Table 4-21 summarizes the results of validation testing on headspace hydrogen concentration during salt well pumping. The average of Resolve-calculated hydrogen concentrations in the headspace during salt well pumping is on average $50 \%$ less than an average estimated from monitoring data (Caley et al. 1996), with a maximum deviation of no more than a factor of 4 . This result is within the acceptability range.

Hydrogen released during salt well pumping is used as a background contribution to the peak sum after a GRE release. While Resolve is non-conservative in its prediction of hydrogen levels during salt well pumping, all of the releases in question are lower than the flammability limit.

\section{Flammable Gas Release Rate}

Table 4-22 summarizes the results of validation testing on flammable gas release rate during salt well pumping. All test cases run in Resolve show saturation or near saturation of the headspace with ammonia. These results causes the flammable gas concentration calculated by Resolve to far exceed the results of LANL's DRAIN code to which Resolve was compared. Resolve results were conservative by an average factor of 16 with one case showing Resolve results to be larger by a factor of 104 . For the two worst cases computed by LANL, Resolve was non-conservative, but was within a factor of 2 . Eleven of the test cases run were outside the acceptability range. This issue was documented in a Discrepancy Report. A spot check indicated that increasing the ventilation rate did not significantly impact the character of the results.

These results are not consistent, to the tester's knowledge, with any monitoring data, anecdotal evidence, or the DRAIN code output. A check was conducted to ensure that this behavior was not the result of an error in the software implementation of the model. Resolve results were conservative because they reflect the conservatism introduced when uncertainty is large. The expert panel was asked to err toward conservatism with most tanks and provide a best estimate for "worst case" tanks. This conservatism ensures that decisions made on the basis of these model results will tend to err on the side of greater safety, and not on the side of higher safety risk. 
Table 4-21. Salt Well Pumping Hydrogen Gas Concentration-Comparison Results.

\begin{tabular}{|c|c|c|c|c|}
\hline Tank ID & $\begin{array}{c}\text { Resolve } \\
\text { Salt Well Pumping } \\
\text { Headspace Hydrogen } \\
\text { Concentration (mole } \\
\text { fraction) }\end{array}$ & $\begin{array}{c}\text { Caley et al. (1996) } \\
\text { Salt Well Pumping } \\
\text { Headspace Hydrogen } \\
\text { Concentration (mole } \\
\text { fraction) }\end{array}$ & $\begin{array}{c}\text { Ratio } \\
\text { (Resolve/ } \\
\text { Caley) }\end{array}$ & $\begin{array}{c}\text { Pass/ } \\
\text { Fail }\end{array}$ \\
\hline S-108 & $6.44 \mathrm{E}-04$ & $6.80 \mathrm{E}-04$ & 0.95 & Pass \\
\hline T-104 & $1.68 \mathrm{E}-04$ & $6.00 \mathrm{E}-04$ & 0.28 & Pass \\
\hline BY-103 & $4.19 \mathrm{E}-04$ & $1.20 \mathrm{E}-03$ & 0.35 & Pass \\
\hline BY-106 & $1.53 \mathrm{E}-03$ & $3.60 \mathrm{E}-03$ & 0.42 & Pass \\
\hline BY-109 & $4.73 \mathrm{E}-04$ & $1.20 \mathrm{E}-03$ & 0.39 & Pass \\
\hline S-110 & $4.74 \mathrm{E}-04$ & $7.20 \mathrm{E}-04$ & 0.66 & Pass \\
\hline
\end{tabular}

Table 4-22. Salt Well Pumping Flammable Gas Release Rate-Comparison Results.

\begin{tabular}{|c|c|c|c|c|c|}
\hline Run ID & Tank ID & $\begin{array}{c}\text { Resolve Mole } \\
\text { Fraction of } \\
\text { Flammable Gases }\end{array}$ & $\begin{array}{c}\text { LANL (1996c, } \\
\text { 1997a, b, c, and d) } \\
\text { Mole Fraction of } \\
\text { Flammable Gases }\end{array}$ & $\begin{array}{c}\text { Ratio } \\
\text { (Resolve/ } \\
\text { LANL) }\end{array}$ & Pass/ Fail \\
\hline SwpFlamRel.1 & A-101 & 0.17 & 0.01 & 16.53 & Fail \\
\hline SwpFlamRel.2 & A-101 & 0.16 & 0.00 & 103.98 & Fail \\
\hline SwpFlamRel.1 & A-101 & 0.17 & 0.01 & 16.53 & Fail \\
\hline SwpFlamRel.1 & A-101 & 0.17 & 0.01 & 16.53 & Fail \\
\hline SwpFlamRel.2 & A-101 & 0.16 & 0.01 & 10.40 & Fail \\
\hline SwpFlamRel.1 & A-101 & 0.17 & 0.01 & 16.53 & Fail \\
\hline SwpFlamRel.3 & S-109 & 0.16 & 0.17 & 0.90 & Pass \\
\hline SwpFlamRel.4 & S-109 & 0.15 & 0.05 & 3.27 & Pass \\
\hline SwpFlamRel.5 & S-109 & 0.15 & 0.03 & 5.12 & Pass \\
\hline SwpFlamRel.6 & S-109 & 0.15 & 0.02 & 7.44 & Pass \\
\hline SwpFlamRel.7 & SX-103 & 0.14 & 0.02 & 6.47 & Pass \\
\hline SwpFlamRel.8 & SX-103 & 0.14 & 0.01 & 23.34 & Fail \\
\hline SwpFlamRel.9 & SX-103 & 0.14 & 0.00 & 34.94 & Fail \\
\hline SwpFlamRel.10 & SX-103 & 0.15 & 0.00 & 51.04 & Fail \\
\hline SwpFlamRel.11 & BY-105 & 0.15 & 0.08 & 1.79 & Pass \\
\hline SwpFlamRel.12 & BY-105 & 0.15 & 0.02 & 5.98 & Pass \\
\hline SwpFlamRel.13 & BY-105 & 0.15 & 0.01 & 10.51 & Fail \\
\hline SwpFlamRel.14 & BY-105 & 0.15 & 0.01 & 11.34 & Fail \\
\hline SwpFlamRel.15 & S-102 & 0.17 & 0.27 & 0.61 & Pass \\
\hline SwpFlamRel.16 & S-102 & 0.16 & 0.08 & 1.86 & Pass \\
\hline SwpFlamRel.17 & S-102 & 0.15 & 0.06 & 2.63 & Pass \\
\hline SwpFlamRel.18 & S-102 & 0.15 & 3.46 & Pass \\
\hline
\end{tabular}




\subsection{VALIDATION: AMMONIA RELEASES DURING BUOYANT DISPLACEMENT GAS RELEASE EVENTS}

Abstract: The validation of the ammonia release model for BD GREs was an integral part of the development of the ammonia release model. The details of the model as well as a comparison of the model predictions with the available monitoring data during BD GREs for Tanks 241-SY-101, 241-SY-103, and 241-AN-105 are found in the Analysis Framework document (Slezak et al. 2000). In general, the ammonia release model gave results for headspace ammonia concentration as a function of time into a GRE that were in fair agreement with the monitoring data. The expert panel decided that the model was adequate for determining the ammonia contribution to headspace flammability but advised against the use of the model for determination of toxicological consequences due to ammonia.

Requirements: Refined Safety Analysis Methodology for Flammable Gas Risk Assessment in the Hanford Site Tanks (Slezak et al. 2000).

References and Inputs: Refined Safety Analysis Methodology for Flammable Gas Risk Assessment in the Hanford Site Tanks (Slezak et al. 2000).

E-mails to Wu-Ching Cheng with ammonia monitoring data (Wilkins 1997a, 1997b, 1997c).

Acceptance Criteria: If the ammonia concentration determined from monitoring data was less than $1 / 10$ of the lower flammability limit, as was the case for all the data used in this test, peak ammonia concentrations predicted by the model within an order of magnitude of the monitoring value were acceptable.

Results: The peak concentrations for the tanks modeled as compared with monitoring data (Wilkins 1997a, 1997b, 1997c) are shown in Table 4-23. The results indicate the model is in fair agreement with monitoring data, and well within the acceptability range. Considering that the lower flammability limit of ammonia is $150,000 \mathrm{ppm}$, the model is adequate for predicting flammability risk due to ammonia releases during buoyant displacement releases.

Table 4-23. Peak Ammonia Concentrations During Buoyant Displacement ReleasesComparison Results.

\begin{tabular}{|l|l|l|l|}
\hline \multicolumn{1}{|c|}{ Tank } & \multicolumn{1}{c|}{ GRE Time } & \multicolumn{1}{c|}{ Pilkins (1997a, 1997b, 1997c) } & \multicolumn{1}{c|}{ Model Prediction } \\
\hline SY-101 & June 1993 & 13,000 & 18,000 \\
\hline AN-105 & May 1996 & 600 & 390 \\
\hline AN-105 & April 1997 & 115 & 135 \\
\hline AN-105 & December 1997 & 110 & 135 \\
\hline SY-103 & November 1997 & 1,100 & 2,600 \\
\hline
\end{tabular}




\subsection{VALIDATION: AMMONIA RELEASES DURING STEADY-STATE OPERATION}

Abstract: Steady-state headspace ammonia concentrations were determined using the ammonia model in Resolve applied to Tanks 241-AW-101 and 241-SY-101 and compared with available corresponding headspace monitoring data (Wilkins et al. 1997). Model results are in good agreement with monitoring results.

Requirements: Refined Safety Analysis Methodology for Flammable Gas Risk Assessment in the Hanford Site Tanks, Part 2: Analysis Framework for Double-Shell Tanks (Slezak et al. 1998).

References and Inputs: Refined Safety Analysis Methodology for Flammable Gas Risk Assessment in the Hanford Site Tanks, Part 2: Analysis Framework for Double-Shell Tanks (Slezak et al. 1998).

Results of Vapor Space Monitoring of Flammable Gas Watch List Tanks (Wilkins et al. 1997).

Acceptance Criteria: If the ammonia concentration determined from monitoring data was less than $1 / 10$ of the lower flammability limit, as was the case for all the data used in this test, peak ammonia concentrations predicted by the model within an order of magnitude of the monitoring value were acceptable.

Results: Table 4-25 shows the comparison between model calculations and monitoring data (Wilkins et al. 1997) during steady-state operation. Good agreement is indicated, especially considering that the lower flammability limit for ammonia is $150,000 \mathrm{ppm}$. Table $4-24$ shows the input and calculated model parameters for the two tanks.

Table 4-24. Steady-State Headspace Ammonia Concentration in Tanks 241-AW-101 and 241-SY-101-Inputs and Intermediate Calculation Values.

\begin{tabular}{|c|c|c|c|}
\hline Parameter & Description of Parameter & AW-101 & SY-101 \\
\hline Input & Diffusivity of ammonia in water & $2.8 \mathrm{E}-9$ & $3.0 \mathrm{E}-9$ \\
\hline $\mathrm{D}_{\mathrm{l}}, \mathrm{m}^{2} / \mathrm{s}$ & Crust thickness & 0.05 & 1.27 \\
\hline$\delta, \mathrm{m}$ & Tortuosity & 3 & 3 \\
\hline$\phi$, unitless & Temperature & 100 & 77.9 \\
\hline $\mathrm{HRT}$ & Ventilation rate & 0.047 & 0.236 \\
\hline $\mathrm{Q}, \mathrm{m}^{3} / \mathrm{s}$ & Molar volume & 0.0253 & 0.0253 \\
\hline$\nu, \mathrm{m}^{3} / \mathrm{mole}$ & & & \\
\hline Calculated Values & Liquid phase mass transfer coeff. & $1.87 \mathrm{E}-8$ & $2.36 \mathrm{E}-9$ \\
\hline $\mathrm{h}_{\mathrm{l}}, \mathrm{m} / \mathrm{s}$ & Gas phase mass transfer coeff. & 0.029 & $1.7 \mathrm{E}-3$ \\
\hline $\mathrm{h}_{\mathrm{g}}, \mathrm{m} / \mathrm{s}$ & Overall mass transfer coefficient & $1.87 \mathrm{E}-8$ & $2.36 \mathrm{E}-9$ \\
\hline $\mathrm{h}, \mathrm{m} / \mathrm{s}$ & Headspace ammonia concen. & $7.18 \mathrm{E}-4$ & $1.47 \mathrm{E}-3$ \\
\hline $\mathrm{C}, \mathrm{mole} / \mathrm{m}^{3}$ & Headspace ammonia concen. & 18 & 37 \\
\hline $\mathrm{C}, \mathrm{ppm}$ & & & \\
\hline
\end{tabular}


RPP-6873 REV 0

Table 4-25. Steady-State Headspace Ammonia Concentration in Tanks 241-AW-101 and 241-SY-101-Comparison Results.

\begin{tabular}{|c|c|c|}
\hline Tank & $\begin{array}{c}\text { Wilkins et al. (1997) } \\
\text { Monitoring Data, ppm }\end{array}$ & Model Prediction, ppm \\
\hline AW-101 & 7 & 18 \\
\hline SY-101 & 43 & 37 \\
\hline
\end{tabular}

\subsection{VALIDATION: AMMONIA RELEASES DURING MIXER PUMP OPERATION}

Abstract: Headspace ammonia concentrations during mixer pump operations in Tank 241-SY-101 are available for comparison with model predictions. Values of 25 to $58 \mathrm{ppm}$ ammonia are reported from January 1 to March 30, 1998 (Conner and Koreske 1998). Values of 100 to $200 \mathrm{ppm}$ are reported for April 12, 1993, during the first set of operations after installation of the mixer pump (Stewart et al. 1994). The ammonia model predicts a value of $46 \mathrm{ppm}$ ammonia in the headspace. The ammonia release rate has two contributions, one from diffusion out of the waste surface and one from the retained gas released from the waste voids when the waste is disturbed. The steady-state release rate was used for the surface release without the surface renewal term, because Tank 241-SY-101 had a significant crust that was not disrupted by the circulation of liquids by the mixer pump.

Requirements: Refined Safety Analysis Methodology for Flammable Gas Risk Assessment in the Hanford Site Tanks, Part 2: Analysis Framework for Double-Shell Tanks (Slezak et al. 1998).

References and Inputs: Quarterly Review of 241-SY-101 Mixer Pump Data: April-June 1998 (Conner and Koreske 1998).

Refined Safety Analysis Methodology for Flammable Gas Risk Assessment in the Hanford Site Tanks, Part 2: Analysis Framework for Double-Shell Tanks (Slezak et al. 1998).

Mitigation of Tank 241-Sy-101 by Pump Mixing: Results of Full-Scale Testing (Stewart et al. 1994).

Acceptance Criteria: If the ammonia concentration determined from monitoring data was less than 1/10 of the lower flammability limit, as was the case for all the data used in this test, peak ammonia concentrations predicted by the model within an order of magnitude of the monitoring value were acceptable.

Results: Values of 25 to 58 ppm ammonia are reported from January 1 to March 30,1998 (Conner and Koreske 1998). Values of 100 to $200 \mathrm{ppm}$ are reported for April 12, 1993, during the first set of operations after installation of the mixer pump (Stewart et al. 1994). The ammonia model predicts a value of $46 \mathrm{ppm}$ ammonia in the headspace which is in good agreement with the more recent monitoring data. Inputs and intermediate calculation results are shown in Table 4-26. 
Table 4-26. Ammonia Releases During Mixer Operation-Inputs and Intermediate Calculation Values.

\begin{tabular}{|l|l|}
\hline \multicolumn{1}{|c|}{ Parameter } & \multicolumn{1}{|c|}{ Value } \\
\hline Mean void fraction in settled solids before mixer pump operation & 0.059 \\
\hline Void fraction in settled solids after mixer pump operation & 0.040 \\
\hline Thickness of settled solids (non-convective) layer, $\mathrm{m}$ & 2.31 \\
\hline Retained gas pressure, atm & 2 \\
\hline Retained gas volume, standard cubic meters & 1894 \\
\hline Fraction of settled solids volume disturbed per mixer pump run & $1 / 6$ \\
\hline Volume of gas released per mixer pump run, $\mathrm{m}^{3}$ & 6 \\
\hline Mole fraction ammonia in retained gas & 0.12 \\
\hline Ammonia release rate from retained gas during mixer pump operation, mole/s & $9.5 \mathrm{E}-5$ \\
\hline Ammonia release rate from waste surface due to steady-state processes, mole/s & $3.48 \mathrm{E}-4$ \\
\hline Ventilation Rate, $\mathrm{m}^{3} / \mathrm{s}$ & 0.24 \\
\hline Headspace ammonia concentration, ppm & 46 \\
\hline
\end{tabular}

\subsection{VALIDATION: AMMONIA RELEASE DURING WASTE TRANSFERS}

Abstract: Data exist for ammonia releases during waste transfers. In particular, spreadsheet "sy102NH3Ju199thrujun00.xls" (Hedengren 2000a) reports measured headspace ammonia concentrations in Tank 241-SY-102 from July 1999 to June 2000 while it was receiving waste (and dilution water) pumped from Tanks 241-S-102, 241-S-106, 241-SX-106, 241-U-103, 241-U-105, and 241-U-102. In addition, diluted waste (1:1 dilution) from Tank 241-SY-101 was transferred subsurface into Tank 241-SY-102 during this time. The AF model accounts for ammonia concentrations during waste transfers in the receiver tank by summing steady-state, surface renewal, and waste void releases. This test was designed to compare the Resolvepredicted headspace ammonia concentrations in a receiver tank during waste transfer against measured values.

Requirements: Hanford Gas Release Event Safety Analysis Tool Version 2.5 Software Verification and Validation Plan (Hodges 1999).

Refined Safety Analysis Methodology for Flammable Gas Risk Assessment in the Hanford Site Tanks, Part 2: Analysis Framework for Double-Shell Tanks (Slezak et al. 1998).

References and Inputs: Spreadsheet "sy102NH3Ju199thrujun00.xls" (Hedengren 2000a) with measured headspace ammonia concentrations in Tank 241-SY-102.

Spreadsheet "sw pumping data.xls" (Hedengren 2000b) with duration and amounts of waste transferred into Tank 241-SY-102.

“FilterResolveResults.sh," Version 1.2 (McCornak 1999). 
Spreadsheet "Ammonia Release During Waste Transfers. xls" (Riddle 2000) was used to collect data and make comparisons.

General Test Description: To model the dissolved ammonia releases from surface renewal, a waste transfer operation was modeled with a transfer volume equal to the total amount of transferred waste (307,000 gal.) ("sw pumping data.xls" [Hedengren 2000b]) and the transfer rate equal to the total volume divided by the length of the operation (184 days).

To model the ammonia releases from waste voids caused by the waste disturbance of the transfer operation, a single globally waste-disturbing Insertion/Removal operation was modeled with a duration of 184 days.

A Tank 241-SY-102 Waste Transfer analysis was run in Resolve 2.5 using a seed of 123456789 and a sample size of 200 . The ammonia values for surface renewal plus continuous releases and the values for undissolved gas releases were removed from the debug output using the "FilterResolveResults.sh" (McCornak 1999) filter tool.

Acceptance Criteria: If the ammonia concentration determined from monitoring data was less than $1 / 10$ of the lower flammability limit, as was the case for all the data used in this test, peak ammonia concentrations predicted by the model within an order of magnitude of the monitoring value were acceptable.

Results: Table 4-27 summarizes the results from this test. Resolve-calculated headspace ammonia concentrations during waste transfers are conservative by a factor of about 2.7 . This is well within the acceptable range. It should be pointed out that these values are a small fraction of the lower flammability limit for ammonia $(150,000 \mathrm{ppm})$.

Table 4-27. Ammonia Headspace Concentrations in the Receiver Tank During Waste TransfersComparison Results.

\begin{tabular}{|c|c|c|c|c|c|}
\hline \multicolumn{2}{|c|}{ Resolve-Predicted Headspace Ammonia } & \multicolumn{3}{c|}{ Headspace Ammonia Monitoring Data } \\
\hline $\begin{array}{c}\text { Continuous } \\
\text { and Surface } \\
\text { Disruption } \\
\text { Sources (ppm) }\end{array}$ & $\begin{array}{c}\text { Waste } \\
\text { Disturbance } \\
\text { (ppm) }\end{array}$ & $\begin{array}{c}\text { Total } \\
\text { Concentration } \\
\text { (ppm) }\end{array}$ & $\begin{array}{c}\text { 5th Percentile } \\
\text { (ppm) }\end{array}$ & $\begin{array}{c}\text { Most Likely } \\
\text { [median] } \\
\text { (ppm) }\end{array}$ & $\begin{array}{c}\text { 95th } \\
\text { Percentile } \\
\text { (ppm) }\end{array}$ \\
\hline 38 & 1909 & 1947 & 61.3 & 385 & 734 \\
\hline
\end{tabular}




\subsection{VALIDATION: COMBUSTION MODEL OUTPUT COMPARISON TO EXPERIMENTAL DATA}

Abstract: The AF's combustion model is primarily concerned with the pressure consequences of a burn. The peak pressure of a burn is then used to determine the tank damage state, the fraction of suspended waste released, and the release volume. The AF's combustion model also determines combustion type (detonation or deflagration) for use in determining the mass of waste suspended. Burn type information is also outputted to the user as a metric for assessing flammable gas risk and control effectiveness. Clearly, the combustion model is crucial to the consequence results computed by the tool.

There are a number of areas of technical uncertainty surrounding the determination of peak pressure, flammability limits, and detonation cell size. These include uncertainty regarding the $\mathrm{N}_{2} \mathrm{O}-\mathrm{NH}_{3}$ and $\mathrm{N}_{2} \mathrm{O}-\mathrm{CH}_{4}$ reaction mechanisms, the degree of participation of $\mathrm{N}_{2} \mathrm{O}$ in a burn, and flammability limits in multiple oxidizer systems. In addition, the impact of nitrogen dilution, ammonia, and methane on detonation cell size are not well understood. The Refined Safety Analysis Methodology adopts a best-estimate approach for safety analysis to proceed despite an incomplete state of knowledge.

Experimental data of peak combustion pressures and flammability limits for fuel-oxidizer mixtures characteristic of those found in Hanford tank waste-retained gas are available (Phahl and Shepherd 1997). Experimental data are also available for detonation cell sizes in many different mixtures (Stamps et al. 1991, Tieszen et al. 1987, Akbar et al. 1997, Pfahl et al. 1998). Detonation cell size is a key predictor of Deflagration to Detonation Transitions (DDT).

The AF/AT combustion model was validated via comparison to these experimental data.

Requirements: Refined Safety Analysis Methodology for Flammable Gas Risk Assessment in the Hanford Site Tanks, Part 1: Analysis Framework for Single-Shell Tanks (Slezak and Williams 1998).

References and Inputs: Flammability, Ignition Energy and Flame Speeds in $\mathrm{NH}_{3}-\mathrm{H}_{2}-\mathrm{CH}_{4}-\mathrm{N}_{2} \mathrm{O}-\mathrm{O}_{2}-\mathrm{N}_{2}$ Mixtures (Pfahl and Shepherd 1997).

Hydrogen-Air-Diluent Detonation Study for Nuclear Reactor Safety Analyses (Stamps et al. 1991).

Detonability of H2-Air-Diluent Mixtures (Tieszen et al. 1987).

Detonations in $\mathrm{H}_{2}-\mathrm{N}_{2} \mathrm{O}-\mathrm{CH}_{4}-\mathrm{NH}_{3}-\mathrm{O}_{2}-\mathrm{N}_{2}$ Mixtures (Akbar et al. 1997).

Detonation Cell Width Measurements for $\mathrm{H}_{2}-\mathrm{N}_{2} \mathrm{O}-\mathrm{N}_{2}-\mathrm{O}_{2}-\mathrm{CH}_{4}-\mathrm{NH}_{3}$ Mixtures (Pfahl et al. 1998).

"FilterResolveResults.sh," Version 1.2 (McCornak 1999).

Resolve Version 2.20 (Humphreys and Young 1999). 
Spreadsheet "Combustion Model Validation.xls" (Riddle 1999g) was used to collect input and output data as well as to perform unit conversions and calculations.

General Test Procedure: Three validation exercises were performed. Peak pressures after burns, lean flammability limits, and detonation cell sizes as computed by Resolve were compared to experimental data. For clarity, the discussions of test procedure, acceptance criteria, and results are handled separately for the three parameters tested.

\section{Peak Combustion Pressure}

Phahl and Shepherd (1997) reports peak pressure values for combustion of gas mixtures that are similar to representative retained gas compositions. A specific case, Mixture 29, was selected for comparison because it was most representative of typical tank waste-retained gas $\left(29 \% \mathrm{H}_{2}\right.$, $24 \% \mathrm{~N}_{2} \mathrm{O}, 35 \% \mathrm{~N}_{2}, 1 \% \mathrm{CH}_{4}, 11 \% \mathrm{NH}_{3}$ ).

An AFE input file was created such that the source gas composition was the same as the gas mixtures used in the experiments. Also, a number of GRE and headspace parameters were controlled such that the final fraction of original source gas mixture in the headspace was the same as the fractions used in the experiments. For the exact values used, refer to the spreadsheet, "Combustion Model Validation.xls" (Riddle 1999g). All input files were Tank 241-A-101 Sensitivity Analyses with a sample of 200 and a seed of 631581312 ; they were run in Resolve 2.20.

The parameter release\%pressure was removed from debug output using the "FilterResolveResults.sh" (McCornak 1999) filter tool.

Acceptance Criteria: For comparisons of distributions, the distributions must be visually similar; that is, the distributions being compared must be of the same order of magnitude and must trend in a similar pattern.

Results: Table 4-28 and Figure 4-3 summarize the results of validation testing on peak combustion pressure. The Resolve-calculated values for peak pressure are in good agreement or are slightly conservative when compared with experimental data (Phahl and Shepherd 1997) over the range of source gas concentrations from the lean flammability limit to concentrations sufficient to generate dome-failing pressures. Beyond approximately dome-failing concentrations, a discontinuity was noted in the calculation of combustion pressure for high source gas concentrations in the headspace.

Up to the lean-rich transition, Resolve overpredicts pressure by a factor of up to 2. After the lean-rich transition, the curve is discontinuous and the model varies around the experimentally measured pressure by a factor of less than 1.5. Overestimation of the combustion pressure, when the pressure is sufficient to fail the dome, is potentially non-conservative from the perspective that it overestimates the dilution of the initial waste plume release (a larger plume volume is simulated). On the other hand, overestimation of combustion pressure is conservative from the perspective that it will predict a more sever tank damage state (a dome failure may be simulated when only dome cracking would actually occur). An overestimation of up to a factor of 2 is 
consistent with the difference between adiabatic-isochoric-complete-combustion (AICC) pressure and pressures measured in experimental facilities that are not very adiabatic.

The discontinuity has been traced to a problem in the model formulation. The model equations have been corrected in the final Analysis Framework document (Slezak et al. 2000) but were not corrected in the code because of time limitations, and also because several considerations indicated that the impact on consequences was not significant. First, the discontinuity occurs at source gas concentrations where it does not affect the determination of tank failure mode; therefore, it does not affect the mass of waste suspended and released. Second, a factor of 2 difference is obscured by the relatively greater stochastic uncertainty in the source term, which varies by more than an order of magnitude. Third, significant deviation from the experimentally observed pressures occurs only at concentrations of flammable gas roughly six times those observed in the largest recorded Tank 241-SY-101 release. This is not to say that such releases are impossible from current or future waste configurations; rather, the deviation will only rarely come into play for any cases in a Monte Carlo simulation and has virtually no effect on the results of the analysis.

Experimental data for peak pressures, Table 4-28, indicate no combustion pressure for mixtures of between $90 \%$ and $100 \%$ Mixture $29\left(29 \% \mathrm{H}_{2}, 24 \% \mathrm{~N}_{2} \mathrm{O}, 35 \% \mathrm{~N}_{2}, 1 \% \mathrm{CH}_{4}, 11 \% \mathrm{NH}_{3}\right)$ in air. This is because the rich flammability limit (RFL) was exceeded at these levels. However, Resolve predicts that the Mixture 29 is self-flammable. The limited data in Phahl and Shepherd (1997) on flammability limits in mixed oxidizer-mixed fuel systems and the extremely large ignition energies required for initiation make determination of the true RFL for this mixture impossible. Resolve erred on the conservative side of calculating a burn when none was observed in the experiment.

Table 4-28. Peak Pressure for Burns of Mixture $29\left(29 \% \mathrm{H}_{2}, 24 \% \mathrm{~N}_{2} \mathrm{O}, 35 \% \mathrm{~N}_{2}, 1 \% \mathrm{CH}_{4}\right.$, $11 \% \mathrm{NH}_{3}$ )-Comparison Results.

\begin{tabular}{|c|c|c|}
\hline $\begin{array}{c}\text { Fraction of Mixture 29 } \\
\text { in Air }\end{array}$ & Resolve Peak Pressure [psig] & $\begin{array}{c}\text { Pfahl and Shepherd (1997) } \\
\text { Peak Pressure [psig] }\end{array}$ \\
\hline 0.14 & 3 & 4 \\
\hline 0.15 & 8 & 10 \\
\hline 0.175 & 29 & 22 \\
\hline 0.2 & 53 & 33 \\
\hline 0.25 & 73 & 51 \\
\hline 0.5 & 104 & 95 \\
\hline 0.7 & 88 & 114 \\
\hline 0.9 & 118 & 115 \\
\hline 1 & 157 & 0 \\
\hline
\end{tabular}


Figure 4-3. Peak Pressure for Burns of Mixture $29\left(29 \% \mathrm{H}_{2}, 24 \% \mathrm{~N}_{2} \mathrm{O}, 35 \% \mathrm{~N}_{2}, 1 \% \mathrm{CH}_{4}\right.$, $11 \% \mathrm{NH}_{3}$ )-Comparison Results.

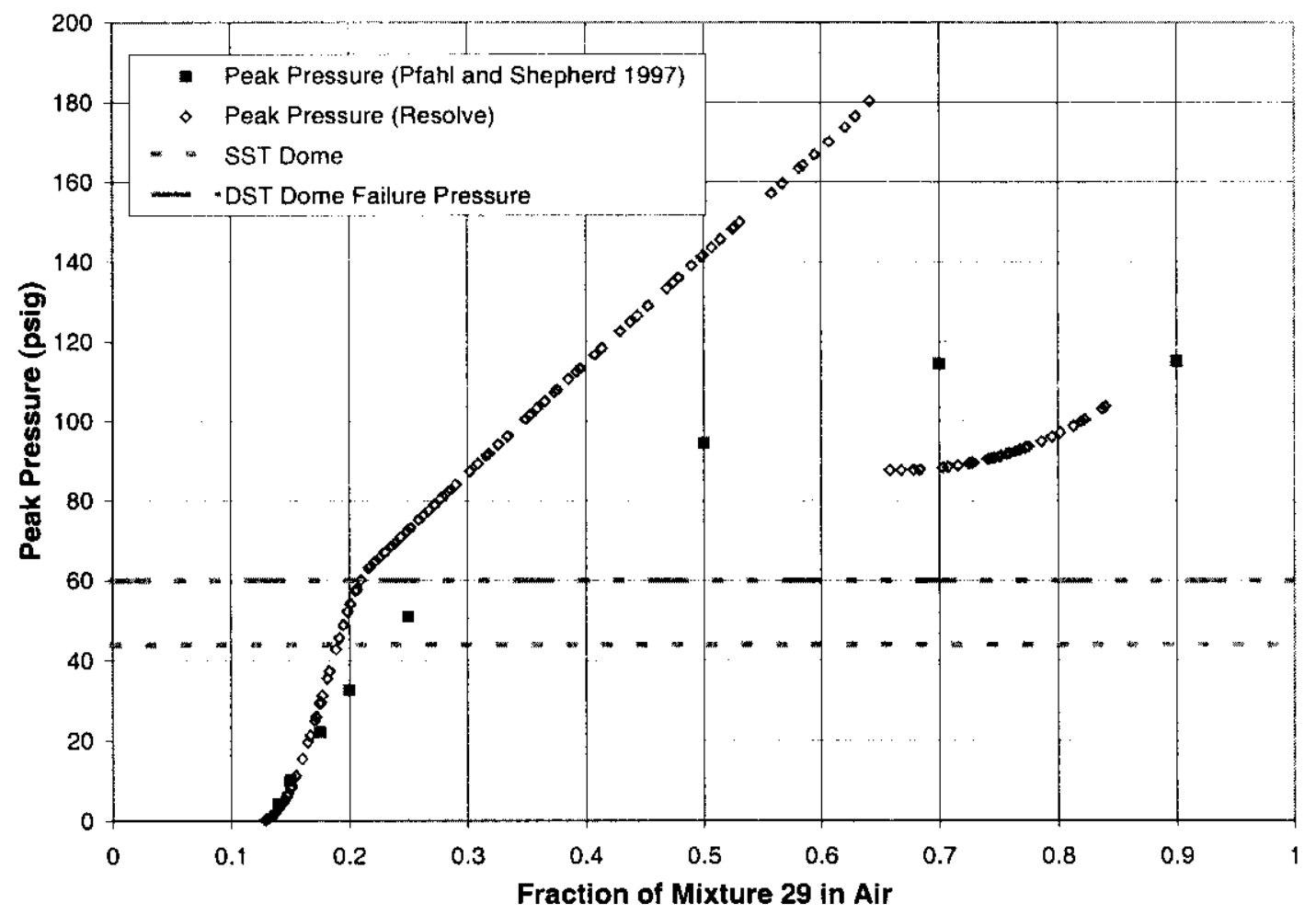

\section{Lean Flammability Limit}

For the three gas mixtures used in the peak pressure experiments, the flammability limits were also measured. The measured lean flammability limits were compared to lean flammability limits calculated from Resolve 2.20 debug output. This was done for a case of each experimental mixture $(27,28$, and 29) nearest the lean flammability limit (see Table 4-29).

Acceptance Criteria: For validation testing comparing a point value to a point value, the Resolve-calculated point value must be within the range of no more than 2 orders of magnitude conservative and 1 order of magnitude non-conservative to be acceptable.

Results: Table 4-30 summarizes the results of this test. Resolve-calculated lean flammability limits were within $20 \%$ of those determined in experiments, which is quite good considering the technical uncertainty surrounding flammability limits in complex (multiple oxidizer, multiple fuel) mixtures similar to those found in waste tank-retained gas. The Resolve results are within the acceptability range. 
Table 4-29. Lean Flammability Limit Test-Experimental Mixture Compositions.

\begin{tabular}{|c|}
\hline Experimental Mixture Compositions \\
\hline Mixture $27\left(40 \% \mathrm{H}_{2}, 40 \% \mathrm{~N}_{2} \mathrm{O}, 20 \% \mathrm{CH}_{4}\right)$ \\
\hline Mixture $28\left(35 \% \mathrm{H}_{2}, 35 \% \mathrm{~N}_{2} \mathrm{O}, 10 \% \mathrm{CH}_{4}, 20 \% \mathrm{NH}_{3}\right)$ \\
\hline Mixture $29\left(29 \% \mathrm{H}_{2}, 24 \% \mathrm{~N}_{2} \mathrm{O}, 11 \% \mathrm{NH}_{3}, 35 \% \mathrm{~N}_{2}, 1 \% \mathrm{CH}_{4}\right)$ \\
\hline
\end{tabular}

Table 4-30. Lean Flammability Limits-Comparison Results.

\begin{tabular}{|c|c|c|c|c|}
\hline Case & $\begin{array}{c}\text { Resolve } \\
\text { Calculated LFL }\end{array}$ & $\begin{array}{c}\text { Pfahl and } \\
\text { Shepherd (1997) } \\
\text { Experimentally } \\
\text { Measured LFL }\end{array}$ & $\begin{array}{c}\text { Ratio (Resolve/ } \\
\text { Phahl and } \\
\text { Shepherd) }\end{array}$ & Pass/ Fail \\
\hline Mixture 27 & 0.0714 & 0.07 & 1.01 & PASS \\
\hline Mixture 28 & 0.0827 & 0.09 & 0.91 & PASS \\
\hline Mixture 29 & 0.1218 & 0.14 & 0.86 & PASS \\
\hline
\end{tabular}

\section{Detonation Cell Size}

Tieszen et al. (1987), Stamps et al. (1991), Akbar et al. (1997), and Pfahl et al. (1998) report detonation cell sizes for a variety of gas mixtures. These data were used to create empirical curve fits that are then used in the AF model to determine the detonation cell size. In this test, the output from the software implementation of the model was compared to the experimental data.

The following five cases were designed:

- Stoichiometric $\mathrm{H}_{2}-\mathrm{N}_{2} \mathrm{O}$ in Varying \% Air

- Stoichiometric $\mathrm{H}_{2}-\mathrm{N}_{2} \mathrm{O}$ in Varying $\% \mathrm{~N}_{2}$

- Varying $\% \mathrm{H}_{2}$ in $\mathrm{N}_{2} \mathrm{O}$

- Varying $\% \mathrm{H}_{2}$ in $\mathrm{N}_{2} \mathrm{O}$ with Constant $30 \%$ dilution with $\mathrm{N}_{2}$

- Varying $\% \mathrm{H}_{2}$ in Air.

AFE input files were created such that the source gas composition was the same as those used in the experiments. For the exact values used, refer to spreadsheet "Combustion Model

Validation.xls" (Riddle 1999g). All input files were Tank 241-A-101 Sensitivity Analyses with a sample of 500 and a seed of 684712320 .

The debug parameter lambda, the detonation cell size in millimeters computed by Resolve, was removed from debug output using the "FilterResolveResults.sh" (McCornak 1999) tool. 
Acceptance Criteria: For comparisons of distributions, the distributions must be visually similar; that is, the distributions being compared must be of the same order of magnitude and must trend in a similar pattern.

Results: Refer to Figures 4-4 through 4-7 for a visual comparison of the Resolve-calculated detonation cell sizes and detonation cell sizes measured in experiments. The AF model uses a best-fit to available data in order to determine the donation cell size for mixtures. Results from the software implantation of the fitting curves were compared to the available data as shown in Figures 4-4 through 4-7. From the figures, it appeared that the Resolve software interim results closely matched the experimental data. No discrepancies were discovered. 
Figure 4-4. Detonation Model Case 1: Stoichiometric $\mathrm{H}_{2}-\mathrm{N}_{2} \mathrm{O}$ in Varying \% Air.

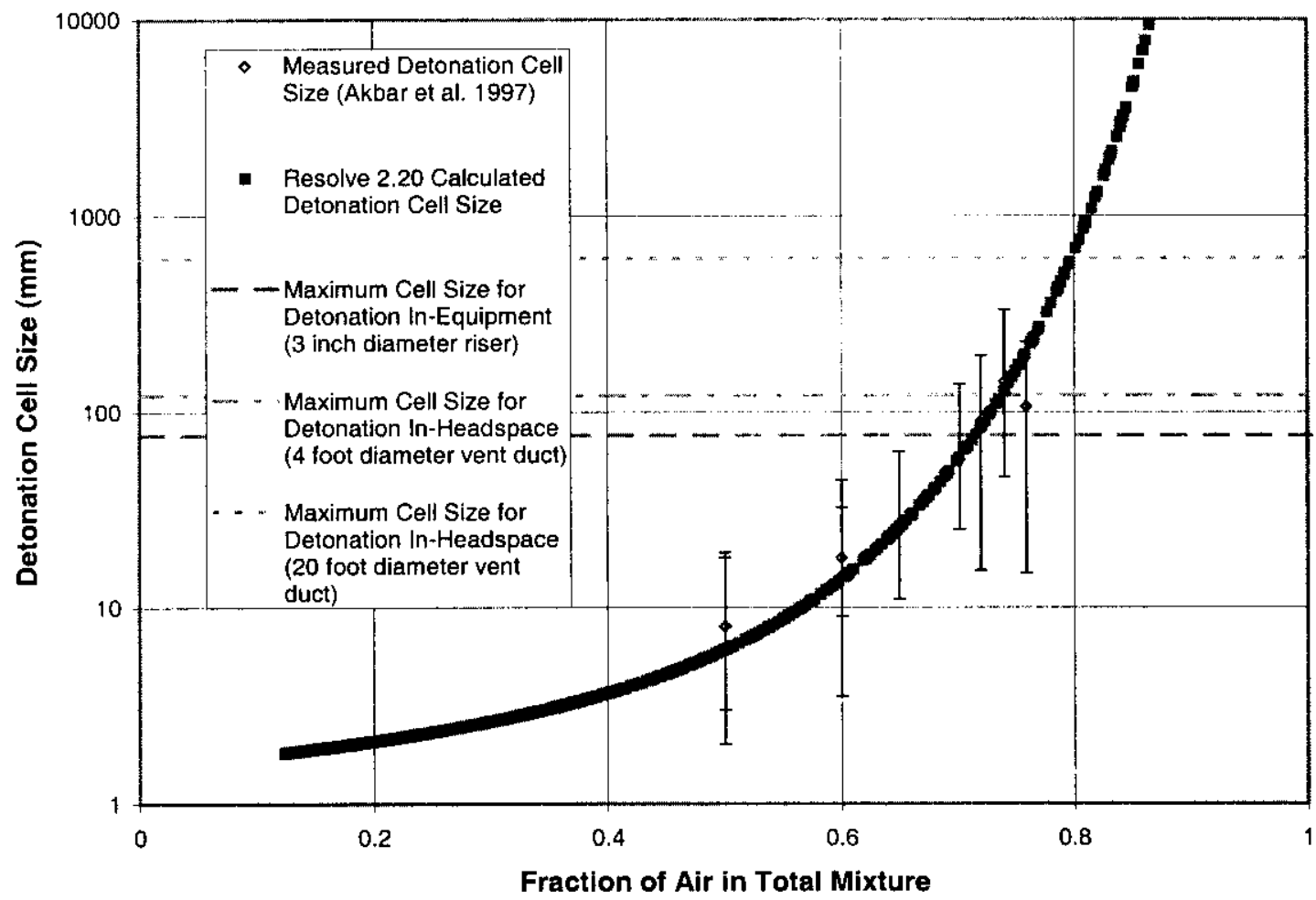

Figure 4-5. Detonation Model Case 2: Stoichiometric $\mathrm{H}_{2}-\mathrm{N}_{2} \mathrm{O}$ in Varying $\% \mathrm{~N}_{2}$.

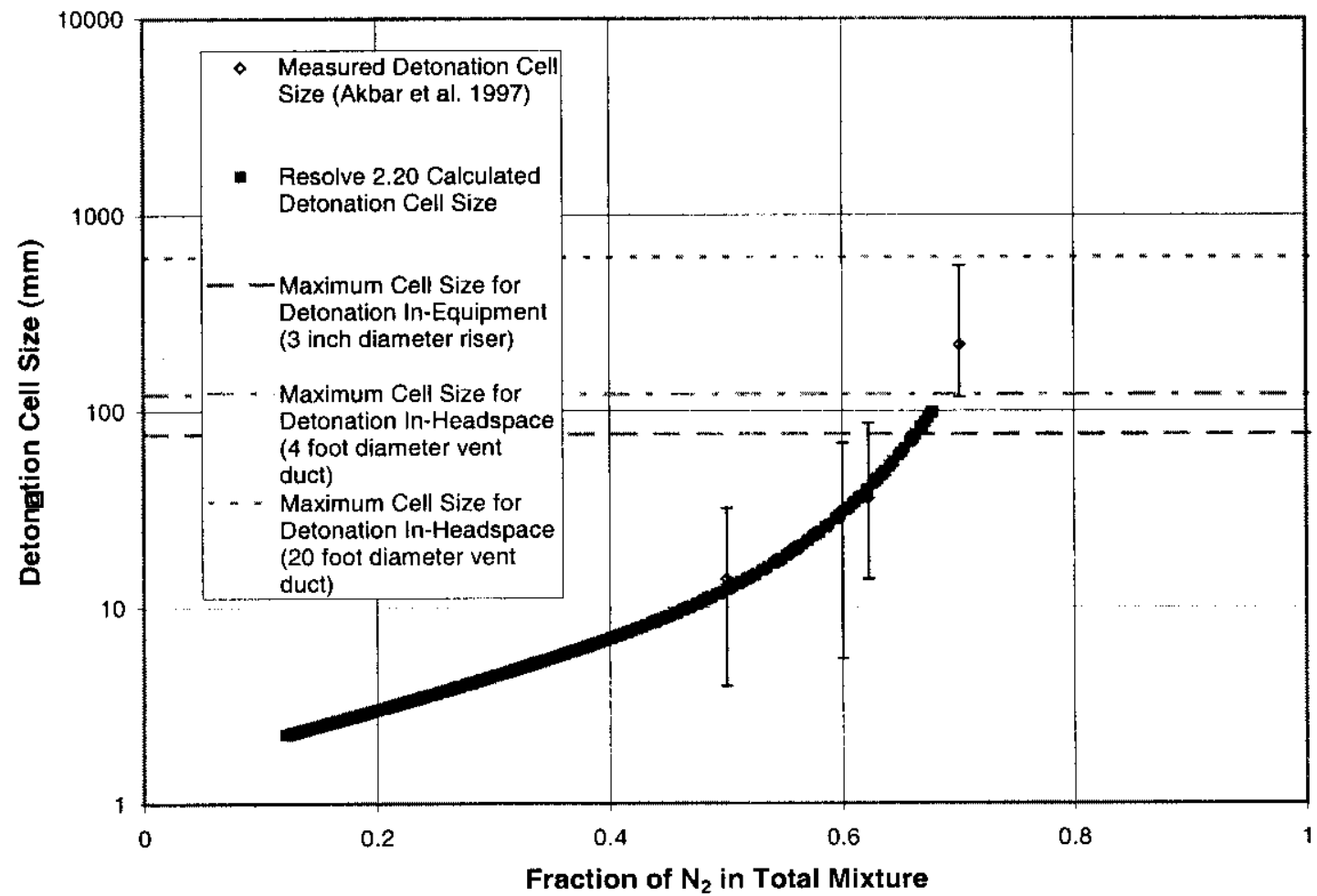


Figure 4-6. Detonation Model Cases 3 and 4: Varying $\% \mathrm{H}_{2}$ in $\mathrm{N}_{2} \mathrm{O}$ and Varying $\% \mathrm{H}_{2}$ in $\mathrm{N}_{2} \mathrm{O}$ with Constant $30 \%$ Dilution with $\mathrm{N}_{2}$.

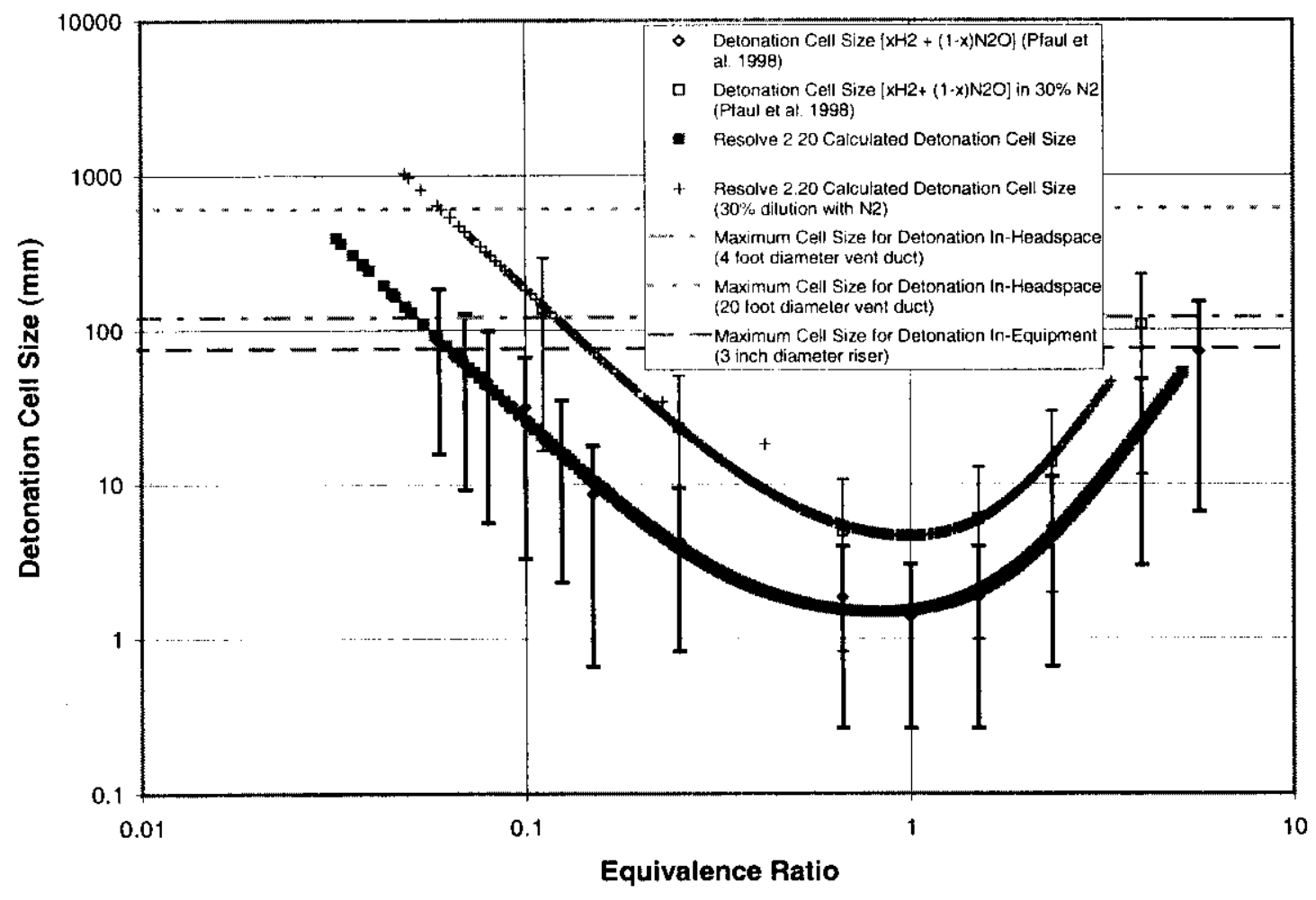

Figure 4-7. Detonation Model Case 5: Varying $\% \mathrm{H}_{2}$ in Air.

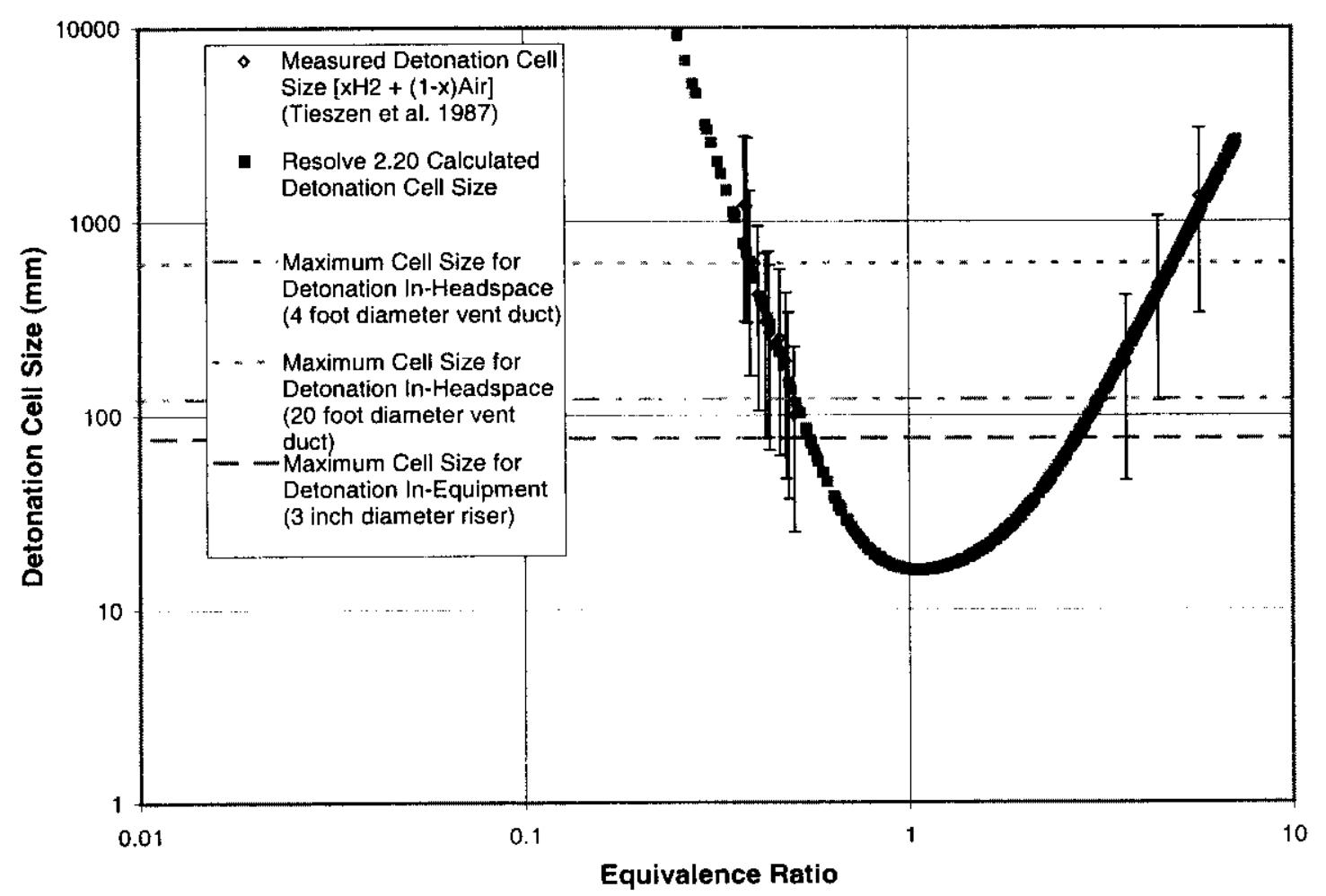




\subsection{VALIDATION: PANEL-BASED UNCERTAINTY DISTRIBUTION VALIDATION}

Abstract: A significant amount of technical uncertainty surrounds several of the parameters required for calculating flammable gas risk. The uncertainty arises because of limited availability of some tank or waste characterization data, and/or because current technical understanding of the phenomena involved is not complete. Therefore, one aspect of the Refined Safety Analysis Methodology was to capture current best-understandings of the phenomena involved and tank/waste configuration by asking an expert panel to quantify uncertainty distributions for parameters that were considered risk-significant and for which a high degree of technical uncertainty existed.

While high technical uncertainty characterized the state of knowledge surrounding the parameters which the expert panel was asked to quantify, validation of some of these parameters was possible. For some of the parameters limited data were available. Also, other expert panels and alternate calculation methods can be used to validate the panel-based uncertainty distributions currently used in Resolve. As more data become available, the Analysis Tool permits replacement of the panel-based uncertainty distributions with data-based distributions. In fact, the validation exercises for comparing void fraction data and inferred BD GRE durations to panel-based distributions became obsolete because the relevant panel-based were replaced by data-based distributions in the Relational Database.

The panel provided values for the mass of respirable waste suspended/released in a headspace after a burn; these values were validated against independent expert judgments (Han and Leach 1996, LANL 1996b).

Requirements: Hanford Gas Release Event Safety Analysis Tool Version 2.5 Software Verification and Validation Plan (Hodges 1999).

References and Inputs: Validation Calculations for the Enhanced Safety Analysis Methodology for Flammable Gas Risk Assessment in Hanford Site Tanks-Analysis Framework (Gelbard and Cheng 1998).

A Safety Assessment for Salt Well Jet Pumping Operations in Tank 241-A-101: Hanford Site, Richland, Washington (LANL 1996b).

DELPHI Expert Panel Evaluations of Hanford High Level Waste Tank Failure Modes and Release Quantities (Han and Leach 1996).

Spreadsheet "shmsgred.xls" (Stewart 1998).

Resolve Version 2.20 (Humphreys and Young 1998).

Spreadsheet "Elicited Parameter Validation.xls" (Riddle 1999i) was used to collect input and output data as well as to perform unit conversions and calculations.

General Test Procedure: An independent expert panel, the DELPHI panel, has estimated amounts of respirable waste that would be suspended in the tank headspace after flammable gas accidents that lead to specific tank failure modes (Han and Leach 1996). They also estimated the 
amounts of respirable waste that would be released external to the tank for the same accidents. In addition, the LANL (1996b) Salt Well Pumping Safety Assessment reports estimates of mass released following certain accident scenarios.

Resolve uses panel-based uncertainty distributions for respirable and transportable waste suspended in the headspace, which is conditioned on tank damage state. The amount of suspended waste that is released is determined separately. For accidents that cause dome failure, all the suspended mass is said to be released. For accidents that cause dome cracking or HEPA failure the mass released is based on the volume that would have to be released in order to depressurize the tank. The peak pressure in the tank is dependent on a number of factors, but for dome-cracking accidents, the mass released tends to be in the range of $50 \%$ to $80 \%$ of the mass suspended. For HEPA failing accidents the range is between $20 \%$ and $50 \%$.

The DEPHI panel estimates (Han and Leach 1996) and the LANL model predictions (1996b) were compared against the panel-based uncertainty distributions currently used in Resolve for respirable mass suspended in an SST for the relevant tank damage states.

Acceptance Criteria: For validation testing comparing a point value to a distribution, the Resolve distribution must encompass the alternate point estimates within its $5^{\text {th }}$ to $95^{\text {th }}$ percentile range.

Results: Table 4-31 summarizes the results of this test. The panel-based distributions for mass of respirable waste suspended range over other comparable and independent expert estimates as reported by Han and Leach (1996) and values reported in LANL (1996b). These results met acceptance criteria for this test.

Table 4-31. Mass of Respirable Waste Suspended/Released-Comparison Results.

\begin{tabular}{|c|c|c|c|c|c|c|}
\hline $\begin{array}{c}\text { Damage } \\
\text { State }\end{array}$ & $\begin{array}{c}\text { Resolve 5 } \\
\text { Percentile } \\
{[\mathrm{kg}]}\end{array}$ & $\begin{array}{c}\text { Resolve 50 } \\
\text { Percentile } \\
{[\mathbf{k g}]}\end{array}$ & $\begin{array}{c}\text { Resolve 95 }_{\text {th }} \\
\text { Percentile } \\
{[\mathbf{k g}]}\end{array}$ & $\begin{array}{c}\text { Delphi Panel Estimates } \\
\text { (Han and Leach 1996) } \\
{[\mathrm{kg}]}\end{array}$ & $\begin{array}{c}\text { LANL Model } \\
(\mathbf{1 9 9 6 b})[\mathrm{kg}]\end{array}$ & Pass/ Fail \\
\hline $\begin{array}{c}\text { No Dome } \\
\text { Damage }\end{array}$ & $4 \mathrm{E}-05$ & 0.025 & 83 & $\begin{array}{c}0.0063 \text { suspended } \\
0.0049 \text { released }\end{array}$ & 3.8 released & Pass \\
\hline $\begin{array}{c}\text { Dome } \\
\text { Cracks }\end{array}$ & $6 \mathrm{E}-04$ & 0.55 & 83 & $\begin{array}{c}4.2 \text { suspended } \\
0.02 \text { released }\end{array}$ & $\begin{array}{c}\text { not provided } \\
\text { separately }\end{array}$ & Pass \\
\hline $\begin{array}{c}\text { Dome } \\
\text { Collapse }\end{array}$ & 0.07 & 5.5 & 475 & not credible & 100 released & Pass \\
\hline
\end{tabular}




\section{RPP-6873 REV 0}

\subsection{VALIDATION: DOUBLE-SHELL TANK STEADY-STATE HEADSPACE GAS CONCENTRATIONS}

Abstract: Data exist for retained gas composition based on Retained Gas Sample (RGS) analyses. Data exist for ammonia, hydrogen, methane, nitrogen, and nitrous oxide retained gas concentrations in five DSTs. For the remaining tanks without RGS data, distributions describing the gas concentrations were derived based on the RGS data from all 14 tanks that have been RGS sampled. The tank-specific (5 DSTs with RGS data) and the aggregate data-based distributions were incorporated into the Relational Database.

While data show little correlation between steady-state headspace gas composition measurements and retained gas composition measurements (Barker et al. 1999), the Analysis Framework assumes that the composition of retained gas released into the headspace remains constant as it forms the steady-state headspace composition. Since steady-state releases mix to form flammable gas concentrations that are small relative to the Lower Flammability Limit, this approximation has virtually no impact on computed flammable gas risk.

The AF model prediction of steady-state headspace gas concentrations was validated against the tanks with RGS data. This test checked that the data-based distributions in the Relational Database were being handled and sampled properly in the software.

Requirements: Hanford Gas Release Event Safety Analysis Tool Version 2.5 Software Verification and Validation Plan (Hodges 1999).

Flammable Gas Safety Analysis Data Review (Barker et al. 1999).

References and Inputs: A spreadsheet, "rgs FinalSumTable 990818.xls" (Barker 1999e), contains the distributions for hydrogen and nitrogen concentrations.

A spreadsheet, "rgs dist data CH4 \& N2O ratio.xls" (Barker 1999d), contains the distributions for methane and nitrous oxide concentrations.

Resolve Version 2.50 (Humphreys and Young 1999).

A spreadsheet, "DST Headspace Gas Generation Results.xls" (Barker 2000a), was used to collect input and output data as well as to perform unit conversions.

General Test Procedure: The spreadsheets "rgs FinalSumTable 990818.xls" (Barker 1999e) and "rgs dist data CH4 \& N2O ratio.xls" (Barker 1999d) contain the analysis of preliminary RGS results from nine single-shell tanks (SSTs) and five double-shell tanks as recommended in the Data Analysis Workshops (Barker et al. 1999). For the steady-state headspace gas composition test, the set of all 28 double-shell tanks was selected. Benchmark analysis cases were created for each of these tanks with a sample size of 100 (corresponding to at least 200 steady-state gas concentration calculations) and a seed of 90000000 . 


\section{RPP-6873 REV 0}

The test cases were run in Resolve 2.50 , and the calculated steady-state headspace gas concentrations for ammonia, hydrogen, methane, nitrogen, and nitrous oxide (debug parameters release \%x\%ammonia, release \% x\% hydrogen, release\%x\%methane, release $\%$ \% $\%$ nitrogen, release\%x\%nitrousOxide, and release $\% x \%$ total) were removed from the debug output using the text editor KEDIT ${ }^{\mathrm{TM}} 1$ using a filtering macro, "first.kex" (Barker 2000b). For the tanks with RGS data, the values were compared to the measured values. The debug data were analyzed on a tank-by-tank basis using the spreadsheet "DST Headspace Gas Generation Results.xls" (Barker 2000a).

Acceptance Criteria: Resolve results must be within 1 standard deviation of the RGS value or the mean of the RGS distributions as appropriate.

\section{$\underline{\text { Results: }}$}

\section{Steady-State Headspace Ammonia Concentration}

Table 4-32 provides a summary of the results for the steady-state headspace ammonia concentration test. The Resolve-calculated values for steady-state headspace ammonia concentrations in tanks with measured RGS data are almost exactly as measured (Barker 1999e). This is within the acceptable range for this comparison.

\section{Steady-State Headspace Methane Concentration}

Table 4-33 provides a summary of the results for the steady-state headspace methane concentration test. Methane is described in the Resolve database and by Barker (1999d) as a ratio of the methane concentration to the sum of the methane and hydrogen concentrations. This use of a ratio allows the model to account for a wide variation in measured gas concentrations while not overspecifying the gas composition. The Resolve-calculated values for steady-state headspace methane concentration ratios in tanks with measured RGS data are almost exactly as measured (Barker 1999d). This is within the acceptable range for this comparison.

\section{Steady-State Headspace Nitrogen Concentration}

Table 4-34 provides a summary of the results for the steady-state headspace nitrogen concentration test. The Resolve-calculated values for steady-state headspace nitrogen concentrations in tanks with measured RGS data are almost exactly as measured (Barker 1999e). This is within the acceptable range for this comparison.

\section{Steady-State Headspace Nitrous Oxide Concentration}

Table 4-35 provides a summary of the results for the steady-state headspace nitrous oxide concentration test. Nitrous oxide is described in the Resolve database and by Barker (1999d) as a ratio of the nitrous oxide concentration to the sum of the methane, nitrous oxide, and hydrogen concentrations. This use of a ratio allows the model to account for a wide variation in measured gas concentrations while not overspecifying the gas composition. The Resolve-calculated values for steady-state headspace nitrous oxide concentration ratios in tanks with measured RGS data are almost exactly as measured (Barker 1999d). This is within the acceptable range for this comparison.

\footnotetext{
${ }^{1} \mathrm{KEDIT}^{\mathrm{TM}}$ is a trademark of Mansfield Software Group, Inc., Storrs, CT.
} 
Table 4-32. Steady-State Headspace Ammonia Concentration for Tanks with RGS Data.

\begin{tabular}{|c|c|c|c|c|}
\hline Tank & $\begin{array}{c}\text { Barker (1999e) } \\
\text { Ammonia Concentration } \\
\text { from RGS Data (mole\%) }\end{array}$ & $\begin{array}{c}\text { Resolve- Steady-State } \\
\text { Ammonia Concentration } \\
\text { (mole\%) }\end{array}$ & $\begin{array}{c}\text { Ratio } \\
\text { (Resolve/ } \\
\text { Barker) }\end{array}$ & Pass/Fail \\
\hline AN-103 & 0.7136 & 0.7136 & 1.00 & Pass \\
\hline AN-104 & 1.1344 & 1.1344 & 1.00 & Pass \\
\hline AN-105 & 0.4853 & 0.4853 & 1.00 & Pass \\
\hline AW-101 & 0.6000 & 0.6000 & 1.00 & Pass \\
\hline SY-101 & 9.5172 & 9.5172 & 1.00 & Pass \\
\hline
\end{tabular}

Table 4-33. Steady-State Headspace Methane Concentration Ratio for Tanks with RGS Data.

\begin{tabular}{|c|c|c|c|c|}
\hline Tank & $\begin{array}{c}\text { Barker (1999d) } \\
\text { Methane Concentration } \\
\text { Ratio from RGS Data }\end{array}$ & $\begin{array}{c}\text { Resolve- Steady-State } \\
\text { Methane Concentration } \\
\text { Ratio }\end{array}$ & $\begin{array}{c}\text { Ratio } \\
\text { (Resolve/ } \\
\text { Barker) }\end{array}$ & Pass/Fail \\
\hline AN-103 & 0.0850 & 0.0850 & 1.00 & Pass \\
\hline AN-104 & 0.0595 & 0.0595 & 1.00 & Pass \\
\hline AN-105 & 0.0216 & 0.0216 & 1.00 & Pass \\
\hline AW-101 & 0.2100 & 0.2100 & 1.00 & Pass \\
\hline SY-101 & 0.0877 & 0.0877 & 1.00 & Pass \\
\hline
\end{tabular}

Table 4-34. Steady-State Headspace Nitrogen Concentration for Tanks with RGS Data.

\begin{tabular}{|c|c|c|c|c|}
\hline Tank & $\begin{array}{c}\text { Barker (1999e) } \\
\text { Nitrogen Concentration } \\
\text { from RGS Data (mole\%) }\end{array}$ & $\begin{array}{c}\text { Resolve- Steady-State } \\
\text { Nitrogen Concentration } \\
\text { (mole\%) }\end{array}$ & $\begin{array}{c}\text { Ratio } \\
\text { (Resolve/ } \\
\text { Barker) }\end{array}$ & Pass/Fail \\
\hline AN-103 & 28.27 & 28.27 & 1.00 & Pass \\
\hline AN-104 & 29.07 & 29.07 & 1.00 & Pass \\
\hline AN-105 & 22.54 & 22.54 & 1.00 & Pass \\
\hline AW-101 & 53.73 & 53.73 & 1.00 & Pass \\
\hline SY-101 & 32.30 & 32.30 & 1.00 & Pass \\
\hline
\end{tabular}

Table 4-35. Steady-State Headspace Nitrous Oxide Concentration Ratio for Tanks with RGS Data.

\begin{tabular}{|c|c|c|c|c|}
\hline Tank & $\begin{array}{c}\text { Barker (1999d) } \\
\text { Nitrous Oxide Concentration } \\
\text { Ratio from RGS Data }\end{array}$ & $\begin{array}{c}\text { Resolve- Steady-State } \\
\text { Nitrous Oxide Concentration } \\
\text { Ratio }\end{array}$ & $\begin{array}{c}\text { Ratio } \\
\text { (Resolve/ } \\
\text { Barker) }\end{array}$ & Pass/Fail \\
\hline AN-103 & 0.0556 & 0.0556 & 1.00 & Pass \\
\hline AN-104 & 0.3150 & 0.3150 & 1.00 & Pass \\
\hline AN-105 & 0.1761 & 0.1761 & 1.00 & Pass \\
\hline AW-101 & 0.1300 & 0.1300 & 1.00 & Pass \\
\hline SY-101 & 0.3644 & 0.3644 & 1.00 & Pass \\
\hline
\end{tabular}




\subsection{VALIDATION: RADIOLOGICAL AND TOXICOLOGICAL CONSEQUENCES COMPARISON TO AUTHORIZATION BASIS}

Abstract: The purpose of this validation was to compare Resolve 2.5-predicted and FSARreported (HNF 1999) onsite radiological and toxicological consequences due to a release from an SST, given a deflagration resulting in a dome collapse.

The AF/AT methodology for determining consequences is similar to that used in the FSAR, with three best-estimate modifications. First, the AF/AT model uses a probability distribution for meteorological conditions based on Hanford Site-specific measurements, as opposed to the deterministic $50^{\text {th }}$ and $99^{\text {th }}$ percentile meteorological conditions used in the FSAR calculations. Second, the AF/AT models the initial release of waste as occupying a right cylinder volume with a width equal the width of the tank, and a height such that the cylinder's volume is equal to that needed to return the tank headspace to atmospheric pressure. This modification was included in the model to account for initial dilution of released waste at the release site due to lofting and buoyancy effects. Third, Resolve uses an uncertainty distribution for Unit Liter Dose (ULD).

Requirements: Hanford Gas Release Event Safety Analysis Tool Version 2.5 Software Verification and Validation Plan (Hodges 1999).

Refined Safety Analysis Methodology for Flammable Gas Risk Assessment in the Hanford Site Tanks, Part 1: Analysis Framework for Single-Shell Tanks (Slezak and Williams 1998).

References and Inputs: Tank Waste Remediation System Final Safety Analysis Report (HNF 1999).

"SST_onsite..xls" (Lavender 2000), a spreadsheet used to collect data and calculate results.

General Test Procedure: All the assumptions used in the FSAR (HNF 1999)calculations can be replicated in Resolve, but because of the stochastic nature of the analysis, finding cases where Resolve sampled values were equivalent to FSAR point estimates was difficult. Therefore, a spreadsheet was created that implemented the formulas found in Resolve 2.5 (Lavender 2000). This spreadsheet allowed individual parameter values to be adjusted to match those used in the FSAR calculations. A check was made to ensure that the spreadsheet results matched those calculated by Resolve.

A Tank 241-A-101 Sensitivity Analysis, with no controls, was run in Resolve 2.5. The mass of waste suspended was set to $5.6 \mathrm{~kg}$ and the ULD was set to $220,000 \mathrm{~Sv} / \mathrm{L}$. All other parameters were left as their default values. A dome-failing case was identified in the debug output and the specific interim input values were entered into the spreadsheet. For the accident in question, the spreadsheet calculated onsite consequences of $2.03 \mathrm{~Sv}$ and 3.39 fraction-of-guidelines, while Resolve 2.5 calculated consequences of $2.05 \mathrm{~Sv}$ and 3.41 fraction-of-guidelines for this case.

Acceptance Criteria: Resolve results must be no more than 2 orders of magnitude conservative and no more than 1 order of magnitude non-conservative to be acceptable. 
$\underline{\text { Results: }}$

\section{Radiological Consequences}

The FSAR assumed a release of 4L of SST waste. Using the default Tank 241-A-101 value for waste average density of $1.801 \mathrm{~g} / \mathrm{ml}$, the quantity of material suspended was $7.2 \mathrm{~kg}$. Substituting $7.2 \mathrm{~kg}$ into the spreadsheet as the mass of respirable waste released, the onsite radiological consequences were calculated to be $2.62 \mathrm{~Sv}$. The reported onsite dose consequence in the FSAR for the same release is $9.9 \mathrm{~Sv}$.

The three modifications noted above, stochastic meteorology, volume release, and ULD distribution, needed to be accounted for. In the case setup, the ULD was set to the value used in the FSAR analysis. The difference in meteorological conditions was accounted for by multiplying the Resolve-calculated consequences by the ratio of the X/Q reported in the FSAR (that was, 5.33E-03 50 $0^{\text {th }}$ percentile) to the stochastic X/Q for Resolve Version 2.5 (that was, 1.70E-03). The result was an onsite radiological dose of $8.2 \mathrm{~Sv}$. The volume release factor then was the remaining difference between the Resolve value and the FSAR value. Resolve results for radiological consequences were within the acceptable range, and matched closely with the values reported in the FSAR when adjustments were made for model modifications.

\section{Toxicological Consequences}

Using the same input file and the same SST dome-failing case identified above, the Resolve results were adjusted to FSAR assumptions regarding waste surface dryness (SST solids), accident frequency (Unlikely), and meteorology $\left(50^{\text {th }}\right.$ percentile) using the spreadsheet. These adjustments yielded an onsite toxicological fraction-of-guidelines of 153, while the FSAR reported a value of 420 for this same accident; therefore, the consequences calculated in Resolve Version 2.5 for this instance were within on order of magnitude of the sum-of-fractions reported in the FSAR. Resolve results for toxicological consequences were within the acceptable range, and matched closely with the values reported in the FSAR when adjustments were made for model modifications.

\subsection{VALIDATION: RISK MODEL-FREQUENCY OF HEPA FAILURES OR WORSE}

Abstract: A validation test was performed to compare the calculated frequencies of GRE deflagrations resulting in HEPA filter failures to the Hanford Site HEPA filter failure empirical data. The FSAR assumed that a HEPA filter failure due to a GRE deflagration was an anticipated event (at least 1 in 100 years); however, based on observations, there are no recorded HEPA filter failures due to flammable gas deflagrations or detonations in approximately 7,000 tank years. Thus, based on empirical data, the frequency was estimated to be $1.4 \mathrm{E}-04 / \mathrm{yr}$, or unlikely. However, errors in data recording or other factors (like changed waste conditions) may have occurred that resulted in missed observations. Applying a student's " $T$ " Test of $50 \%$ confidence, the frequency was estimated to be $4.3 \mathrm{E}-04 / \mathrm{yr}$ or less.

Requirements: Hanford Gas Release Event Safety Analysis Tool Version 2.5 Software Verification and Validation Plan (Hodges 1999).

References and Inputs: None. 
General Test Procedure: The Analysis Tool Resolve Version 2.5 was run for each of the 100 Series single-shell tanks. The analyses were benchmark cases, and the statistics for the Onsite Rad: HEPA failure data set were checked. The data used for this evaluation were the mean HEPA failure frequency statistics.

Acceptance Criteria: Resolve results must be no more than 1 order of magnitude nonconservative, and no more than 2 orders of magnitude conservative to be acceptable.

Results: Based on current tank characteristics, HEPA failure frequencies ranged from 0/yr to $2.43 \mathrm{E}-02 / \mathrm{yr}$. There were no calculated flammable gas deflagrations - due either to the characteristics of the waste or the characteristics of the GREs - in those tanks with frequencies equal to $0 / y r$. For those events that resulted in flammable gas deflagrations and subsequent HEPA filter failures, the frequencies ranged from 7.86E-11/yr to $2.43 \mathrm{E}-02 / \mathrm{yr}$. However, the 7,000 tank years include all tanks regardless of the potential for a flammable gas deflagration or detonation, so tanks which showed no HEPA failing accidents were included in the analysis.

The average value of all calculated mean frequencies for HEPA filter failures is $8.99 \mathrm{E}-04 / \mathrm{yr}$. This is within an order of magnitude of the comparative value (4.3E-4 failures/yr) and is considered acceptable. The Resolve predicted frequency of HEPA failures matched field observations well, particularly considering the uncertainties involved in the observation record and in the modeling. 
RPP-6873 REV 0

This page is intentionally left blank. 


\subsection{DISCREPANCY REPORT STATUS}

As defined in the Hanford Gas Release Event Safety Analysis Tool Version 2.5 Verification and Validation Plan (Hodges 1999), the discrepancy reporting process allows for observations of deviations from expected behavior to be noted and addressed. Discrepancy Reports (DR) are assigned a severity level (Table 5-1) by the user that can range from "Severe" to "Low." Complete documentation of the DR process is found in Process Description 3-2, Discrepancy Management (SNL 1998c).

Table 5-1. Discrepancy Report Severity Levels.

\begin{tabular}{|l|l|}
\hline \multicolumn{1}{|c|}{ Severity Level } & \multicolumn{1}{c|}{ Description } \\
\hline Severe & $\begin{array}{l}\text { The system is not functioning at all, or it is not functioning } \\
\text { correctly such that the mission is being affected, and there is } \\
\text { no acceptable workaround. }\end{array}$ \\
\hline High & $\begin{array}{l}\text { The system is functioning, but operations have been } \\
\text { significantly impacted. A workaround may exist, but the } \\
\text { workaround caused extensive effort for the operators. }\end{array}$ \\
\hline Medium & $\begin{array}{l}\text { The system is functioning with an acceptable workaround, or } \\
\text { some aspect of the system is not working, but it is not } \\
\text { impacting the mission. }\end{array}$ \\
\hline Low & \begin{tabular}{l} 
The system is functioning, but could be functioning better. \\
\hline
\end{tabular} \\
\hline
\end{tabular}

The DR process entails disseminating issues to all interested parties, including personnel outside the V\&V and development teams. The Document Management System serves as a central location for all submitted DRs and provides a status for each. After an analyst has submitted a $\mathrm{DR}$, it is reviewed by the development team and assigned an internal priority within the scope of all ongoing development tasks. DRs that are addressed by the development team are marked as "pending." Responsibility then lies with the original submitter to reevaluate the DR and concur with whether or not the original issue has been satisfactorily addressed. In some cases, with the concurrence of the customer, DRs are marked as "deferred" and will be addressed in later versions of the software. When the submitter completely agrees that the issue has been resolved, the DR is marked as "closed." Each DR, in addition to noting an issue, serves as a record of actions taken to resolve the issue

During the spring of 1999, the issuance of Discrepancy Reports moved from an e-mail-based system to an automated client-server-based system. DRs that were issued prior to the launch of this system were referenced with the tester's initials (or in some cases the initials of the test) and a sequential number for DRs issued by that tester; for example, WMG-12 would be the $12^{\text {th }}$ DR issued by William M. Guerra. Under the automated system, DRs were assigned ID numbers in the order in which they were issued; for example, DR \#50 would be the $50^{\text {th }}$ DR issued in the 
system. DRs issued under the previous system that were not closed as of the launch of the new system were migrated to the new system and given new ID numbers.

The current status of all Discrepancy Reports is noted in Table 5-2. The table contents are based on results of a query of the Discrepancy Report database on August 25, 2000, plus information on DRs resolved prior to the launch of the Discrepancy Report database. All issues that were expected to have a significant impact on software output, Severe- and High-severity DRs, have been resolved as of the release of Resolve 2.5.

Of the 12 medium-severity deferred DRs (see Table 5-2), 1 was assigned to the GUI, 2 were assigned to the database, and the remainder were assigned to documentation and/or the Analysis Framework. The GUI DR documents an issue with the calculation of the "number of events" statistic for BD GREs. The Database DRs describe issues with the Tank 241-SY-102 data and the assignment choice for salt well pumping ignition control strategy in tanks that are not currently being pumped. These issues do not significantly impact the use of the software.

The AF has 10 deferred DRs assigned to it. These DRs deal with issues related to equations or requests for clarification. These issues has already been addressed in the software implementation, and are resolved with the release of the Analysis Framework Rev. 3 (Slezak et al. 2000). Five additional DRs are assigned to the SRS and SDD. These DRs address changed requirements for the software, either new requirements and deleted requirements, that have yet to be reflected in the documentation. These issues do not impact the use of the tool.

The database and V\&V processes both have one low-severity DR each. None of the lowseverity issues impact the use of the software.

Table 5-1. Status and Severity of Discrepancy Reports.

\begin{tabular}{|c|c|c|c|c|}
\hline & Severe & High & Medium & Low \\
\hline Open & 0 & 0 & 0 & 0 \\
\hline Pending Closure & 0 & 0 & 0 & 0 \\
\hline Deferred & 0 & 0 & 12 & 8 \\
\hline Pending Deferral & 0 & 0 & 0 & 0 \\
\hline Reevaluate & 0 & 0 & 0 & 0 \\
\hline Dispositioned & 0 & 0 & 0 & 0 \\
\hline Reassigned & 0 & 0 & 0 & 0 \\
\hline Closed (Automated System) & 11 & 108 & 128 & 33 \\
\hline Closed (E-mail System) & \multicolumn{3}{|c|}{348} \\
\hline Total & \multicolumn{3}{|c|}{648} \\
\hline
\end{tabular}




\section{RPP-6873 REV 0}

\subsection{SUMMARY EVALUATION}

During the time the Resolve Version 2.5 has been under development, it has undergone two extensive V\&V testing cycles. These testing cycles accomplished all activities prescribed in the Resolve Version 2.0 (Hodges 1998d) and Resolve Version 2.5 V\&V Plans (Hodges 1999). Testing of the AFE entailed thousands of analysis cases, a line-by-line source code review, and the comparison to independent sources of over 20 interim calculation results from all phenomenological stages of a hypothetical flammable gas accident. In addition, a multidisciplinary team reviewed project documents for traceability to source requirements and rederived equations from basic science and published relationships. The database and GUI were reviewed for compliance to requirements and data handling features were tested.

V\&V activities found that 18 interim model results, at all phenomenological stages of a hypothetical flammable gas accident, compared suitably to appropriate benchmark values as established by tank data, experimental data, or by expert judgements. In addition, all issues expected to significantly impact the applicability of the software results to Refined Safety Analysis (RSA) safety evaluations-discovered during the detailed code review, requirements traceability, and equation rederivation activities—were resolved.

Testing also indicated four parameters calculated by the model that lie outside prior established ranges for one or more tanks. For example, the calculation of high flammable gas concentrations during salt well pumping resulted from conservatism in the way the model predicts ammonia concentrations during salt well pumping. The expert panel was asked to err toward conservatism with most tanks and provide a best estimate for "worst case" tanks. This conservatism ensures that decisions made on the basis of these model results will tend to err on the side of greater safety, and not on the side of higher safety risk.

Comparisons between Resolve runs of consequence values for burns in waste-intruding equipment, while trending as expected, showed higher consequence values than expected by expert judgment. There are no data on actual burns in waste-intruding equipment, so it is preferable for the model to calculate consequences that bound those likely to be seen in any real event. There is no absolute method for determining the accuracy of expert judgment in these cases.

Testing of the Buoyant Displacement Model indicated that model results for Tank 241-SY-101 do not match historical data precisely. This difference arose from the incompatibility of sparse existing data with the assumption of the model that liquid density in the tanks is constant. In fact, it is known that liquid densities in tanks that exhibit buoyant displacement behavior vary over time during a buoyant release cycle. The Tank 241-SY-101 analysis was an exception, and results for the other BD tanks were acceptable.

The model for calculating combustion pressure during a hypothetical gas burn in a tank produced results in pressure estimates that deviate from relevant experimental results by up to a factor of 2 . This difference was noted in the evaluation of some rare, high-consequence accidents. It should be noted, however, that this deviation had little or no impact on risk calculations because of the relatively greater uncertainty in determining the source term of an accident. 
While the goal of this verification and validation report was not to determine the acceptability or usefulness of the tool, results from testing provide insight into the correct use and interpretation of model results. For example, the Model Comparison Testing activity noted that, for model results to be useful, the user must verify that any perceived trend in the results is greater than the stochastically generated instability in the results.

The results of verification and validation tasks demonstrate that the Analysis Framework and its software implementation in Resolve are consistent with project requirements. In addition, model predictions for flammable gas risk and interim model results were consistent with and compared acceptably to tank data, results from other codes, and alternate expert judgement. The Analysis Framework and Resolve achieve their intended purpose of providing a decision support tool that evaluates risk plus uncertainty from flammable gas accidents and quantifies flammable gas accident control effectiveness in Hanford Site waste tanks. 


\subsection{REFERENCES}

\subsection{DOCUMENTS}

Akbar, R., M. Kaneshige, E. Schultz, and J. Shepherd, 1997, Detonations in $\mathrm{H}_{2}-\mathrm{N}_{2} \mathrm{O}-\mathrm{CH}_{4}-\mathrm{NH}_{3}-\mathrm{O}_{2}-\mathrm{N}_{2}$ Mixtures, Explosion Dynamics Laboratory Report FM97-3, California Institute of Technology, Pasadena, California.

Antoniak, Z. I., and K. P. Recknagle, 1997, Initial Parametric Study of the Flammability of Plume Releases in Hanford Waste Tanks, PNNL-11639, Pacific Northwest National Laboratory, Richland, Washington.

Barker, S. A., W. B. Barton, B. D. Board, C. J. Byrne, A. B. Webb, D. J. Braun, J. M: Grigsby, and J. Young, 1998, Gas Release Event Safety Analysis Tool Acceptance and Validation Report, Resolve! Version 1.4, Revision 0, Lockheed Martin Hanford Corporation, DESH, Fluor Daniel Northwest, G\&P Consulting, MSI, Hanford, Washington.

Barker, S. A., W. B. Barton, D. R. Bratzel, M. Epstien,. P. A. Gauglitz, G. D. Johnson, S. N. Maruvada, C. E. Olson, M. L. Sauer, S. E. Slezak, C. W. Stewart, and J. Young, 1999, Flammable Gas Safety Analysis Data Review, SNL-000198, Sandia National Laboratories, Albuquerque, New Mexico.

Caley, S. M., L. A. Mahoney, and P. A. Gauglitz, 1996, Summary of Tank Information Relating Salt Well Pumping to Flammable Gas Issues, PNNL-11335, Pacific Northwest National Laboratory, Richland, Washington.

Conner, J. M., and G. M. Koreske, 1998, Quarterly Review of 241-SY-101 Mixer Pump Data: April-June 1998, HNF-3402, Rev. 0, Lockheed Martin Hanford Corporation, Process Control Division, Hanford Nuclear Facility, Richland, Washington.

Gelbard, F., and W. Cheng, 1998, Validation Calculations for the Enhanced Safety Analysis Methodology for Flammable Gas Risk Assessment in Hanford Site Tanks Analysis Framework, 6805:GRESA:98-0053, Sandia National Laboratories, Albuquerque, New Mexico.

Green, D. W., Perry's Chemical Engineers' Handbook, Sixth Edition, McGraw-Hill Book Company, New York, New York.

Grier, W., 1998, Computer Software Quality Assurance Requirements, HNF-PRO-309, Rev 0, Hanford Nuclear Facility, Richland, Washington.

Guerra, W. M., and J. C. Kingson, 1998, "Table B-20," Innovative Technology Solutions Corporation, Albuquerque, New Mexico. 
Han, F. C., and L. Leach, 1996, DELPHI Expert Panel Evaluations of Hanford High Level Waste Tank Failure Modes and Release Quantities, WHC-SD-TWR-RPT-003, Rev. 0, Westinghouse Hanford Company, Richland, Washington.

Hanlon, B. M., 1997, Waste Tank Summary Report for the Month Ending March 31, 1997, HNF-EP-0182-108, Hanford Nuclear Facility, Richland, Washington.

Hey, B. E., 1994, GXQ 4.0 Program Users' Guide, WHC-SD-SWD-3002, Rev. 1A, Westinghouse Hanford Company, Richland, Washington.

Hey, B. E., 1998, Models and Data for Stochastic Treatment of X/Q, BEH-98-016, a letter dated March 20 that was written to Gerald D. Johnson of Duke Engineering \& Services Hanford, Richland, Washington, by Brit E. Hey of Flour Daniel Northwest, Richland, Washington.

HNF, 1999, Tank Waste Remediation System Final Safety Analysis Report, HNF-SD-WM-SAR-067, Rev. 0, Fluor Daniel Hanford, Inc., Richland, Washington.

Hodges, A. L., 1998a, Hanford Gas Release Event Safety Analysis Tool Verification and Validation Review and Action Plan Draft, Revision 1.4, Sandia National Laboratories, Albuquerque, New Mexico.

Hodges, A. L., 1998b, Hanford Gas Release Event Safety Analysis Tool Verification and Validation Review Status Report, Revision 1.6, Sandia National Laboratories, Albuquerque, New Mexico.

Hodges, A. L., 1998c, Hanford Gas Release Event Safety Analysis Tool Verification and Validation Review Status Report, Revision 1.12, Sandia National Laboratories, Albuquerque, New Mexico.

Hodges, A. L., 1998d, Hanford Gas Release Event Safety Analysis Tool Version 2.0 Software Verification and Validation Plan, SNL-000073, Version 1.1, Sandia National Laboratories, Albuquerque, New Mexico.

Hodges, A. L., 1999, Hanford Gas Release Event Safety Analysis Tool Version 2.5 Software Verification and Validation Plan, SNL-000202 Rev. 1.2, Sandia National Laboratories, Albuquerque, New Mexico.

Humphreys, S. L., 1997, Software Design Folder, "Create an Inverse Error Function Using an Inverse Exponential Function," Sandia National Laboratories, Albuquerque, New Mexico.

Humphreys, S. L., 1998a, Software Requirements Specification (SRS) for the Gas Release Event Safety Analysis Tool, SNL-000112, Rev 2.2, Sandia National Laboratories, Albuquerque, New Mexico.

Humphreys, S. L., 1998b, Software Design Description (SDD) for the Gas Release Event Safety Analysis Tool, Resolve Version 2.0, SNL-000115, Sandia National Laboratories, Albuquerque, New Mexico. 
Humphreys, S. L., 1999, Proposed Data Review Workshop Changes to the Refined Safety Analysis Tool, Resolve Version 2.50, SNL-000197, Sandia National Laboratories, Albuquerque, New Mexico.

Innovative Technology Solutions Corporation, 1997a, Software System Test Plan (SSTP), Revision 0, Safety-Controls Optimization by Performance Evaluation Analysis Tool, SCOPE-AT Version 1.0, Innovative Technology Solutions Corporation, Albuquerque, New Mexico.

Innovative Technology Solutions Corporation, 1997b, Software System Test Plan (SSTP), Revision 1, Resolve! Gas Release Event Safety Analysis Tool, Resolve! Version 1, Innovative Technology Solutions Corporation, Albuquerque, New Mexico.

Innovative Technology Solutions Corporation, 1998a, Software System Test Plan (SSTP)

Revision 1 Addendum, Resolve! Gas Release Event Safety Analysis Tool, Resolve! Version 1.4, Innovative Technology Solutions Corporation, Albuquerque, New Mexico.

Innovative Technology Solutions Corporation, 1998b, Gas Release Events Safety Analysis Tool, Resolve Version 1.51, Software Systems Test Report (SSTR), Innovative Technology Solutions Corporation, Albuquerque, New Mexico.

LANL, 1996a, A Safety Assessment of Rotary Mode Core Sampling in Flammable Gas Single Shell Tanks: Hanford Site, Richland, Washington, WHC-SD-WM-SAD-035 Rev. 0A, Los Alamos National Laboratory, Los Alamos, New Mexico.

LANL, 1996b, A Safety Assessment for Salt Well Jet Pumping Operations in Tank 241-A-101: Hanford Site, Richland, Washington, WHC-SD-WM-SAD-036, Rev. 0, Los Alamos National Laboratories.

LANL, 1996c, A Safety Assessment for Salt Well Pumping in Tank 241-A-101: Hanford Site, Richland, Washington, WHC-SD-WM-SAD-036, Appendix I, Los Alamos National Laboratory, Los Alamos, New Mexico.

LANL, 1997a, Checklist Evaluation Report for Salt Well Pumping Single Transfer Operations in Tank 241-S-109, Hanford Site, Richland, Washington, WHC-SD-WM-SAD-036, Rev 0, Los Alamos National Laboratory, Los Alamos, New Mexico.

LANL, 1997b, Checklist Evaluation Report for Salt Well Pumping Single Transfer Operations in Tank 241-SX-103, Hanford Site, Richland, Washington, WHC-SD-WM-SAD-036, Rev 0, Los Alamos National Laboratory, Los Alamos, New Mexico.

LANL, 1997c, Checklist Evaluation Report for Salt Well Pumping Single Transfer Operations in Tank 241-BY-105, Hanford Site, Richland, Washington, WHC-SD-WM-SAD-036, Rev 0, Los Alamos National Laboratory, Los Alamos, New Mexico. 
LANL, 1997d, Checklist Evaluation Report for Salt Well Pumping Single Transfer Operations in Tank 241-S-102, Hanford Site, Richland, Washington, WHC-SD-WM-SAD-036, Rev 0, Los Alamos National Laboratory, Los Alamos, New Mexico.

McGlinchey, L. F., W. C. Cheng, A. L. Hodges, S. E. Slezak, S. G. Ashbaugh, W. M. Guerra, and A. Riddle, 1999, Refined Safety Analysis Tool Software Verification and Validation Report, Resolve Version 2.0, SNL-000149, Sandia National Laboratories, Albuquerque, New Mexico.

Meyer, P. A., M. E. Brewster, S. A. Bryan, G. Chen, L. R. Pederson, C. W. Stewart, and G. Terrones, 1997, Gas Retention and Release Behavior in Hanford Double-Shell Waste Tanks, PNNL-11536 Rev. 1, Pacific Northwest National Laboratory, Richland, Washington.

Olson, C. E., 1998, Radioactive Waste Management Program Quality Assurance Program Plan, SNL-RWM PROGRAM-QAPP, Rev 2, Sandia National Laboratories, Albuquerque, New Mexico.

Pfahl, U., and J. Shepherd, 1997, Flammability, Ignition Energy and Flame Speeds in $\mathrm{NH}_{3}-\mathrm{H}_{2}-\mathrm{CH}_{4}-\mathrm{N}_{2} \mathrm{O}-\mathrm{O}_{2}-\mathrm{N}_{2}$ Mixtures, Explosion Dynamics Laboratory Report FM97-4R1, California Institute of Technology, Pasadena, California.

Pfahl, U., E. Schultz, and J. E. Shepherd, 1998, Detonation Cell Width Measurements for $\mathrm{H}_{2}-\mathrm{N}_{2} \mathrm{O}-\mathrm{N}_{2}-\mathrm{O}_{2}-\mathrm{CH}_{4}-\mathrm{NH}_{3}$ Mixtures, Explosion e. Dynamics Laboratory Report FM98-5, California Institute of Technology, Pasadena, California.

Slezak, S. E., and D. C. Williams, 1998, Refined Safety Analysis Methodology for Flammable Gas Risk Assessment in the Hanford Site Tanks, Part 1: Analysis Framework for SingleShell Tanks, HNF-SD-WM-ES-410, Rev. 2, Sandia National Laboratories, Albuquerque, New Mexico.

Slezak, S. E., W. C. Cheng, and F. Gelbard, 1998, Refined Safety Analysis Methodology for Flammable Gas Risk Assessment in the Hanford Site Tanks, Part 2: Analysis Framework for Double-Shell Tanks, HNF-SD-WM-ES-410, Sandia National Laboratories, Albuquerque, New Mexico.

Slezak, S. E., 1998, Refined Safety Analysis Methodology for Flammable Gas Risk Assessment in Hanford Site Tanks, Implementation Details for the Analysis Framework, HNF-SD-WM-ES-410 Supplement, Sandia National Laboratories, Albuquerque, New Mexico.

Slezak, S. E., and A. L. Hodges, 1998, Hanford Gas Release Event Safety Analysis Tool 2.0 Comparison Test Cases, Version 1.0, Revision 1.2, Sandia National Laboratories, Albuquerque, New Mexico.

Slezak, S. E., W. C. Cheng, and F. Gelbard, 1999, Refined Safety Analysis Methodology for Flammable Gas Risk Assessment in the Hanford Site Tanks: Implementation Details for the Analysis Framework, Sandia National Laboratories, Albuquerque, New Mexico. 
Slezak, S. E., D. C. Williams, W. C. Cheng, and D. R. Bratzel, 2000, Refined Safety Analysis Methodology for Flammable Gas Risk Assessment in the Hanford Site Tanks,

HNF-SD-WM-ES-410, Rev. 3, Sandia National Laboratories, Albuquerque, New Mexico.

SNL, 1998a, Radioactive Waste Management Program, Quality Assurance Program Plan, Rev. 2, SNL-000148, Sandia National Laboratories, Albuquerque, New Mexico.

SNL, 1998b, Refined Safety Analysis FY1999 Project Plan, Version 3.0d, Sandia National Laboratories, Albuquerque, New Mexico.

SNL, 1998c, Refined Safety Analysis Project, Project Quality Assurance Plan (PQAP), Rev. 2, Sandia National Laboratories, Albuquerque, New Mexico.

SNL, 1998d, Test Procedure/Case Template, Rev. 1.1, Sandia National Laboratories, Albuquerque, New Mexico.

SNL, 6534-GRESAT-003, 1998e, Refined Safety Analysis Tool, Software Management Plan (SMP), Revision 2.0, SNL-0000151, Sandia National Laboratories, Albuquerque, New Mexico.

SNL, 2000, Sandia National Laboratories, Refined Safety Analysis Project, FY2000 Project Quality Assurance Plan (PQAP), Rev. 4, SNL-000217, Sandia National Laboratories, Albuquerque, New Mexico.

Stamps, D., W. Benedick, and S. Tieszen, 1991, Hydrogen-Air-Diluent Detonation Study for Nuclear Reactor Safety Analyses, NUREG/CG-5525 (SAND89-2398), Sandia National Laboratories, Albuquerque, New Mexico.

Stewart, C. W., J. D. Hudson, J. R. Friley, F. E. Panisko, Z. I. Antoniak, J. J. Irwin, J. G. Fadeff, L. F. Efferding, T. E. Michener, N. W. Kirch, and D. A. Reynolds, 1994, Mitigation of Tank 241-SY-101 by Pump Mixing: Results of Full-Scale Testing PNNL 9959, Pacific Northwest National Laboratory, Richland, Washington.

Stewart, C. W., J. M. Alzheimer, M. E. Brewster, G. Chen, R. E. Mendoza, H. C. Reid, C. L. Shepard, and G. Terrones, 1996, In Situ Rheology and Gas Volume in Hanford Double-Shell Waste Tanks, PNNL-11296, Pacific Northwest National Laboratory, Richland, Washington.

Tieszen, S. R., M. P. Sherman, W. B. Benedick, and M. Berman, 1987, Detonability of H2-Air-Diluent Mixtures, NUREG/CR-4905 (SAND85-1263), Sandia National Laboratories, Albuquerque, New Mexico.

Van Kueren, J., 1996, Toxic Chemical Considerations for Tank Farm Releases, WHC-SD-WM-SARR-011 Rev. 2, Westinghouse Hanford Company, Richland, Washington. 
Van Kueren, J., 1998, Tank Waste Compositions and Atmospheric Dispersion Coefficients for Use in Safety Analysis Consequence Assessment, WHC-SD-WM-SARR-016, Rev. 2, Section 4.3, Westinghouse Hanford Company, Richland, Washington.

Wilkins, N. E., R. E. Bauer, and D. M. Ogden, 1997, Results of Vapor Space Monitoring of Flammable Gas Watch List Tanks, HNF-SD-WM-TI-797, Rev. 2, Hanford Nuclear Facility, Richland, Washington.

Young, E. R., 1998, Refined Safety Analysis Tool, Resolve Version 2.0, User Guide, SNL-000146, Sandia National Laboratories, Albuquerque, New Mexico.

Zerkel, D., R. Oldenborg, J. Lyman, D. Breshears, and H. Fry, 1997, Final Report: Plume Dispersion in Hanford Waste Tanks, LA-UR-97-2718, Los Alamos National Laboratory, Los Alamos, New Mexico.

\subsection{COMPUTER CODES}

Barker, S. A., 2000b, “first.kex," CH2M HILL Hanford Group, Inc., Richland, Washington.

Humphreys, S. L., and E. R. Young, 1998-1999, Resolve Versions 1.80, 1.85, 1.91, 1.92, 2.16, $2.20,2.21,2.22,2.23,2.24,2.5$, Sandia National Laboratories, Albuquerque, New Mexico.

McCornak, M., 1999, "FilterResolveResults.sh," Revision 1.2, a Bourne shell script for removing parameters from debug text files depending on certain criteria, Sandia National Laboratories, Albuquerque, New Mexico.

Microsoft ${ }^{\circledast}$ Windows $98^{\circledast}$ Resource Kit.

\subsection{E-MAIL COMMUNICATIONS, INFORMAL DOCUMENTS}

Ashbaugh, S. G., 1998a, "stat1.xls," Innovative Technology Solutions Corporation, Albuquerque, New Mexico.

Ashbaugh, S. G., 1998b, "stat2.xls," Innovative Technology Solutions Corporation, Albuquerque, New Mexico.

Barker, S. A., 1999a, "NonBD_GRE - Sum2C_Shms 0819.xls," spreadsheet, Lockheed Martin Hanford Corporation, Richland, Washington.

Barker, S. A., 1999b, "New RDB Distributions 990831 (sab).xls," spreadsheet containing analysis for distributions, Lockheed Martin Hanford Corporation, Richland, Washington. 
Barker, S. A., 1999c, "RDB input waste form 990819.xls," spreadsheet containing updates to tank waste form classification, Lockheed Martin Hanford Corporation, Richland, Washington.

Barker, S. A., 1999d, "rgs dist data CH4 \& N2O ratio.xls," spreadsheet containing the distributions for methane and nitrous oxide concentrations, Lockheed Martin Hanford Corporation, Richland, Washington.

Barker, S. A., 1999e, "rgs FinalSumTable 990818.xls," spreadsheet containing the distributions for hydrogen and nitrogen concentrations, Lockheed Martin Hanford Corporation, Richland, Washington.

Barker, S. A., 2000a, "DST Headspace Gas Generation Results.xls," spreadsheet used to collect input and output data as well as to perform unit conversions, CH2M HILL Hanford Group, Inc., Richland, Washington.

Grigsby, M., 1997, "SST GRE Safety Analysis Tool-Validation Test Cases," memo sent December 2 to K. Washington, Duke Engineering \& Services, Inc., Richland, Washington.

Grigsby, M., 1998, e-mail from Michael Grigsby to Anderson Riddle dated October 29 requesting information for AF model validation tests, Duke Engineering \& Services, Inc., Richland, Washington.

Hedengren, D. C., 2000a, "sy102NH3Jul99thrujun00.xls," spreadsheet with measured headspace ammonia concentrations in SY-102 from July 1999 to June 2000, Lockheed Martin, Richland, Washington.

Hedengren, D. C., 2000b, "sw pumping data.xls," spreadsheet with duration and amounts of waste transferred into SY-102, Lockheed Martin, Richland, Washington.

Hodges, A. L., 1998e, Refined Safety Analysis Project Design Review V\&V Status, October 16, Sandia National Laboratories, Albuquerque, New Mexico.

Lavender, J. C., 2000, "SST_onsite..xls," spreadsheet used to collect data and calculate results, H. M. Chew \& Associates, Inc., Richland, Washington.

Riddle, A., 1998, “Personal Notes, Design Review" dated October 15-16,

Riddle, A., 1999a, "Design Review Notes," dated 1/20/99, Sandia National Laboratories, Albuquerque, New Mexico.

Riddle, A., 1999b, "BD GRE Volume, Duration, and Period Validation.xls," spreadsheet used to collect input and output data as well as to perform unit conversions and calculations, Sandia National Laboratories, Albuquerque, New Mexico.

Riddle, A., 1999c, "NON-BD GRE minDuration Validation.xls," Sandia National Laboratories, Albuquerque, New Mexico. 


\section{RPP-6873 REV 0}

Riddle, A., 1999e, "Plume Time-at-Risk Validation.xIs," spreadsheet used to collect input and output data as well as to perform unit conversions, Sandia National Laboratories, Albuquerque, New Mexico.

Riddle, A., 1999f, "Salt Well Pumping Validation.xls," spreadsheet used to collect input and output data as well as to perform unit conversions and calculations, Sandia National Laboratories, Albuquerque, New Mexico.

Riddle, A., 1999g, "Combustion Model Validation.xls," spreadsheet used to collect input and output data as well as to perform unit conversions and calculations, Sandia National Laboratories, Albuquerque, New Mexico.

Riddle, A., 1999h, "Dose Model Verification.xls," spreadsheet used to collect input and output data, perform unit conversions, and calculate expected results, Sandia National Laboratories, Albuquerque, New Mexico.

Riddle, A., 1999i, "Elicited Parameter Validation.xls," spreadsheet used to collect input and output data as well as to perform unit conversions and calculations, Sandia National Laboratories, Albuquerque, New Mexico.

Riddle, A., 2000,"Ammonia Release During Waste Transfers.xls," spreadsheet used to collect data and make comparisons, Sandia National Laboratories, Albuquerque, New Mexico.

Riddle, A., and A. L. Hodges, 1998, "Comparison_Test_Cases_2.20.xls," spreadsheet containing the details of each input file required for individual test construction for each test case, Sandia National Laboratories, Albuquerque, New Mexico.

Stewart, C. W., 1998, "shmsgred.xls," spreadsheet dated May 1998, Pacific Northwest National Laboratory, Richland, Washington.

Wilkins, N. E., 1997a, e-mail from Nancy Wilkins to Wu-Ching Cheng dated November 19 with ammonia monitoring data for Tank 241-AN-105, Hanford Nuclear Facility, Richland, Washington.

Wilkins, N. E., 1997b, e-mail from Nancy Wilkins to Wu-Ching Cheng dated November 20 with ammonia monitoring data for Tank 241-AW-101, Hanford Nuclear Facility, Richland, Washington.

Wilkins, N. E., 1997c, e-mail from Nancy Wilkins to Wu-Ching Cheng dated November 21 with arnmonia monitoring data for Tank 241-SY-101, Hanford Nuclear Facility, Richland, Washington.

Young, J., 1998, e-mail from Jonathan Young to Michael Grigsby dated October 29 requesting information for AF model validation tests, Sandia National Laboratories, Albuquerque, New Mexico. 